LBNL-51130

\title{
On Leakage and Seepage from Geologic Carbon Sequestration Sites
}

\author{
C.M. Oldenburg, A.J.A. Unger, R.P. Hepple, and P.D. Jordan
}

June 2002

\author{
Earth Sciences Division \\ Ernest Orlando Lawrence Berkeley National Laboratory \\ Berkeley, CA 94720
}

BP-DOE CRADA

Health, Safety, and Environmental Risk Assessment for Leakage of $\mathrm{CO}_{2}$ from Deep Geologic Storage Sites

Task 1. Report on modeled surface leakage rates for a range of scenarios for $\mathrm{CO}_{2}$ sequestration in geologic formations

This work was supported in part by a Cooperative Research and Development Agreement (CRADA) between BP Corporation North America, as part of the $\mathrm{CO}_{2}$ Capture Project (CCP) of the Joint Industry Program (JIP), and the U.S. Department of Energy (DOE) through the National Energy Technologies Laboratory (NETL), and by the Ernest Orlando Lawrence Berkeley National Laboratory, managed for the U.S. Department of Energy under contract DE- 


\section{DISCLAIMER}

This report was prepared as an account of work sponsored by an agency of the United States Government. Neither the United States Government nor any agency thereof, nor any of their employees, makes any warranty, express or implied, or assumes any legal liability or responsibility for the accuracy, completeness, or usefulness fo any information, apparatus, product, or process disclosed, or represents that its use would not infringe privately held rights. Reference herein to any specific commercial product, process, or service by trade name, trademark, manufacturer, or otherwise does not necessarily constitute or imply its endorsement, recommendation, or favoring by the United States Government or any agency thereof. The views and opinions of authors expressed herein do not necessarily state or reflect those of the United States Government or any agency thereof. 


\section{TABLE OF CONTENTS}

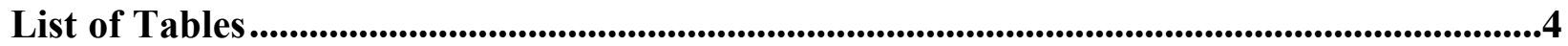

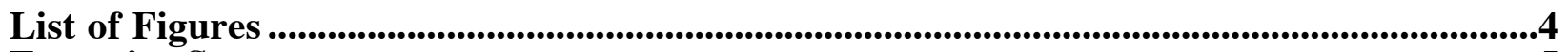

Executive Summary ........................................................................................................................................5

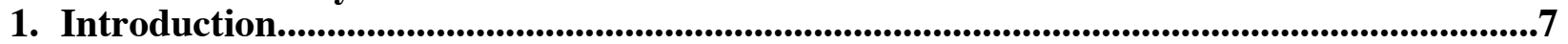

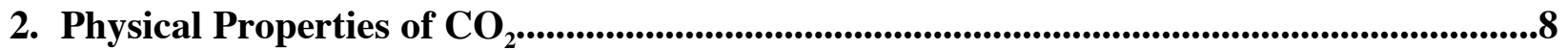

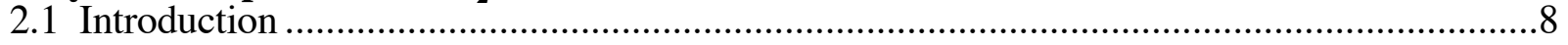

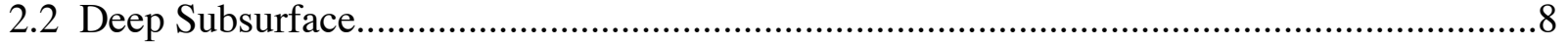

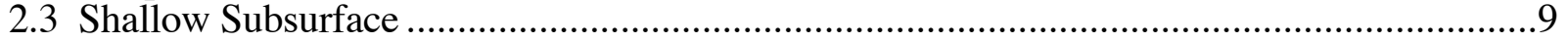

3. Conceptual Models of $\mathrm{CO}_{2}$ Migration............................................................................................9

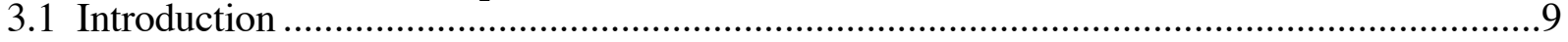

3.2 Effects of Permeability and Capillarity ..............................................................................

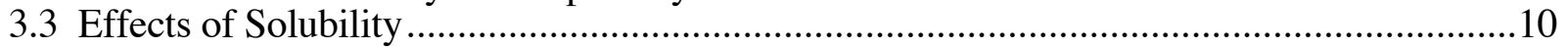

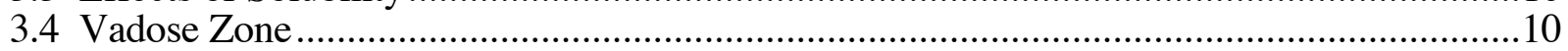

3.5 Site-Specific Analogs of Leakage and Seepage.................................................................11

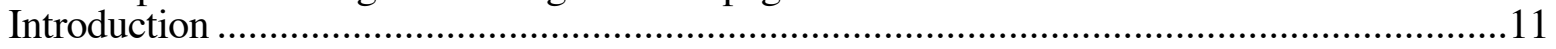

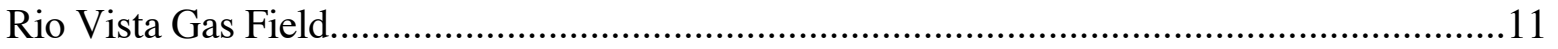

Gas Storage Disaster, Hutchinson, Kansas ...................................................................... 16

Seepage from Leroy Gas Storage Facility, Wyoming .......................................................16

Summary of Analog Leakage and Seepage ............................................................................17

3.6 Simple Estimates of Seepage Flux and Implications for Health Risk....................................17

Diffuse Seepage....................................................................................................................17

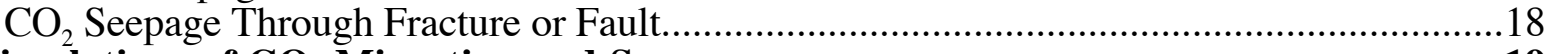

4. Simulations of $\mathrm{CO}_{2}$ Migration and Seepage.............................................................19

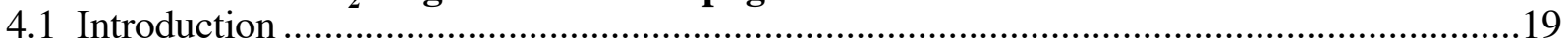

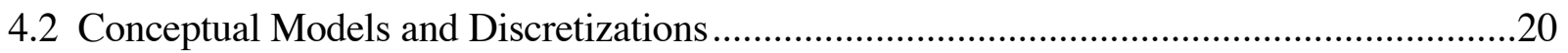

4.3 Case 1. Attenuation of $\mathrm{CO}_{2}$ by the Saturated Zone .....................................................2.

4.4 Case 2. Attenuation of $\mathrm{CO}_{2}$ by the Vadose Zone ...........................................................22

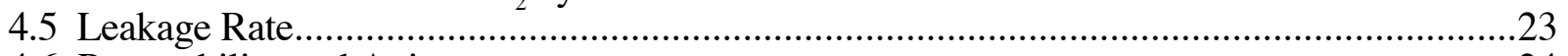

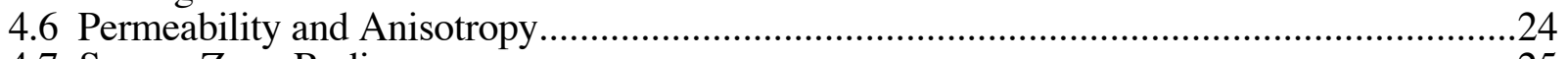

4.7 Source Zone Radius......................................................................................................25

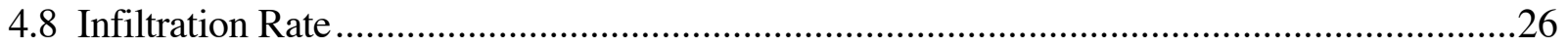

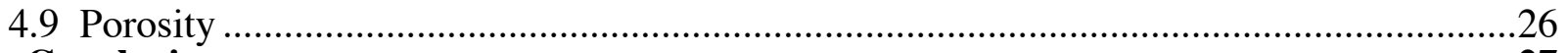

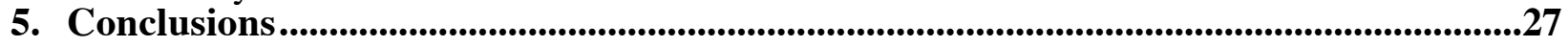

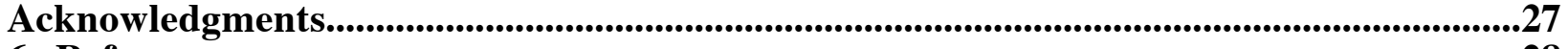

6. References ….......................................................................................................................................28 


\section{LIST OF TABLES}

Table 4.1: Hydrogeological properties of the saturated and vadose zones for the base scenario.

\section{LIST OF FIGURES}

Figure 2.1. Phase diagram for $\mathrm{CO}_{2}$ with approximate $\mathrm{P}, \mathrm{T}$ path.

Figure 2.2. Density as a function of pressure at three different temperatures.

Figure 2.3. Viscosity as a function of pressure at three different temperatures.

Figure 2.4. Solubility of $\mathrm{CO}_{2}$ in water as a function of pressure at $\mathrm{T}=40{ }^{\circ} \mathrm{C}$.

Figure 2.5. Density as a function of concentration in the system $\mathrm{CO}_{2}$-air.

Figure 2.6. Viscosity as a function of concentration in the system $\mathrm{CO}_{2}$-air.

Figure 3.1. Hypothetical radius of a spherical $\mathrm{CO}_{2}$ bubble.

Figure 3.2. Location map of the Rio Vista area.

Figure 3.3. Cross section of the Rio Vista gas reservoirs.

Figure 3.4. Gas migration schematic for Rio Vista.

Figure 4.1. Numerical mesh for the saturated zone model.

Figure 4.2. Numerical mesh for the vadose zone model.

Figure 4.3. (a) Water saturations and (b) the mass fraction of $\mathrm{CO}_{2}$ in the gas phasee.

Figure 4.4. (a) Water saturations at a time of 0.5 years and (b) the mass fraction of $\mathrm{CO}_{2}$.

Figure 4.5. (a) Water saturations at a time of one year and (b) the mass fraction of $\mathrm{CO}_{2}$.

Figure 4.6. (a) Water saturations at a time of ten years and (b) the mass fraction of $\mathrm{CO}_{2}$.

Figure 4.7. Contours and vectors (a) $4 \times 10^{4} \mathrm{~kg} \mathrm{yr}^{-1}$, (b) $4 \times 10^{5} \mathrm{~kg} \mathrm{yr}^{-1}$ and (c) $4 \times 10^{6} \mathrm{~kg} \mathrm{yr}^{-1}$.

Figure 4.8. The maximum surface mole fraction of $\mathrm{CO}_{2}$ in the gas phase.

Figure 4.9. The maximum surface flux of $\mathrm{CO}_{2}$. as a function of time.

Figure 4.10. Contours and vectors (a) $1 \times 10^{-12} \mathrm{~m}^{2}$, (b) $1 \times 10^{-11} \mathrm{~m}^{2}$, (c) $1 \times 10^{-10} \mathrm{~m}^{2}$ (d) $1 \times 10^{-9} \mathrm{~m}^{2}$.

Figure 4.11. Contours and vectors (a) $1: 1$, (b) $10: 1$, (c) $100: 1$ and (d) $1000: 1$.

Figure 4.12. The maximum surface flux of $\mathrm{CO}_{2}$ for permeability scenarios.

Figure 4.13. The maximum surface flux of $\mathrm{CO}_{2}$ for anisotropy scenarios.

Figure 4.14. Contours and vectors (a) $100 \mathrm{~m}$, (b) $10 \mathrm{~m}$ and (c) $1000 \mathrm{~m}$.

Figure 4.15. The maximum seepage flux of $\mathrm{CO}_{2}$ for source radius scenarios.

Figure 4.16. Contours and vectors (a) $0.1 \mathrm{~m} \mathrm{yr}^{-1}$, (b) $0.0 \mathrm{~m} \mathrm{yr}^{-1}$, (c) $0.5 \mathrm{~m} \mathrm{yr}^{-1}$ (d) $0.02 \mathrm{~m} \mathrm{yr}^{-1}$.

Figure 4.17. The maximum seepage flux of $\mathrm{CO}_{2}$ for infiltration rate scenarios.

Figure 4.18. Contours and vectors (a) 0.2 , (b) 0.4 and (c) 0.1 .

Figure 4.19. The maximum surface flux of $\mathrm{CO}_{2}$ for porosity scenarios. 


\section{EXECUTIVE SUMMARY}

Geologic carbon sequestration involves the injection of large quantities of carbon dioxide $\left(\mathrm{CO}_{2}\right)$ into geological formations such as depleted oil and gas reservoirs and brine formations. Pressure and buoyancy forces provide a driving force for stored $\mathrm{CO}_{2}$ to leak from sequestration target formations. Leaking $\mathrm{CO}_{2}$ will migrate upwards until it reaches the shallow subsurface, at which point it may begin to seep out of the ground causing both failure of the carbon sequestration project and potential health, safety, and environmental risks. The purpose of this report is to present our work on modeling $\mathrm{CO}_{2}$ transport from geologic carbon sequestration sites as part of our studies on health and safety risk assessment for geologic carbon sequestration. Before presenting model results, we discuss some fundamental aspects and analogs of subsurface $\mathrm{CO}_{2}$ migration.

$\mathrm{CO}_{2}$ is a supercritical fluid at depths greater than approximately $700 \mathrm{~m}$ in the earth. Although the density and viscosity of supercritical $\mathrm{CO}_{2}$ are much larger than $\mathrm{CO}_{2}$ gas density and viscosity, $\mathrm{CO}_{2}$ is buoyant and relatively inviscid compared with ground water at all depths in the earth. At shallow depths and in the vadose zone, $\mathrm{CO}_{2}$ is a dense gas, slightly less viscous than air. Carbon dioxide solubility in water is approximately 50 times larger than that of air. Molecular diffusivity of $\mathrm{CO}_{2}$ is similar to that of other common gases.

As $\mathrm{CO}_{2}$ migrates upwards by pressure gradient or buoyancy forces, it will tend to spread out against low-permeability formations and cap rocks. The permeabilities of cap rocks consisting of shales and clays are very low, and in many cases capillary gas-entry pressures further restrict $\mathrm{CO}_{2}$ from entering the cap rock. However, permeability is a scale-dependent property, and permeability increases as the length scale of interest increases. The spreading of $\mathrm{CO}_{2}$ against overlying low-permeability formations will lead to an increase in the effective length scale of the flow, along with corresponding increase in effective permeability. In addition, depressurization leads to dramatic volume expansion for $\mathrm{CO}_{2}$ near the critical pressure of 73.8 bars. For these reasons, the likelihood of $\mathrm{CO}_{2}$ finding a path upwards increases with time as leakage from the primary target occurs. Limiting this effect is the high solubility of $\mathrm{CO}_{2}$ in water. The process of dissolution may be important for attenuating rising $\mathrm{CO}_{2}$ plumes, however the geometry and form of plume migration can control the degree to which ground water is contacted by the rising plume and thereby control the amount of dissolution. The tendency for upward migration completely reverses in the vadose zone where $\mathrm{CO}_{2}$ is denser than surrounding soil gas. In the vadose zone, $\mathrm{CO}_{2}$ will tend to spread out on top of the water table and buoyancy forces will resist the tendency of the gas to seep out the ground surface.

Analogs to potential $\mathrm{CO}_{2}$ leakage and seepage are found in natural gas fields and in natural gas storage operations. One large depleted natural gas field that could potentially be used as a geologic carbon sequestration site is the Rio Vista Gas Field in California. The reservoir formations and structure at Rio Vista have allowed the accumulation of large amounts of methane $\left(\mathrm{CH}_{4}\right)$, but also allow limited leakage and seepage as evidenced by natural gas seeps. The leakage appears to occur through multiple shale layers and possibly along transmissive faults. The Hutchinson, Kansas, and Leroy, Wyoming gas storage leaks also resulted in seepage and 
demonstrate that gas migration in the subsurface can happen quickly and unexpectedly. While $\mathrm{CH}_{4}$ is a light gas and dissipates quickly in the atmosphere, $\mathrm{CO}_{2}$ is a dense gas that may accumulate in topographically low areas under conditions of low wind where it can create health, safety, and environmental risks.

Using some simple estimates of leakage rate and area over which an average diffusive-style seepage will occur, the seepage flux is of the same order as the terrestrial carbon fluxes caused by root respiration and photosynthesis. These fluxes are not expected to cause any health or safety risk. On the other hand, if the assumed leakage rates result in seepage through smaller areas such as fault or fracture zones, then much higher seepage flux and surface concentrations can result.

We have carried out numerical simulations of $\mathrm{CO}_{2}$ transport under a variety of conditions in the saturated and vadose zones using a multicomponent and multiphase integral finite difference simulator called TOUGH2/EOS7CA. Simulations for a radially symmetric system for a case where $\mathrm{CO}_{2}$ migrates upwards as a large bubble in the saturated zone and where $\mathrm{CO}_{2}$ migrates through the vadose zone produced the following findings:

- Dissolution of $\mathrm{CO}_{2}$ into surrounding groundwater from a rising bubble initially containing $\mathrm{CO}_{2}$ and air $500 \mathrm{~m}$ below the water table strips $\mathrm{CO}_{2}$ from the gas phase and concentrates the less-soluble air. While many factors could influence the degree to which this effect occurs, our initial simulation demonstrates the potential importance of solubility trapping for protection against leaking $\mathrm{CO}_{2}$.

- In the case where $\mathrm{CO}_{2}$ is assumed to be continuously arriving at the water table, the primary control on seepage and near-surface $\mathrm{CO}_{2}$ concentrations is the leakage rate, with high leakage rates leading to both high seepage flux and high concentrations.

- Although seepage fluxes are comparable to typical ecological fluxes, concentrations near the surface are high relative to tree-root mortality levels and may pose a human health risk.

- Permeability and permeability anisotropy are the next most influential properties after leakage rate. Larger permeability leads to more lateral spreading, but the seepage is relatively insensitive to permeability since both lateral and upward transport are enhanced. As vertical permeability decreases relative to horizontal permeability, lateral spreading is strongly enhanced and seepage flux decreases correspondingly.

- Seepage is controlled by the radius of the source, with larger seepage for smaller source zones.

- The infiltration rate in the system affects the liquid saturation in the vadose zone and therefore the amount of water available for dissolution of $\mathrm{CO}_{2}$. However, very little influence on vertical or lateral $\mathrm{CO}_{2}$ migration is observed as a function of infiltration rate.

- The porosity of the system has very little influence on seepage or near-surface concentrations. The observed trends are applicable to the homogeneous permeability field considered.

With these results forming background of understanding of leakage and seepage from geologic carbon sequestration sites, we are in a position to formulate a health and safety risk assessment framework that considers both the subsurface migration as well as the dispersion of $\mathrm{CO}_{2}$ after seepage out of the ground. 


\section{INTRODUCTION}

Geologic carbon sequestration is one strategy for reducing the rate of increase of global atmospheric carbon dioxide $\left(\mathrm{CO}_{2}\right)$ concentrations (IEA, 1997; Reichle, 2000). As used here, the term geologic carbon sequestration refers to the direct injection of supercritical $\mathrm{CO}_{2}$ deep into subsurface target formations. These target formations will typically be either depleted oil and gas reservoirs, or brine-filled permeable formations referred to here as brine formations. Injected $\mathrm{CO}_{2}$ will tend to be trapped by one or more of the following mechanisms: (1) permeability trapping, for example when buoyant supercritical $\mathrm{CO}_{2}$ rises until trapped by a confining caprock; (2) solubility trapping, for example when $\mathrm{CO}_{2}$ dissolves into the aqueous phase in water-saturated formations, or (3) mineralogic trapping, such as occurs when $\mathrm{CO}_{2}$ reacts to produce stable carbonate minerals. When $\mathrm{CO}_{2}$ is trapped in the subsurface by any of these mechanisms, it is effectively sequestered away from the atmosphere where it would otherwise act as a greenhouse gas.

Although the purpose of geologic carbon sequestration is to trap $\mathrm{CO}_{2}$ in the subsurface, there is the risk that injected $\mathrm{CO}_{2}$ will migrate away from the primary target formation. Migration away from the primary target formation is referred to here as leakage. Carbon dioxide that leaks from the primary sequestration target will likely become trapped again as it moves upward and undergoes secondary trapping processes in up-section structural traps and by dissolution processes. In short, leaking $\mathrm{CO}_{2}$ in and of itself is neither a failure of the sequestration project nor a health or environmental risk at the ground surface as long as the $\mathrm{CO}_{2}$ remains underground. However, when $\mathrm{CO}_{2}$ reaches the shallow subsurface and migrates out of the ground into the ambient air, the sequestration process has failed and health and environmental risks arise. In analogy to existing processes whereby water, oil, and gas migrate across the subsurface-ground surface interface, we refer to the migration of $\mathrm{CO}_{2}$ out of the ground as seepage. Aside from the potential health and environmental risks, seepage from geologic carbon sequestration sites more than negates the sequestration objective because the sequestration process itself is energy intensive.

The purpose of this report is to summarize our work aimed at quantifying potential $\mathrm{CO}_{2}$ seepage due to leakage from geologic carbon sequestration sites. The approach we take is to present first the relevant properties of $\mathrm{CO}_{2}$ over the range of conditions from the deep subsurface to the vadose zone (Section 2), and then discuss conceptual models for how leakage might occur (Section 3). The discussion includes consideration of gas reservoir and natural gas storage analogs, along with some simple estimates of seepage based on assumed leakage rates. The conceptual model discussion provides the background for the modeling approach wherein we focus on simulating transport in the vadose zone, the last potential barrier to $\mathrm{CO}_{2}$ seepage (Section 4). Because of the potentially wide range of possible properties of actual future geologic sequestration sites, we carry out sensitivity analyses by means of numerical simulation and derive the trends in seepage flux and near-surface $\mathrm{CO}_{2}$ concentrations that will arise from variations in fundamental hydrogeological properties. 


\section{PHYSICAL PROPERTIES OF $\mathrm{CO}_{2}$}

\subsection{Introduction}

In this section, we discuss the physical properties of carbon dioxide $\left(\mathrm{CO}_{2}\right)$ with an emphasis on the contrast in properties of $\mathrm{CO}_{2}$ relative to water and air in the deep and shallow subsurface, respectively. Carbon dioxide is a colorless and odorless gas with critical pressure $\left(\mathrm{P}_{\mathrm{c}}\right)$ equal to 73.8 bars and critical temperature $\left(\mathrm{T}_{\mathrm{c}}\right)$ equal to $31 .{ }^{\circ} \mathrm{C}$. We present in Figure 2.1 the phase diagram for $\mathrm{CO}_{2}$ showing the gaseous, liquid, solid, and supercritical regions along with an approximate curve representing a $P-T$ path in the subsurface assuming hydrostatic pressure and $25{ }^{\circ} \mathrm{C} \mathrm{km}^{-1}$ geothermal gradient. As shown in Figure 2.1, the geothermal gradient ensures that $\mathrm{CO}_{2}$ will be typically supercritical in the subsurface at depths greater than approximately $700 \mathrm{~m}$.

\subsection{Deep Subsurface}

Within the range of variation of subsurface pressures and temperature between typical carbon sequestration targets and the ground surface, $\mathrm{CO}_{2}$ undergoes large changes in physical properties. The physical properties of pure $\mathrm{CO}_{2}$ are well known, and the density and viscosity values shown below are calculated using a model that has been shown to agree very well with experimental data (Magee et al., 1994; NIST, 1992). In Figure 2.2, we present $\mathrm{CO}_{2}$ density $(\rho)$ over the range of pressures from the ground surface to approximately $2 \mathrm{~km}$ depth for three different temperatures. As shown, the density of $\mathrm{CO}_{2}$ increases drastically as pressure increases around the critical pressure, although this effect decreases at higher temperatures. As shown in Figure 2.2, the density of $\mathrm{CO}_{2}$ is always less than the density of water $\left(\sim 1000 \mathrm{~kg} \mathrm{~m}^{-3}\right)$ or brine. In Figure 2.3, we present $\mathrm{CO}_{2}$ viscosity as a function of pressure at three different typical subsurface temperatures. Although the viscosity of $\mathrm{CO}_{2}$ increases as pressure increases around the critical pressure, $\mathrm{CO}_{2}$ viscosity is always gas-like even at supercritical pressures. For comparison, the viscosity of water at $1 \mathrm{bar}, 25^{\circ} \mathrm{C}$ is approximately $1 . \times 10^{-3} \mathrm{~Pa} \mathrm{~s}$, or more than 10 times greater than the highest viscosity shown in Figure 2.3. Figures 2.2 and 2.3 show that $\mathrm{CO}_{2}$ will always be buoyant in the saturated subsurface, and that $\mathrm{CO}_{2}$ will have the mobility of a gas even at very high pressures.

We present in Figure 2.4 the solubility of $\mathrm{CO}_{2}$ as a function of pressure at $T=40{ }^{\circ} \mathrm{C}$. As shown, $\mathrm{CO}_{2}$ solubility increases steeply at pressures between ambient and critical (1 to 73.8 bars) and then increases more slowly with increasing pressure at constant temperature. However, temperature also affects the solubility of gases. As temperature increases, for example with depth in the subsurface, $\mathrm{CO}_{2}$ solubility in water tends to decrease. Therefore in the subsurface, pressure and temperature are compensating effects and $\mathrm{CO}_{2}$ solubility changes are small along typical $P-T$ paths relevant to geologic carbon sequestration. Nevertheless, exsolution and the formation of $\mathrm{CO}_{2}$ gas bubbles that can rise quickly under buoyancy forces is possible as $\mathrm{CO}_{2}$ saturated ground water migrates in the subsurface. As a rule of thumb, $\mathrm{CO}_{2}$ solubility in water is approximately 50 times larger than that of air. 


\subsection{Shallow Subsurface}

The shallow subsurface, for example near the water table and within the vadose zone, is characterized by pressures and temperatures approximately equal to those at the ground surface, i.e., at ambient atmospheric conditions. In this section, we present the properties of $\mathrm{CO}_{2}$ and dry air mixtures at ambient atmospheric conditions. We present in Figure 2.5 the density of $\mathrm{CO}_{2}$-air mixtures as a function of composition at three different temperatures. As shown in the Figure, $\mathrm{CO}_{2}$ is a dense gas relative to dry air, and the gases behave approximately ideally at atmospheric pressure. Note that the contrast in density between $\mathrm{CO}_{2}$ and actual soil gas will be even larger because soil gas is humid, and humid air is less dense than dry air due to the relatively smaller molecular weight of water $(18 \mathrm{~g} /$ mole $)$ relative to dry air $(28.96 \mathrm{~g} /$ mole $)$. We present in Figure 2.6 the viscosity variation of $\mathrm{CO}_{2}$-air mixtures at the same conditions. As shown, $\mathrm{CO}_{2}$ is less viscous than air, a somewhat nonintuitive relation given the contrast in density.

In addition to density and viscosity, the transport of $\mathrm{CO}_{2}$, especially in the shallow subsurface, may be controlled by molecular diffusivity. The molecular diffusivity of $\mathrm{CO}_{2}$ in air is comparable to other gases and is approximately $1.65 \times 10^{-5} \mathrm{~m}^{2} \mathrm{~s}^{-1}$ at $25{ }^{\circ} \mathrm{C}, 1$ bar (Vargaftik, 1996). Molecular diffusivity decreases as $\mathrm{CO}_{2}$ becomes denser and more liquid-like as pressure increases. As with solubility, pressure and temperature are compensating effects, i.e., increasing pressure tends to decrease diffusivity while increasing temperature increases it.

\section{CONCEPTUAL MODELS OF $\mathrm{CO}_{2}$ MIGRATION}

\subsection{Introduction}

In this section, we discuss transport processes and conceptual models applicable to the transport of $\mathrm{CO}_{2}$ away from a leaking carbon sequestration site, and upwards toward potential seepage out of the ground. In addition to the general conceptual model discussion, we refer to three analog systems where gas leakage and seepage occur, as well as present some simple estimates of seepage based on assumed leakage rates.

\subsection{Effects of Permeability and Capillarity}

As discussed in Section 2, $\mathrm{CO}_{2}$ will be supercritical at depths below approximately $700 \mathrm{~m}$ in the earth. At supercritical conditions, $\mathrm{CO}_{2}$ is a dense, relatively inviscid fluid. Nevertheless, $\mathrm{CO}_{2}$ will always be less dense than the surrounding groundwater and therefore it will tend to migrate upwards. Assuming sufficient $\mathrm{CO}_{2}$ is present to preclude complete dissolution into ground water (see below), upward migration will be restricted by permeability and capillary barriers. The permeability of typical shale cap rocks is on the order of $10^{-16} \mathrm{~m}^{2}$ or smaller (Neuzil, 1994). In addition to low permeability, cap rocks can act as effective capillary barriers due to the large gas-entry pressures (Hippler, 1997; Kaldi and Anderson, 1997). This effect of the cap rock acting as a capillary barrier actually makes irrelevant the need for small cap-rock permeability since gas is prevented from entering the pores if there is insufficient over pressure. In practice, high gas-entry pressure is usually correlated with low permeability. 
Because of upward buoyancy and the presence of low-permeability cap rocks and hydrogeologic barriers in the geologic column, upward migrating $\mathrm{CO}_{2}$ will tend to spread out laterally against permeability and capillary barriers. In so doing, the length scales of the upward migrating plume will increase. Permeability is known to be a scale-dependent quantity, with effective permeability increasing as the scale of the flow increases (e.g., Clauser, 1992). The explanation for the effect is that as the size of the system being sampled increases, the probability of the plume encountering a fast-flow path increases. This is intuitively plausible when one considers the spreading of a buoyant $\mathrm{CO}_{2}$ plume under a caprock that is cut by transmissive faults on a kilometer scale; as spreading expands a plume beyond $1 \mathrm{~km}$ in lateral extent, the transmissive features will be encountered.

To make this discussion less abstract, the increase in scale of flow for a rising spherical bubble of $\mathrm{CO}_{2}$ upward from a depth of $2 \mathrm{~km}$ is shown in Figure 3.1. As shown in the figure, the bubble radius increases drastically as the $\mathrm{CO}_{2}$ changes from supercritical to subcritical corresponding to the decrease in density (see also Figure 2.1, 2.2). This analysis assumes a hydrostatic pressure gradient with $0.1 \mathrm{bar} \mathrm{m}^{-1}$ and geothermal gradient of $25{ }^{\circ} \mathrm{C} \mathrm{km}^{-1}$. The actual increase in lateral spreading of an upward moving $\mathrm{CO}_{2}$ plume may be much more extreme than this spherical model indicates since actual $\mathrm{CO}_{2}$ plumes will spread like a pancake under low-permeability layers.

\subsection{Effects of Solubility}

As we discussed in Section 2, the solubility of $\mathrm{CO}_{2}$ in groundwater is relatively large. The implications for upward-migrating $\mathrm{CO}_{2}$ leaking from a geologic carbon sequestration site are profound. In particular, leaking $\mathrm{CO}_{2}$ will have a large potential to dissolve into ground water. Furthermore, the volume of groundwater available for $\mathrm{CO}_{2}$ dissolution is potentially very large given the depths envisioned for geologic carbon sequestration. Assuming an average $\mathrm{CO}_{2}$ solubility in the aqueous phase of 0.016 by mole fraction ( 0.04 by mass fraction), it would take approximately $10^{11} \mathrm{~kg}$ of water $\left(10^{8} \mathrm{~m}^{3}\right)$ to dissolve $4 \times 10^{9} \mathrm{~kg}$ of $\mathrm{CO}_{2}$. Assuming a porosity of 0.20 , this would correspond to $5 \times 10^{8} \mathrm{~m}^{3}$ of saturated formation. Assuming a $2 \mathrm{~km} \times 2 \mathrm{~km}$ square areal extent of $\mathrm{CO}_{2}$, the necessary volume of water is contained within a saturated thickness of only $125 \mathrm{~m}$ above the sequestration site. Clearly upon upward migration of $\mathrm{CO}_{2}$, there is ample water available to dissolve large amounts of $\mathrm{CO}_{2}$. The key factor for limiting $\mathrm{CO}_{2}$ dissolution is the form of migration insofar as the $\mathrm{CO}_{2}$ leakage may take the form of a connected fast path and never come into contact with sufficient volumes of water. Furthermore, the porous medium itself limits the contact area of gas-filled and water-filled pores. Nevertheless, the high solubility of $\mathrm{CO}_{2}$ in water appears to be a strong potential attenuation factor for leakage of $\mathrm{CO}_{2}$ from primary sequestration sites (see Section 4.3).

\subsection{Vadose Zone}

The upward buoyancy force discussed above is not applicable in the vadose zone. In fact, as shown in Figure 2.5, $\mathrm{CO}_{2}$ is a dense gas relative to air and humid air that will be found in the pore spaces of the vadose zone. Furthermore, $\mathrm{CO}_{2}$ is less viscous than air (Figure 2.6) and more soluble. The implications of these properties for $\mathrm{CO}_{2}$ migration in the shallow subsurface are as follows. First, $\mathrm{CO}_{2}$ will always be denser than ambient soil gas, creating the possibility for $\mathrm{CO}_{2}$ 
to pond above the water table in the vadose zone similar to dense gas flows of volatile organic compound vapors (e.g., Falta et al., 1989). Second, $\mathrm{CO}_{2}$ will flow faster than pure air, all other things being equal, due to its lower viscosity. Finally, $\mathrm{CO}_{2}$ will dissolve into moisture in the vadose zone approximately 50 times more than air. The present ambient $\mathrm{CO}_{2}$ concentration in air is approximately 350 ppmv $(0.035 \%)$. However, ambient soil gas $\mathrm{CO}_{2}$ concentrations can be on the order of $10 \%$ due to root respiration and other biological activity. Therefore, $\mathrm{CO}_{2}$ diffusion in the vadose zone can be upward at shallow depths and downward at deeper levels in the soil column.

Insofar as advective flows in the vadose zone may arise from a steady leakage flux of $\mathrm{CO}_{2}$ from below the water table, the permeability of the vadose zone is important to estimating $\mathrm{CO}_{2}$ seepage. Years of agriculture- and contaminant-related studies have demonstrated the importance of preferential flow in the vadose zone (e.g., Kung et al., 1990a, b; Ghodrati and Jury, 1990; Li and Ghodrati, 1994; Flury et al., 1994). These studies concern water and contaminants moving downward under gravity. Nevertheless, analogous preferential flow processes are expected to occur for $\mathrm{CO}_{2}$ migrating upwards under pressure gradient forces. We will quantify the effects on $\mathrm{CO}_{2}$ seepage of various vadose zone transport scenarios and properties in Section 4.

\subsection{Site-Specific Analogs of Leakage and Seepage}

\section{Introduction}

To place the discussion above in context, we discuss below three analog subsurface systems where gas leakage and seepage are known to occur. In the cases discussed, the gas is methane $\left(\mathrm{CH}_{4}\right)$, which is much less dense than $\mathrm{CO}_{2}$ at all relevant pressures and temperatures, and is less soluble in water than $\mathrm{CO}_{2}$. While seepage of $\mathrm{CH}_{4}$ will buoyantly rise in the air and dissipate quickly, $\mathrm{CO}_{2}$ is a dense gas and may not dissipate under conditions of low wind and valley topography leading to potential health, safety, and environmental risks. Nevertheless, these analog natural gas systems provide important constraints on our understanding of gas migration processes in the subsurface. In addition, depleted gas reservoirs are a promising carbon sequestration target (Oldenburg et al., 2001; Oldenburg and Benson, 2002).

\section{Rio Vista Gas Field}

\section{Setting}

The Rio Vista Gas Field is located in the southwest portion of the Sacramento Valley, and is part of a series of gas fields along a north to northwest trend as shown on Figure 3.2. The field spans either side of the Sacramento River in the vicinity of the town of Rio Vista. To the east of the Sacramento River, the field underlies sub-sea level islands formed by levees along the Sacramento and San Joaquin Rivers, and associated sloughs in the Sacramento-San Joaquin River delta. To the west of the Sacramento River, the field underlies the Montezuma Hills. The Montezuma Hills are low-lying, reaching a maximum elevation of less than 90 meters (300 feet) above sea level. The hills drain predominantly to the Sacramento River to the southeast. The only 
perennial streams in the hills occupy some of these drainages. Minor seasonal streams drain the margins of the hills to the north and west.

The Rio Vista gas field was discovered in 1936 with subsequent production continuing to the present. The field was estimated to have 100 billion cubic meters ( 3.5 trillion cubic feet) of recoverable gas initially. Reserves were estimated to be 6 billion cubic meters (223 billion cubic

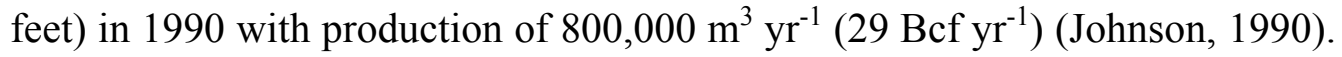

\section{Reservoir Characteristics}

The primary gas reservoir in the Rio Vista gas field is the Domengine sand, a predominantly marine sandstone with shale interbeds. The Domengine resides approximately $1200 \mathrm{~m} \mathrm{(4000 \textrm {ft } )}$ below sea level in the field area as shown on Figure 3.3. Gas plays have also been encountered in all the predominantly sandy formations, and in sand stringers within almost all of the predominantly shaly formations (including the Nortonville), in the Paleogene and upper Cretaceous section. Most notably, gas plays have been encountered in the Markley sand above the Domengine-capping Nortonville shale.

The west-dipping Midland Fault strikes north to northwest through the eastern portion of the Rio Vista Gas Field as shown on Figure 3.2. The units at the reservoir level exhibit normal (down to the west) displacement, and thicken across this fault from east to west indicating syndepositional faulting as shown on Figure 3.3. These characteristics, along with the apparent rapid accumulation of sediment and the overpressuring of deeper shales led Johnson (1990) to characterize the Midland Fault and associated faults as both growth and tectonic faults. Units above the reservoir typically exhibit reverse offset with thickening to the east indicating this fault has been tectonically reactivated in compression since the Miocene (Weber-Band, 1998). Based upon regional structural analysis, Weber-Band (1998) concluded that the Midland Fault and associated faults were likely due primarily to extensional tectonics during deposition of the reservoir units.

West of the Midland fault, the geologic structure in the gas field consists of an elongated, faulted dome. The trend of the dome's axis and the strikes of faults cutting the dome are north to northwest. The faults appear to be sympathetic and antithetic to the Midland Fault. The displacement on these faults does not appear to be greater than the thickness of the Nortonville shale, which caps the Domengine sand as shown on Figure 3.3 (Burroughs, 1968; Johnson, 1990). East of the Midland Fault the gas field consists of the unfaulted eastern half of a north- to northwest-trending, elongated dome. Farther east, the Isleton Gas Field consists of another north- to northwest-trending, elongated dome that is faulted through its eastern limb.

The gas traps in the Rio Vista field are described variously as faulted-dome or updip-fault traps created by offset of reservoir sands against shales with lateral structural closure due to folding (Burroughs, 1968; Johnson, 1990). Gas production is due to natural water-drive (pressure provided by groundwater), which is enhanced by active injection of produced water back into the reservoir (Johnson, 1990). Johnson (1990) states that the individual fault blocks in the field are hydraulically separate. 
The likely source of the gas in the Rio Vista field is the Cretaceous sediments (Johnson, 1990). These strata have a total organic content of $1-2 \%$, which is the highest of any strata in the gas field. The organic matter in the Cretaceous strata also have a reasonable level of maturity.

\section{Regional Geologic Structure}

The Plio-Pleistocene formations (Montezuma and Tehama) west of the Midland Fault form a broad, north-plunging anticline whose axis is located in the center of the Montezuma Hills. The Paleogene formations form a dome adjacent to the west and east side of the Midland Fault as previously mentioned, however, these units form a faulted syncline beneath the center of the Montezuma Hills (Johnson, 1990; Weber-Band, 1998). Early gas exploration in this portion of the Montezuma Hills did not yield any gas (Johnson, 1990).

The Montezuma and Tehama Formations consist of $20-40 \%$ coarse-grained sediments northwest of the Sacramento River, with coarse-grained defined as sand or coarser. These formations consist of 40-60\% coarse sediments southeast of the Sacramento River (Page, 1986).

\section{Hydrogeology}

The water table in the vicinity of the Rio Vista gas field is within approximately 3 meters (10 feet) of the ground surface throughout the area with the exception of the Montezuma Hills (DWR, 1994). The water table depth in the Montezuma Hills may increase to as much as $30 \mathrm{~m}$ $(100 \mathrm{ft})$ beneath the highest ridges (elevation $90 \mathrm{~m}$ ) in the central portion of the hills, however there are perennially wet drainages in this central area at an elevation of approximately $60 \mathrm{~m}(200$ $\mathrm{ft})$.

The maximum horizontal gradient in the vicinity of the Rio Vista Gas Field probably occurs from the center to the edge of the Montezuma Hills, a minimum distance of $6.5 \mathrm{~km}(4 \mathrm{mi})$. Assuming the water table elevation to be $60 \mathrm{~m}(200 \mathrm{ft})$ at the center and sea level at the edge, this yields a gradient of about 0.01 . Gradients outside this area can be expected to be much less due to the flat topography and pervasiveness of perennial water channels.

The average hydraulic conductivity in the Sacramento Valley aquifer is $0.9 \mathrm{~m} \mathrm{~d}^{-1}\left(3 \mathrm{ft} \mathrm{d}^{-1}\right)$ (Williamson et al., 1989). Combining this with the maximum gradient of 0.01 and an estimated effective porosity of $25 \%$ yields an estimated maximum linear groundwater velocity of $15 \mathrm{~m} \mathrm{yr}^{-1}$ $\left(50 \mathrm{ft} \mathrm{yr}^{-1}\right)$. While the hydraulic conductivities in the vicinity of the Rio Vista Gas Field may be higher or lower, they are probably similar to the Sacramento Valley average.

Water pressures are hydrostatic from the water table down to the Cretaceous Delta Shale. Water pressures in the Delta Shale are 5-10\% above hydrostatic (Burroughs, 1968; Johnson, 1990).

The Cretaceous Peterson Sand is the deepest producing zone in the Rio Vista Gas Field. The only hydraulic fracturing effort to enhance gas production in the field was undertaken in this unit at a depth of $2970 \mathrm{~m}(9800 \mathrm{ft})$ with sand injected as the propant. Post-fracturing production indicated that the fracture annealed due to the friability and semi-consolidation of this unit (Johnson, 1990). This test indicates that permeability in this unit, overlying units, and some underlying units is primarily due to porosity rather than fracturing. 


\section{Water Quality}

Shallow groundwater in the vicinity of the Rio Vista Gas Field has a total dissolved solids content (TDS) of 250 to 500 part per million (ppm). The groundwater to the northwest of the Sacramento River classifies as sodium bicarbonate (Evenson, 1985; Johnson, 1985), and to the southeast classifies as either sodium or calcium and chloride or sulfate (Bertoldi et al., 1991).

The base of fresh groundwater (TDS $<2000 \mathrm{ppm}$ ) generally occurs at or just below the contact of the Tehama and Neroly Formations, or a depth of 300 to $550 \mathrm{~ms}$ (1000 to $1800 \mathrm{ft}$ ) below sea level (Page, 1986). The TDS of groundwater in the Markley sand at $800 \mathrm{~m}(240 \mathrm{ft})$ below sea level in the Rio Vista Field is approximately $5000 \mathrm{ppm}$ and the anion and cation content is almost entirely sodium and chloride. The sodium chloride content increases with depth to approximately $17,000 \mathrm{ppm}$ in the Hamilton Sand and then decreases with depth to approximately 8,000 ppm in the Peterson Sand (Johnson, 1990).

\section{Gas Seeps}

No historic gas seeps are located within the footprint of the Rio Vista Gas Field. Six historic gas seeps and two oil seeps are located to the northwest of the field as shown on Figure 3.2 (Hodgson, 1980). All of these seeps are located outside of existing gas fields. They range in distance from 1.5 to $5 \mathrm{~km}$ ( 1 to $3 \mathrm{mi}$ ) from the nearest gas producing well. Four of the gas and one of the oil seeps are located in areas where Neogene sediments form anticlines (Weber-Band, 1998). No gas seeps occur closer than three miles from the Rio Vista or Lindsey Slough gas fields, both of which are along the Midland Fault.

All of the gas seeps located northwest of the Rio Vista Gas Field occur where the water table is shallow. An examination of the gas seeps listed in Hodgson (1980) suggests this is generally true throughout California, presumably due to the greater ease of detecting gas seeps where water is

present. None of the seeps west/northwest of the Rio Vista Gas Field is listed as currently active in Hodgson (1980). Almost all of these seeps are listed as quite active ("gas blowholes" or "bubbles from 20 or more vents") in the late $19^{\text {th }}$ and early $20^{\text {th }}$ century.

Approximately 40 gas seeps are listed as active out of a total of 105 seeps indexed in Hodgson (1980). Of the active seeps, most are noted as showing gas bubbles, or occasional gas bubbles, probably indicating a low flow. Out of the 40 active gas seeps, flow rates are estimated for four seeps. These estimates range from 30 to approximately $1250 \mathrm{~m}^{3} \mathrm{~d}^{-1}$ (this equates to 1 to 45 thousand cubic feet per day $\left(\mathrm{Mcf} \mathrm{d}^{-1}\right)$ ). However two, and maybe three, of these seeps are associated with old or abandoned wells. The only clearly natural gas seep with an estimated flow rate flows from 30 to $85 \mathrm{~m}^{3} \mathrm{~d}^{-1}\left(1\right.$ to $\left.3 \mathrm{Mcf} \mathrm{d}^{-1}\right)$.

\section{Conceptual Model of Gas Migration in the Rio Vista Field}

The following is a conceptual model of gas migration in the Rio Vista Field. Natural gas evolves from organic material in the Cretaceous sediments. As the gas-evolving sediments occur over a broad area around the field, gas likely evolves in the region surrounding the field as shown on Figure 3.4. The gas migrates upsection and is trapped in almost all of the Cretaceous and 
Paleogene sands in the field. Gas migration upsection probably occurs predominantly where fault zones traverse shales, either due to increased relative permeability in the fault zone, or simply due to thinning of the shales. This conceptualization is supported by the hydrostatic pressures in the Paleogene and upper Cretaceous sediments indicating that excess pressure due to consolidation has been able to dissipate.

While the original gas-water interface was offset across the faults, the original gas pool in the Domengine sand was thickest in the center of the dome at the Rio Vista Gas Field (Johnson, 1990; Burroughs, 1968). This indicates that gas migrates laterally into the structural trap, contrary to the interpretation of Johnson (1990) who stated that the fault blocks are hydraulically separate. Lateral migration requires penetration of the gas through numerous normal and reverse faults. Therefore the fault zones in the reservoir sands have a permeability intermediate between the sands and the overlying shales. Gas penetration through the fault zones allows gas to migrate updip into the dome from as far away as the synclinal axis formed by Paleogene and older sediments three miles to the west.

As noted, all of the Paleogene sands in the dome contain gas, including the Markley Sand above the Nortonville Shale. This suggests that gas migrated upsection from the Domengine Sand into the highest Paleogene traps, and then into the overlying post-Paleogene section, through which it migrates to the surface without being trapped. The Cierbo Formation, just above the Paleogene section, consists predominantly of marine conglomerate and sandstone. Gas migrating upsection through the Cierbo probably does not migrate considerably laterally due to the relatively uniform high permeability of this formation.

The overlying Miocene Neroly, Pliocene Tehama, and Pleistocene Montezuma consist of fluvial deposits that grade finer overall from the Neroly to the Montezuma. The Montezuma includes fine-grained lacustrine deposits as well. Significant anisotropy and heterogeneity in the permeability field therefore exists in these formations. As each formation, particularly the Tehama and Montezuma, dips gently to the east toward the Midland Fault in the Rio Vista Gas Field, gas migrating upsection through these units is probably deflected a considerable distance laterally as it flows updip along channel deposits and on the underside of fine-grained beds. The fact that all of the gas seeps in this area are laterally displaced from the Rio Vista Gas Field suggests that lateral gas flow occurs.

The Rio Vista Gas Field is located on the east limb of a north-dipping anticline involving the Montezuma and Tehama Formations (Weber-Band, 1998). Gas migrating to the ground surface from the Rio Vista Gas Field is therefore probably deflected updip toward the south central portion of the Montezuma Hills. No gas seeps have been observed in this area. The reason for this may be that the vadose zone is much thicker here than elsewhere in the area, and any gas flowing out of the water table disperses slightly upon migration through the vadose zone making seeps difficult to detect by field methods available in the early $20^{\text {th }}$ century.

The sourcing of the gas seeps from the gas reservoirs is suggested by the activity of these seeps in the late nineteenth and early twentieth centuries, prior to gas field development, compared to their inactivity in 1980 after gas field development. This timing suggests a maximum travel time for gas from the top of the reservoir to the ground surface of 60 to 80 years. 
The flow rates listed in Hodgson (1980) for currently active seeps suggest very active seeps flow in the range of 30 to $300 \mathrm{~m}^{3} \mathrm{~d}^{-1}$ ( 1 to $10 \mathrm{Mcf} \mathrm{d}^{-1}$ ). Assuming, somewhat conservatively, three undetected seeps flowing for a total of $900 \mathrm{~m}^{3} \mathrm{~d}^{-1}\left(30 \mathrm{Mcf} \mathrm{d}^{-1}\right)$ from the Rio Vista Gas Field prior to development yields an annual leakage rate of $3.3 \times 10^{5} \mathrm{~m}^{3} \mathrm{yr}^{-1}\left(12 \mathrm{MMcf} \mathrm{yr}^{-1}\right)$. Dividing this flow rate by the total recoverable reserves gives an annual leak rate of approximately $0.001 \%$ of the reservoir capacity.

\section{Gas Storage Disaster, Hutchinson, Kansas}

In January, 2001, natural gas burst from the ground beneath two stores in Hutchinson, Kansas. The gas pressure blew out windows in surrounding buildings, and subsequently the gas caught fire and burned down the two stores. In the following days, several geysers of water and gas appeared in the area around Hutchinson, and a gas explosion beneath a trailer home killed two people. The gas escaped to the surface through abandoned brine wells at each location (Allison, 2001).

The gas originated from a natural gas storage facility eight miles from Hutchinson. The facility consisted of solution-mined, salt caverns at depths of 200 to $270 \mathrm{~m}$ (650 to $900 \mathrm{ft})$. The leak occurred through a cracked gas well casing. The leaking gas moved upsection from the casing crack until it encountered a sealing formation. The gas then spread out laterally with some of it moving toward Hutchinson by migrating updip in a plunging anticline, and eventually escaping to the ground surface through the abandoned brine wells. Based upon pressure monitoring in the gas storage facility, the elapsed time from the leak to the first explosion in Hutchinson eight miles away was three days.

\section{Seepage from Leroy Gas Storage Facility, Wyoming}

Gas is stored in a confined sandstone and dolomite aquifer at a depth of $1000 \mathrm{~m}(3300 \mathrm{ft})$ at the Leroy gas-storage facility in Wyoming. A casing failed in 1973 allowing gas to migrate laterally through a formation above the storage aquifer to another well, where it migrated vertically up the outside of the well casing and bubbled out at the ground surface. The failed casing was installed in 1971 and appeared to have failed due to corrosion (Araktingi, 1984).

Gas seepage occurred again in 1978 in the form of bubbling in a creek and pond near two wells within the field. Pressure/inventory data suggest that the leak commenced in 1975 or 1976. Subsequent injection of various tracers into various wells resulted in the appearance of the tracers in the bubbling areas within 9 to 71 days. Subsequent well logging indicated gas migration behind one well casing. A tracer test after repairs to this casing resulted in return to the surface in 163 days.

The timing of bubbling, pressure/inventory data and a computer simulation indicated that the leakage from the storage aquifer occurred only above a threshold pressure. Some of the leaking gas migrated to the surface directly as indicated by cessation of bubbling during periods of low storage pressure. The constant bubbling in other areas led to the presumption that some of the leaking gas was captured in a secondary trap above the storage aquifer from which it migrated to the ground surface year round. 
From 1976 to 1981, the leakage rate from the storage reservoir averaged 3 million $\mathrm{m}^{3} \mathrm{yr}^{-1}$ (110 Mmcf $\mathrm{yr}^{-1}$ ), or approximately $3 \%$ per year of the total gas stored. The source of the leak was not clearly established. Leakage along wellbores, through the caprocks, or along fractures or faults were all posited. Well logging indicated that at least some gas migration was occurring along well bores. A program of well inspection and repairs was instituted to minimize this source of leakage and migration. Subsequent to 1981, the reservoir was operated below the identified threshold pressure leading to a large reduction in leakage.

\section{Summary of Analog Leakage and Seepage}

While in no way exhaustive, the above three cases illustrate several important issues relevant to potential $\mathrm{CO}_{2}$ leakage and seepage. In particular, it is clear from the existence of large natural gas reservoirs and the proven success of underground natural gas storage that gas can be trapped in the subsurface. In addition, the accumulation of large quantities of natural gas is evidence that gas migrates laterally and vertically in the subsurface. The presence of natural gas seeps, and the apparent diminution of seepage as the Rio Vista Gas Field has become depleted, suggest that there may be connections between deep reservoirs and the shallow subsurface where seepage occurs. Direct evidence of such connections comes from the gas storage failures presented. Furthermore, these gas storage failures suggest that gas can be transported quickly and unexpectedly from the deep subsurface, especially through man-made constructs such as abandoned or malfunctioning wells. Although the seepage of $\mathrm{CH}_{4}$ may lead to no local health risk because the light gas dissipates rapidly in the atmosphere, seeping $\mathrm{CO}_{2}$ may accumulate under conditions of low wind and valley topography leading to potential health, safety, and environmental risks. We suggest that further study should be undertaken of natural hydrocarbon seeps as analogs to potential $\mathrm{CO}_{2}$ seeps from geologic carbon sequestration sites.

\subsection{Simple Estimates of Seepage Flux and Implications for Health Risk}

\section{Diffuse Seepage}

In order to estimate potential seepage rates of $\mathrm{CO}_{2}$ returning to the atmosphere from a carbon sequestration storage project, we defined a prototype carbon sequestration project and assumed a leakage rate $\left(\mathrm{kg} \mathrm{s}^{-1}\right)$ of $1 \%$ of the stored $\mathrm{CO}_{2}$ per year. By averaging this leakage rate over a reasonable areal extent, we can estimate a uniform average seepage flux of $\mathrm{CO}_{2}\left(\mathrm{~kg} \mathrm{~m}^{-2} \mathrm{~s}^{-1}\right)$. The prototype project chosen for analysis is in a $10 \mathrm{~m}$ thick brine formation with $30 \%$ porosity and $10 \%$ displacement of brine by $\mathrm{CO}_{2}$. The density of supercritical $\mathrm{CO}_{2}$ is assumed to be $800 \mathrm{~kg} \mathrm{~m}^{-}$

${ }^{3}$, and the project is assumed to have injected $4 \times 10^{6}$ tonnes of $\mathrm{CO}_{2}$ per year for 50 years. The storage capacity of such a formation would be $2.4 \times 10^{5}$ tonnes of $\mathrm{CO}_{2} \mathrm{~km}^{-2}$, so the project would occupy $833 \mathrm{~km}^{2}$ (approximately $1000 \mathrm{~km}^{2}$ or $10 \mathrm{~km} \times 100 \mathrm{~km}$ ). The uniform flux of 2 million tonnes per year of $\mathrm{CO}_{2}$ over this area would be $1.44 \mu \mathrm{mol}$ of $\mathrm{CO}_{2} \mathrm{~m}^{-2} \mathrm{~s}^{-1}$. The calculations for the preceding estimates are given below:

Storage capacity over $1 \mathbf{k m}^{2}=10^{6} \mathrm{~m}^{2} \times 10 \mathrm{~m} \times 0.30 \times 0.10=3 \times 10^{5} \mathrm{~m}^{3}$ 
$3 \times 10^{5} \mathrm{~m}^{3} \mathrm{~km}^{-2} \times 800 \mathrm{~kg} \mathrm{CO}_{2} \mathrm{~m}^{-3} \times 1$ tonne $10^{-3} \mathrm{~kg}^{-1}=\mathbf{2 . 4} \times \mathbf{1 0}$ tonnes $\mathbf{C O}_{2} \mathbf{k m}^{-2}$

Area of project $=4 \times 10^{6}$ tonnes $\mathrm{CO}_{2} \mathrm{yr}^{-1} \times 50 \mathrm{yrs} \times 1 \mathrm{~km}^{2}\left(2.4 \times 10^{5} \text { tonnes) }\right)^{-1}=833 \mathrm{~km}^{2}(3.2)$

Average flux over $1000 \mathrm{~km}^{2}=4 \times 10^{6}$ tonnes $\mathrm{CO}_{2} \mathrm{yr}^{-1}$ x 50 yrs x $0.01 \mathrm{yr}^{-1}$ x $\left(10^{9} \mathrm{~m}^{2}\right)^{-1}$

$$
=0.002 \text { tonnes } \mathrm{CO}_{2} \mathrm{~m}^{-2} \mathrm{yr}^{-1}
$$

$10^{3} \mathrm{~kg}_{\text {tonne }}{ }^{-1} \times 1 \mathrm{~mol} \mathrm{CO}_{2}\left(0.044 \mathrm{~kg} \mathrm{CO}_{2}\right)^{-1} \times 10^{6} \mu \mathrm{mol} \mathrm{mol}{ }^{-1}=2.27 \times 10^{10} \mu \mathrm{mol}$ tonne ${ }^{-1}$

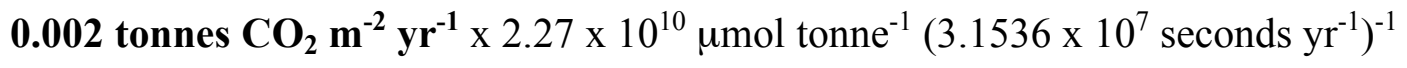

$$
=1.44 \mu \mathrm{mol} \mathrm{CO} \mathrm{Cm}^{-2} \mathrm{~s}^{-1}
$$

Natural carbon fluxes, referred to as net ecosystem exchange (NEE), range between $10 \mu \mathrm{mol} \mathrm{CO}_{2}$ $\mathrm{m}^{-2} \mathrm{~s}^{-1}$ efflux at night due to respiration to $-30 \mu \mathrm{mol} \mathrm{CO}_{2} \mathrm{~m}^{-2} \mathrm{~s}^{-1}$ drawdown due to photosynthesis/carbon fixation during the daytime. Typical values for a temperate broadleaved deciduous forest vary from diurnal growing season maximal ranges of 8 to $-22 \mu \mathrm{mol} \mathrm{CO}_{2} \mathrm{~m}^{-2} \mathrm{~s}^{-1}$ to diurnal minimal ranges of 2 to $0 \mu \mathrm{mol} \mathrm{CO} \mathrm{CO}^{-2} \mathrm{~s}^{-1}$ in the winter (Baldocchi and Wilson, 2001).

Comparison of this range to that calculated in Eq. 3.5 implies that 1\% leakage averaged over the project area would be substantially less than the ecological flux during the temperate, mid-latitude growing season, and comparable to ecological fluxes during the wintertime or in low-productivity ecosystems such as deserts. Such seepage fluxes are not thought to be a concern from a health and safety point of view.

\section{$\mathrm{CO}_{2}$ Seepage Through Fracture or Fault}

If $1 \%$ leakage per year ( 2 million tonnes of $\mathrm{CO}_{2} \mathrm{yr}^{-1}$ ) were concentrated in a fracture or fault, then the flux rate could be much higher. A $1 \mathrm{~m}$ by $1 \mathrm{~km}$ fracture would have a flux of $1.44 \mathrm{~mol} \mathrm{CO}_{2} \mathrm{~m}^{-}$ ${ }^{2} \mathrm{~s}^{-1}$ or $0.0634 \mathrm{~kg} \mathrm{CO}_{2} \mathrm{~m}^{-2} \mathrm{~s}^{-1}$. A $1 \mathrm{~m}$ by $10 \mathrm{~km}$ fault would have a flux rate of $0.144 \mathrm{~mol} \mathrm{CO}_{2} \mathrm{~m}^{-2}$ $\mathrm{s}^{-1}$ or $0.00634 \mathrm{~kg} \mathrm{CO}_{2} \mathrm{~m}^{-2} \mathrm{~s}^{-1}$, and if the fault were $1 \mathrm{~m}$ by $100 \mathrm{~km}$, then the flux rate would be $0.0144 \mathrm{~mol} \mathrm{CO}_{2} \mathrm{~m}^{-2} \mathrm{~s}^{-1}$ or $0.000634 \mathrm{~kg} \mathrm{CO}_{2} \mathrm{~m}^{-2} \mathrm{~s}^{-1}$. In order to assess whether these flux rates are physically reasonable, we would need to estimate the permeability of the conduits for a range of conceivable physical properties. However, the complexity, variability, and uncertainty of the subsurface argue against attempting such quantification. Instead, we have taken the approach of sensitivity analysis, as presented in Section 4. The calculations for the preceding estimates are given below:

$1 \% \mathrm{yr}^{-1}$ focused through a $1 \mathrm{~m}$ wide $\mathrm{x} 1 \mathrm{~km}$ long fault zone 
$2 \times 10^{6}$ tonnes $\mathrm{CO}_{2} \mathrm{yr}^{-1} \times\left(3.156 \times 10^{7} \mathrm{~s} \mathrm{yr}^{-1}\right)^{-1} \times\left(10^{3} \mathrm{~m}^{2}\right)^{-1} \times 2.27 \times 10^{4} \mathrm{~mol}$ tonne $\mathrm{e}^{-1}=$

$1.44 \mathrm{~mol} \mathrm{CO}_{2} \mathrm{~m}^{-2} \mathrm{~s}^{-1}$

$1.44 \mathrm{~mol} \mathrm{CO}_{2} \mathrm{~m}^{-2} \mathrm{~s}^{-1} \times .044 \mathrm{~kg} \mathrm{~mol}^{-1}=\mathbf{0 . 0 6 3 4} \mathbf{~ k g ~ C O}_{2} \mathbf{~ m}^{-2} \mathbf{s}^{-1}$

$1 \% \mathrm{yr}^{-1}$ focused through a $1 \mathrm{~m}$ wide $\mathrm{x} 10 \mathrm{~km}$ long fault zone

$2 \times 10^{6}$ tonnes $\mathrm{CO}_{2} \mathrm{yr}^{-1} \times\left(3.156 \times 10^{7} \mathrm{~s} \mathrm{yr}^{-1}\right)^{-1} \times\left(10^{4} \mathrm{~m}^{2}\right)^{-1} \times 2.27 \times 10^{4} \mathrm{~mol}$ tonne $\mathrm{e}^{-1}=$

$0.144 \mathrm{~mol} \mathrm{CO}_{2} \mathrm{~m}^{-2} \mathrm{~s}^{-1}$

$0.144 \mathrm{~mol} \mathrm{CO}_{2} \mathrm{~m}^{-2} \mathrm{~s}^{-1} \times .044 \mathrm{~kg} \mathrm{~mol}^{-1}=\mathbf{0 . 0 0 6 3 4} \mathbf{k g ~ C O}_{2} \mathbf{~ m}^{-2} \mathbf{s}^{-1}$

$1 \% \mathrm{yr}^{-1}$ focused through a $1 \mathrm{~m}$ wide $\mathrm{x} 100 \mathrm{~km}$ long fault zone

$2 \times 10^{6}$ tonnes $\mathrm{CO}_{2} \mathrm{yr}^{-1} \times\left(3.156 \times 10^{7} \mathrm{~s} \mathrm{yr}^{-1}\right)^{-1} \times\left(10^{5} \mathrm{~m}^{2}\right)^{-1} \times 2.27 \times 10^{4} \mathrm{~mol}_{\text {tonne }}^{-1}=$

$0.0144 \mathrm{~mol} \mathrm{CO}_{2} \mathrm{~m}^{-2} \mathrm{~s}^{-1}$

$0.0144 \mathrm{~mol} \mathrm{CO}_{2} \mathrm{~m}^{-2} \mathrm{~s}^{-1} \times .044 \mathrm{~kg} \mathrm{~mol}^{-1}=\mathbf{0 . 0 0 0 6 3 4} \mathbf{~ k g ~ C O}_{2} \mathbf{~ m}^{-2} \mathbf{s}^{-1}$

\section{SIMULATIONS OF $\mathrm{CO}_{2}$ MIGRATION AND SEEPAGE}

\subsection{Introduction}

In this section, we present analyses of leakage, seepage, and near-surface $\mathrm{CO}_{2}$ concentrations based on two-dimensional radial calculations of the fate and transport of $\mathrm{CO}_{2}$ in the subsurface. Rather than defining detailed geological and hydrological systems for seepage analysis, we have adopted the approach of sensitivity analysis. In this approach, the effects of various properties of the system, for example porosity, permeability, and leakage rate, can be simulated. This approach allows us to gain an understanding of the trends in seepage rate and near surface $\mathrm{CO}_{2}$ concentrations that we can expect for natural systems with various combinations of properties. The sensitivity analysis is based on a scenario where leaking $\mathrm{CO}_{2}$ reaches the water table at a constant rate, for example through a potential high-permeability zone with direct connection to a $\mathrm{CO}_{2}$ accumulation. We also present simulation results for a case where a large-volume bubble of $1.07 \times 10^{7} \mathrm{~kg}$ of $\mathrm{CO}_{2}$ has collected $500 \mathrm{~m}$ below the surface representing 2.69 years of leakage from a reservoir that contains $4 \times 10^{9} \mathrm{~kg}$ of $\mathrm{CO}_{2}$ and leaks at a rate of $0.1 \% \mathrm{yr}^{-1}$. This bubble is released catastrophically and migrates upwards through the saturated zone towards the ground surface. The idea here is to test the estimates made in Section 3 on solubility trapping.

All numerical simulations presented in this report were performed using TOUGH2 (Pruess et al., 1999) with a special module called EOS7CA applicable to flow and transport of $\mathrm{CO}_{2}$ and air in subsurface systems. EOS7CA models the subsurface flow and transport of aqueous and gas phases containing five components $\left(\mathrm{H} 2 \mathrm{O}\right.$, brine, $\mathrm{CO}_{2}$, gas tracer, and air) under isothermal or nonisothermal conditions. EOS7CA is a modification of EOS7C, developed previously for 
modeling $\mathrm{CO}_{2}$ injection into depleted natural gas reservoirs for carbon sequestration with enhanced gas recovery (Oldenburg et al., 2001; Oldenburg and Benson, 2002). EOS7CA uses real gas mixture properties calculated using the Peng-Robinson equation of state model. Air is approximated in EOS7CA as a mixture of $79 \%$ nitrogen and $21 \%$ oxygen by volume. Solubility of $\mathrm{CO}_{2}$ in the aqueous phase is modeled by Henry's Law, with Henry's coefficients calculated from Cramer (1982). Viscosity is estimated using the method of Chung et al. (1988) as described by Poling et al. (2001). TOUGH2/EOS7C was recently compared with three other reservoir simulators on carbon sequestration problems and showed good agreement in property estimates and flow and transport simulation results.

\subsection{Conceptual Models and Discretizations}

The underlying conceptual model is based on a geological reservoir of $\mathrm{CO}_{2}$ located $1 \mathrm{~km}$ below

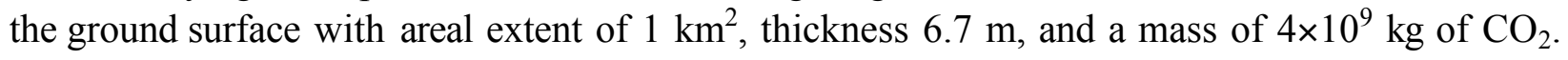
The hydrogeological properties of the system for the base-case scenario are listed on Table 4.1.

Table 4.1: Hydrogeological properties of the saturated and vadose zones for the base scenario.

\begin{tabular}{|l|l|l|}
\hline \multicolumn{1}{|c|}{ Property } & \multicolumn{1}{|c|}{ Value } & \multicolumn{1}{c|}{ Units } \\
\hline \hline Permeability $\left(k_{r}=k_{\mathrm{Z}}\right)$ & $1 \times 10^{-12}(1 \mathrm{Darcy})$ & $\mathrm{m}^{2}$ \\
\hline Porosity $(\phi)$ & 0.2 & - \\
\hline Infiltration rate $(i)$ & 10. & $\mathrm{~cm} \mathrm{yr}^{-1}$ \\
\hline Residual water saturation $\left(S_{l r}\right)$ & 0.1 & - \\
\hline Residual gas saturation $\left(S_{\mathrm{gr}}\right)$ & 0.01 & - \\
\hline van Genuchten $(1980) \alpha$ & $1 \times 10^{-4}$ & $\mathrm{~Pa}^{-1}$ \\
\hline van Genuchten $(1980) m$ & 0.2 & - \\
\hline
\end{tabular}

Figure 4.1 depicts the mesh used to simulate the transport of the $\mathrm{CO}_{2}$ bubble upward from a depth of $500 \mathrm{~m}$ in the saturated zone. The model is in cylindrical coordinates with the Cartesian axis located in the z-direction. The model contains a vadose zone that is $30 \mathrm{~m}$ thick, and a saturated zone that is $750 \mathrm{~m}$ thick. The mesh contains $90 \times 95$ grid blocks with a minimum and maximum radial discretization of $6.66 \mathrm{~m}$ and $40 \mathrm{~m}$, respectively. The vertical discretization in the vadose and saturated zones is $1.5 \mathrm{~m}$ ( 20 grid blocks) and $10 \mathrm{~m}$ ( 75 grid blocks), respectively. The source zone for the bubble was located 500 to $530 \mathrm{~m}$ below the water table over a radial distance of $100 \mathrm{~m}$. The bubble contained an initial gas saturation of 0.9 , while the mass fraction of $\mathrm{CO}_{2}$ in the gas bubble was 0.6 and the air mass fraction was 0.4. In total, the bubble contained of $1.07 \times 10^{7} \mathrm{~kg}$ of $\mathrm{CO}_{2}$. 
Figure 4.2 depicts the mesh used to simulate the transport of $\mathrm{CO}_{2}$ through the vadose zone. The model is also in cylindrical coordinates with the Cartesian axis located in the z-direction. The model contains a vadose zone that is $30 \mathrm{~m}$ thick, and a saturated zone that is $5 \mathrm{~m}$ thick. The mesh contains $20 \times 120$ nodes with a minimum and maximum radial discretization of $5 \mathrm{~m}$ and $30 \mathrm{~m}$, respectively. The vertical discretization is uniformly $1.75 \mathrm{~m}$. For the base-case scenario, $\mathrm{CO}_{2}$ is injected over a radial distance of $100 \mathrm{~m}$, which is the assumed area over which leakage from the reservoir occurs. The leakage rate is $4 \times 10^{6} \mathrm{~kg} \mathrm{yr}^{-1}$ which represents a leakage rate of $0.1 \% \mathrm{yr}^{-1}$.

For both conceptual models, the bottom boundary is used to enforce a hydrostatic condition while the top boundary is used to enforce an atmospheric pressure condition of gas phase pressure equal to $100 \mathrm{kPa}$. In addition, the gas-phase $\mathrm{CO}_{2}$ concentration at the top of the system is held at the present-day atmospheric concentration corresponding to $350 \mathrm{ppmv}$. The righthand side boundary is used to enforce the hydrostatic condition below the water table and the atmospheric condition in the vadose zone. The left-hand side boundary represents a no-flow condition applicable for symmetry about the z-axis. Recharge entering the top of the domain is in equilibrium with the $350 \mathrm{ppmv}$ atmospheric $\mathrm{CO}_{2}$ concentration.

\subsection{Case 1. Attenuation of $\mathrm{CO}_{2}$ by the Saturated Zone}

Given that reservoirs for deep geological sequestration of $\mathrm{CO}_{2}$ are located at significant depths below the water table, this simulation attempts to provide a bounding estimate on the ability of the saturated zone to prevent $\mathrm{CO}_{2}$ leaks from reaching the surface. In this case, we placed a bubble of $\mathrm{CO}_{2}$-air mixture $500 \mathrm{~m}$ below the water table. This scenario applies to the case where a $\mathrm{CO}_{2}$ leak collects beneath a structural trap with subsequent catastrophic failure releasing the bubble and allowing it to migrate to the water table. In terms of our base-case scenario, The bubble contains $1.07 \times 10^{7} \mathrm{~kg}$ of $\mathrm{CO}_{2}$ which represents 2.69 years of leakage at a rate of $4 \times 10^{6} \mathrm{~kg}$ $\mathrm{yr}^{-1}$.

The initial water saturation and mass fraction of $\mathrm{CO}_{2}$ in the gas phase are shown on Figures 4.3a and $4.3 \mathrm{~b}$, respectively. At this point, it is important to note that the residual water and gas saturations are 0.1 and 0.001 , respectively. After 0.5 years of migration, the top of the bubble is within $100 \mathrm{~m}$ of the water table as shown on Figure 4.4a. Figure $4.4 \mathrm{~b}$ shows that the mobile portion of the bubble is essentially composed of pure air while the $\mathrm{CO}_{2}$ has dissolved into the water phase around the source zone and has not moved. The solubility of $\mathrm{CO}_{2}$ in water is approximately 50 times greater than air (see Section 2). The gas phase saturation has decreased from 0.9 at initial time to 0.03 within the source zone of the bubble reflecting both the advective loss of air upwards, as well as the dissolution of $\mathrm{CO}_{2}$ into the water phase. As time increases from $1.0 \mathrm{yr}$ (Figure 4.5) to $10 \mathrm{yrs}$ (Figure 4.6), the bubble has reached the water table allowing the air to leave the system while the $\mathrm{CO}_{2}$ has remained dissolved in the saturated zone.

Although it may not be entirely realistic to consider the bubble to be composed of 0.4 mole fraction of air, it is possible that it could consist of other equally insoluble gas contaminants (e.g., nitrogen oxides) allowing analogous chromatographic separation of $\mathrm{CO}_{2}$ out of the bubble as it advects upwards. If the bubble consisted of pure $\mathrm{CO}_{2}$, it would collapse without significant upward migration as it dissolves into the surrounding water. In conclusion, our simulations 
indicate that for these conditions the entire water column above the source zone and beneath the water table would have to reach maximum solubility concentrations of $\mathrm{CO}_{2}$ before there could be any risk of direct surface seepage of $\mathrm{CO}_{2}$, even if less soluble gases were already discharging at the surface. Therefore, it appears that the saturated zone effectively attenuates the migration of $\mathrm{CO}_{2}$ from a leaky reservoir under this conceptual model.

This conclusion must be considered in light of various mitigating issues that remain to be investigated. First, the solubility of $\mathrm{CO}_{2}$ in brines is markedly lower than that in the fresh water simulated here. However, the large volume of water available for dissolution of $\mathrm{CO}_{2}$ migrating from the deep subsurface would seem to compensate for lower $\mathrm{CO}_{2}$ solubilities and suggest that this result will still hold for the case of brine formations. However, it is also important to note that different conceptual models of bubbles may behave quite differently. For example, the bubble in this analysis is a two-phase mixture (aqueous and gas phases with residual saturations), while another conceptual model equally valid might have a pure single-phase gas bubble, in which case the contact area for dissolution into the surrounding aqueous phase is greatly reduced, with corresponding reduction in dissolution potential over the time period of upward rise. This latter case may be the analyzed in a future study. In addition, the simulation was carried out in a homogeneous porous medium. In a heterogeneous system, the $\mathrm{CO}_{2}$ could occupy preferential flow paths and never contact the bulk of the volume of water in the saturated formation. Furthermore, the water in this case was assumed to be initially devoid of $\mathrm{CO}_{2}$, whereas actual systems may already contain dissolved $\mathrm{CO}_{2}$, the effect of which would be to decrease $\mathrm{CO}_{2}$ dissolution from the bubble. Finally, the above simulation was carried out at $15{ }^{\circ} \mathrm{C}$, and $\mathrm{CO}_{2}$ solubility is known to decrease at the higher temperatures expected at $500 \mathrm{~m}$ depth.

\subsection{Case 2. Attenuation of $\mathrm{CO}_{2}$ by the Vadose Zone}

The second scenario assumes that a constant rate of $\mathrm{CO}_{2}$ leaks from the same reservoir and reaches the water table due to the action of a high-permeability conduit circumventing the influence of the saturated zone. As part of this scenario, we adjusted the hydrogeological properties of the vadose zone, the leakage rate, and source radius. The exposure risk of $\mathrm{CO}_{2}$ at the ground surface will be quantified by comparison to the both the ecological flux of $\mathrm{CO}_{2}$ which is $4.4 \times 10^{-7} \mathrm{~kg} \mathrm{~s} \mathrm{~m}^{-2}$ as well as the mole fraction of $\mathrm{CO}_{2}$ in the gas phase in soil at which tree mortality occurs which is 0.3 . These values were obtained by measurement from Mammoth Mountain, $\mathrm{CA}$ where magmatic gas emissions of $\mathrm{CO}_{2}$ have caused widespread damage to surface vegetation, and have also endangered human life (Farrar et al., 1995, 1999).

Following the prior analysis of the ability of the saturated zone to attenuate the migration of $\mathrm{CO}_{2}$, we adopt a worst-case scenario where we assume that $\mathrm{CO}_{2}$ from the leaky reservoir discharges at the water table. The objective of this analysis is to determine the influence of hydrogeological properties of the vadose zone and leakage characteristics of the reservoir on the maximum surface flux of $\mathrm{CO}_{2}$ as well as the maximum surface mole fraction of $\mathrm{CO}_{2}$ relative to the base scenario. Specifically, we varied six parameters including the permeability, anisotropy, porosity, infiltration rate, source zone leakage rate, and source zone radius to determine the effects on seepage flux and near-surface concentration. For this analysis, we assumed a fixed and conservative vadose zone thickness of $30 \mathrm{~m}$. For our base scenario, we assume that $\mathrm{CO}_{2}$ leaks at 
a rate of $4 \times 10^{6} \mathrm{~kg} \mathrm{yr}^{-1}$ over a radius of $100 \mathrm{~m}$ representing a reservoir of $4 \times 10^{9} \mathrm{~kg}$ of $\mathrm{CO}_{2}$ leaking at a rate of $0.1 \% \mathrm{yr}^{-1}$. Hydrogeological properties for the base case (see Table 4.1) were determined by ensuring that gas phase pressures arising from the $\mathrm{CO}_{2}$ leak do not significantly displace the water table.

\subsection{Leakage Rate}

The primary parameter controlling the seepage and concentration of $\mathrm{CO}_{2}$ at the ground surface is the leakage rate from the reservoir. For our base-case scenario, the maximum leakage rate that could be simulated without significantly perturbing that water table was $4 \times 10^{6} \mathrm{~kg} \mathrm{yr}^{-1}$. This value is equivalent to $0.1 \% \mathrm{yr}^{-1}$ leaking from a reservoir containing $4 \times 10^{9} \mathrm{~kg}$ of $\mathrm{CO}_{2}$. For the sensitivity analysis, we decreased the leakage rate from $4 \times 10^{6} \mathrm{~kg} \mathrm{yr}^{-1}$ to $4 \times 10^{5} \mathrm{~kg} \mathrm{yr}^{-1}$ and $4 \times 10^{4}$ $\mathrm{kg} \mathrm{yr}^{-1}$ to determine the impact of these rates on the surface concentrations of $\mathrm{CO}_{2}$. As described earlier, all hydrogeological parameters for the base-case scenario are provided in Table 4.1, while the radius of the source zone and thickness of the vadose zone were fixed at $100 \mathrm{~m}$ and $30 \mathrm{~m}$, respectively.

Figure 4.7 shows vertical cross-sections of the mass fraction of $\mathrm{CO}_{2}$ in the gas phase, the water saturation, and gas phase pore velocity vectors for leakage rates of (a) $4 \times 10^{4} \mathrm{~kg} \mathrm{yr}^{-1}$, (b) $4 \times 10^{5} \mathrm{~kg}$ $\mathrm{yr}^{-1}$, and (c) $4 \times 10^{6} \mathrm{~kg} \mathrm{yr}^{-1}$ at a time of 100 years after the start of leakage. These figures clearly demonstrate that although the $\mathrm{CO}_{2}$ forms a dense gas phase (approximately twice that of the ambient air (Section 2)) directly above the source zone, there is very little lateral spreading of $\mathrm{CO}_{2}$ on the water table. In fact, the $\mathrm{CO}_{2}$ plume spreads a maximum of $120 \mathrm{~m}$ beyond the radius of the source zone for the highest leakage rate. Instead, the $\mathrm{CO}_{2}$ plume reaches the ground surface for all injection rates indicating that the vadose zone does not act as an effective attenuation mechanism for leakage of $\mathrm{CO}_{2}$ from a reservoir under this scenario.

Rather than assume that the leakage rate remains constant until the reservoir is depleted, we examine an alternative approach where the leakage rate is proportional to the amount of $\mathrm{CO}_{2}$ remaining in the reservoir. Letting $V_{t}$ and $V_{0}$ be the mass of $\mathrm{CO}_{2}$ in the reservoir [kg] at time $t$ and initial time, $q$ be the leakage rate $\left[\mathrm{kg} \mathrm{yr}^{-1}\right]$, and $\lambda$ be the leakage decay rate $\left[\% V \mathrm{yr}^{-1}\right]$, the mass remaining in the reservoir and leakage rate as a function of time are given by:

$$
\begin{aligned}
& V(t)=V_{0} \exp \{-\lambda t\} \\
& q(t)=\lambda V_{0} \exp \{-\lambda t\}
\end{aligned}
$$

The leakage rate calculated by Eq. (4.2) will provide a less conservative, but perhaps more realistic, estimate of the actual leakage rate from a subsurface reservoir.

Figure 4.8a shows the maximum surface mole fraction of $\mathrm{CO}_{2}$ as a function of time while Figure $4.8 \mathrm{~b}$ shows the total flow of $\mathrm{CO}_{2}$ across the surface boundary as a function of time for all three 
leakage rates without decay, as well as with leakage decay. Note that a leakage rate with decay where $\lambda=4 \times 10^{-3} \mathrm{yr}^{-1}$ and $V_{0}=4 \times 10^{9} \mathrm{~kg}$ is intended to be analogous to a constant leakage rate of $4 \times 10^{6} \mathrm{~kg} \mathrm{yr}^{-1}$. In general, Figure $4.8 \mathrm{a}$ demonstrates that the surface mole fraction rapidly reaches peak levels whereas deviations between leakage rates with and without decay only occur at late times. At late times, the constant injection rate goes to zero as a step function once all of the $\mathrm{CO}_{2}$ in the reservoir has been depleted (1000 years for $\left.q=4 \times 10^{6} \mathrm{~kg} \mathrm{yr}^{-1}\right)$ whereas the $\mathrm{CO}_{2}$ leakage with decay declines exponentially beyond this point. Figure $4.8 \mathrm{~b}$ shows that for a constant leakage rate of $4 \times 10^{6} \mathrm{~kg} \mathrm{yr}^{-1}\left(0.127 \mathrm{~kg} \mathrm{~s}^{-1}\right)$, the total flow of $\mathrm{CO}_{2}$ across the surface boundary is $0.103 \mathrm{~kg} \mathrm{~s}^{-1}$ which is slightly less than the source rate. As the leakage rate decreases to $4 \times 10^{5} \mathrm{~kg} \mathrm{yr}^{-1}\left(1.27 \times 10^{-2} \mathrm{~kg} \mathrm{~s}^{-1}\right)$ and to $4 \times 10^{4} \mathrm{~kg} \mathrm{yr}^{-1}\left(1.27 \times 10^{-3} \mathrm{~kg} \mathrm{~s}^{-1}\right)$, the total flow of $\mathrm{CO}_{2}$ across the surface is $4.31 \times 10^{-3} \mathrm{~kg} \mathrm{~s}^{-1}$ and $4.47 \times 10^{-5} \mathrm{~kg} \mathrm{~s}^{-1}$ indicating that the vadose zone provides significantly more storage of the $\mathrm{CO}_{2}$.

Figure 4.9 is intended to demonstrate the $\mathrm{CO}_{2}$ surface exposure risk measured as the maximum surface flux of $\mathrm{CO}_{2}$ as well as the maximum surface mole fraction of $\mathrm{CO}_{2}$ as a function of the three constant injection rates. For the base-case scenario, the maximum surface flux of $\mathrm{CO}_{2}$ only exceeds the ecological flux at which vegetation consumes $\mathrm{CO}_{2}$ during transpiration of $4.4 \times 10^{-7} \mathrm{~kg}$ $\mathrm{m}^{-2} \mathrm{~s}^{-1}$ for the highest leakage rate. Despite this, the maximum surface mole fraction of $\mathrm{CO}_{2}$ exceeds the observed levels at which tree mortality was observed to occur at Mammoth Mountain, CA. (Farrar et al., 1995, 1999) for leakage rates of $4 \times 10^{5} \mathrm{~kg} \mathrm{yr}^{-1}$ and higher. Therefore, we conclude that although the maximum surface flux of $\mathrm{CO}_{2}$ appears to be quite small, the maximum surface mole fraction of $\mathrm{CO}_{2}$ does appear to pose a significant health risk.

\subsection{Permeability and Anisotropy}

After the injection rate, the second two most sensitive parameters controlling the surface seepage and concentration of $\mathrm{CO}_{2}$ are the permeability and anisotropy of the vadose zone. As part of a sensitivity analysis, we increased the radial and vertical permeabilities, $k_{r}$ and $k_{z}$, from the basecase value of $1 \times 10^{-12} \mathrm{~m}^{2}$ to $1 \times 10^{-11} \mathrm{~m}^{2}, 1 \times 10^{-10} \mathrm{~m}^{2}$, and $1 \times 10^{-9} \mathrm{~m}^{2}$. Similarly, we also increased the anisotropy of $k_{r}: k_{z}$ from 1:1 in the base case to 10:1. 100:1 and 1000:1. All other hydrogeological parameters shown on Table 4.1 were held constant. The leakage rate was also varied from $4 \times 10^{6} \mathrm{~kg} \mathrm{yr}^{-1}$ to $4 \times 10^{5} \mathrm{~kg} \mathrm{yr}^{-1}$ and $4 \times 10^{4} \mathrm{~kg} \mathrm{yr}^{-1}$.

Figure 4.10 and 4.11 show vertical cross-sections of the mole fraction of $\mathrm{CO}_{2}$ in the gas phase, the water saturation, and the pore velocity vectors for a leakage rate of $4 \times 10^{5} \mathrm{~kg} \mathrm{yr}^{-1}$ for the case of increasing permeability and anisotropy, respectively. Both Figures 4.10 and 4.11 show the base-case result discussed above. Figure 4.10 shows that as both the horizontal and vertical permeability are increased from (a) $1 \times 10^{-12} \mathrm{~m}^{2}$ to (b) $1 \times 10^{-11} \mathrm{~m}^{2}$, (c) $1 \times 10^{-10} \mathrm{~m}^{2}$ and (d) $1 \times 10^{-9}$ $\mathrm{m}^{2}$, horizontal spreading of the plume increases dramatically while vertical spreading is reduced. Figure 4.11 shows that as the anisotropy is increased from (a) 1:1 to (b) 10:1, (c) 100:1 and (d) $1000: 1$, the same trend of increased horizontal spreading and decreased vertical spreading is shown. This trend is more prominent for the anisotropy case because the vertical permeability, $k_{z}$, remains fixed at the lowest value of $1 \times 10^{-12} \mathrm{~m}^{2}$ forcing the $\mathrm{CO}_{2}$ to be preferentially transported horizontally. 
Figure 4.12 and 4.13 show the time evolution of the maximum surface mole fraction of $\mathrm{CO}_{2}$ across the ground surface for the case of increasing permeability and increasing anisotropy, respectively. Examination of these figures indicates that for the highest leakage rate of $4 \times 10^{6} \mathrm{~kg}$ $\mathrm{yr}^{-1}$, the maximum mole fraction of $\mathrm{CO}_{2}$ is much more sensitive to anisotropy than permeability. This effect is diminished for the lower leakage rates. This observation can be correlated to the greater decrease in flow of $\mathrm{CO}_{2}$ across the surface due to an increase in anisotropy relative to permeability. This is due to the increase in storage of $\mathrm{CO}_{2}$ in the vadose zone as it is preferentially transported horizontally and is consistent with the increase in horizontal spreading shown on Figure 4.11 relative to Figure 4.10.

The sensitivity of the surface $\mathrm{CO}_{2}$ exposure risk to an increase in the permeability and the anisotropy is shown on Figure 4.9. For a leakage rate of $4 \times 10^{6} \mathrm{~kg} \mathrm{yr}^{-1}$, the maximum surface flux of $\mathrm{CO}_{2}$ is relatively insensitive to an increase in permeability but is very sensitive to an increase in anisotropy. Specifically, the maximum surface flux of $\mathrm{CO}_{2}$ is greater than the ecological flux for the full range of permeabilities used in the sensitivity analysis, whereas only an anisotropy ratio of 1:1 and 10:1 are greater than the ecological flux. As the leakage rate decreases to $4 \times 10^{5} \mathrm{~kg}$ $\mathrm{yr}^{-1}$ and $4 \times 10^{4} \mathrm{~kg} \mathrm{yr}^{-1}$, the leakage flux is always less than the ecological flux independent of variations in permeability and porosity. For a leakage rate of $4 \times 10^{6} \mathrm{~kg} \mathrm{yr}^{-1}$, the maximum surface mole fraction of $\mathrm{CO}_{2}$ exceeds the tree mortality value of 0.3 for all ranges of permeability and all values of anisotropy from 1:1 to 100:1. As the leakage rate decreases to $4 \times 10^{5} \mathrm{~kg} \mathrm{yr}^{-1}$, both a permeability of $1 \times 10^{-11} \mathrm{~m}^{2}$ and an anisotropy of 10:1 are close to the tree mortality limit with all other values of permeability and anisotropy below this threshold.

\subsection{Source Zone Radius}

The radius of the source zone over which leakage occurs is a geometrical consideration of the problem geometry and is analogous to assuming that the migration pathway that $\mathrm{CO}_{2}$ has followed to the water table is confined to within a single borehole, or is laterally extensive due to multiple fault orientations and intersections between the reservoir and the ground surface. As part of a sensitivity analysis, we adjusted the source radius from the base-case value of $100 \mathrm{~m}$ to a maximum value of $1000 \mathrm{~m}$ and a minimum value of $10 \mathrm{~m}$. All hydrogeological parameters shown on Table 4.1 were held constant. The leakage rate was also varied from $4 \times 10^{6} \mathrm{~kg} \mathrm{yr}^{-1}$ to $4 \times 10^{5} \mathrm{~kg} \mathrm{yr}^{-1}$ and $4 \times 10^{4} \mathrm{~kg} \mathrm{yr}^{-1}$.

Figure 4.14 shows a vertical cross section of the mass fraction of $\mathrm{CO}_{2}$ in the gas phase, the water saturation, and the gas phase pore velocity vectors for a leakage rate of $4 \times 10^{5} \mathrm{~kg} \mathrm{yr}^{-1}$ with a source radius of (a) $100 \mathrm{~m}$, (b) $10 \mathrm{~m}$, and (c) $1000 \mathrm{~m}$. As the source radius is decreased by an order-of-magnitude to $10 \mathrm{~m}$, the gas phase pressure increases significantly around the source zone perturbing the water table. The width of the $\mathrm{CO}_{2}$ plume emanating from the $10 \mathrm{~m}$ source zone is only slightly smaller than that of the base case. This indicates that for a leakage rate of $4 \times 10^{5} \mathrm{~kg}$ $\mathrm{yr}^{-1}$, the $\mathrm{CO}_{2}$ plume extends out a minimum radial distance of $130 \mathrm{~m}$ from the origin and is not simply confined to a radius of the source zone as might be inferred from the base case. As the source radius is increased by an order-of-magnitude to $1000 \mathrm{~m}$, the flux of $\mathrm{CO}_{2}$ decreases 
dramatically yielding significantly lower mole fractions of $\mathrm{CO}_{2}$ in the gas phase along the source zone.

Figure 4.15 shows the time evolution of the maximum surface mole fraction of $\mathrm{CO}_{2}$ as well as the total flow of $\mathrm{CO}_{2}$ across the ground surface as a function of source radius. These figures show that the smallest source radius causes the greatest seepage of $\mathrm{CO}_{2}$ for a given leakage rate. As the source zone radius increases from $10 \mathrm{~m}$ to $100 \mathrm{~m}$ and $1000 \mathrm{~m}$, the seepage of $\mathrm{CO}_{2}$ drops dramatically for all three leakage rates. This is also shown on Figure 4.9 where the maximum seepage flux of $\mathrm{CO}_{2}$ is significantly larger than the ecological flux except for the lowest leakage rate. For comparison, the seepage for a leakage rate of $4 \times 10^{6} \mathrm{~kg} \mathrm{yr}^{-1}$ approaches the maximum values measured around the Horseshoe Lake tree-kill area at Mammoth Mountain, CA (Sorey et al., 1999). Not surprisingly, the maximum surface mole fraction of $\mathrm{CO}_{2}$ also exceeds the treemortality limit. As the source radius is increased to $1000 \mathrm{~m}$, the surface exposure risk of $\mathrm{CO}_{2}$ is below both the ecological flux and tree mortality limits for all three leakage rates implying that the potential human health risk may be small as well.

\subsection{Infiltration Rate}

Water infiltrating through the vadose zone is in equilibrium with atmospheric concentrations of $\mathrm{CO}_{2}$ that are orders-of-magnitude lower than the values above the source zone in the base-case scenario. Therefore, this water has the capacity to attenuate the upward migration of $\mathrm{CO}_{2}$ through the vadose zone as it continually dissolves $\mathrm{CO}_{2}$ from the gas phase. As part of a sensitivity analysis, we increased the infiltration rate from the base-case scenario value of $0.1 \mathrm{~m}$ $\mathrm{yr}^{-1}$ to $0.5 \mathrm{~m} \mathrm{yr}^{-1}$, and decreased it to $0.02 \mathrm{~m} \mathrm{yr}^{-1}$ and $0.0 \mathrm{~m} \mathrm{yr}^{-1}$. All hydrogeological parameters shown on Table 4.1 were held constant. The leakage rate was also varied from $4 \times 10^{6} \mathrm{~kg} \mathrm{yr}^{-1}$ to $4 \times 10^{5} \mathrm{~kg} \mathrm{yr}^{-1}$ and $4 \times 10^{4} \mathrm{~kg} \mathrm{yr}^{-1}$.

Figure 4.16 shows a vertical cross section with the mole fraction of $\mathrm{CO}_{2}$ in the gas phase, the water saturation, and the gas phase pore velocity vectors for a leakage rate of $4 \times 10^{5} \mathrm{~kg} \mathrm{yr}^{-1}$ and infiltration rates of (a) $0.1 \mathrm{~m} \mathrm{yr}^{-1}$, (b) $0.0 \mathrm{~m} \mathrm{yr}^{-1}$, (c) $0.5 \mathrm{~m} \mathrm{yr}^{-1}$ and (d) $0.02 \mathrm{~m} \mathrm{yr}^{-1}$. Examination of Figure 4.16 shows that variability in the infiltration rate, and consequently water saturations in the vadose zone, have very little influence on both the lateral and vertical migration of the $\mathrm{CO}_{2}$ plume in the vadose zone. This same conclusion can be inferred from Figures 4.17 and 4.9 which show that the surface exposure risk of $\mathrm{CO}_{2}$ does not deviate significantly from the base-case scenario due to variability in the infiltration rate for all three leakage rates.

\subsection{Porosity}

The porosity of the vadose zone has the potential to influence the horizontal and vertical spreading of the $\mathrm{CO}_{2}$ plume by changing the pore volume available to the gas phase $\mathrm{CO}_{2}$ plume. A decrease in porosity should increase spreading while an increase in porosity should decrease spreading. As part of a sensitivity analysis, we doubled the porosity from the base-case scenario value of 0.2 to 0.4 and alternatively halved it to 0.1 . All other hydrogeological parameters shown on Table 4.1 were held constant. The leakage rate was also varied from $4 \times 10^{6} \mathrm{~kg} \mathrm{yr}^{-1}$ to $4 \times 10^{5} \mathrm{~kg}$ $\mathrm{yr}^{-1}$ and $4 \times 10^{4} \mathrm{~kg} \mathrm{yr}^{-1}$. 
Figure 4.18 shows a vertical cross-section with the mass fraction of $\mathrm{CO}_{2}$ in the gas phase, the water saturation, and the gas phase pore velocity vectors for a leakage rate of $4 \times 10^{5} \mathrm{~kg} \mathrm{yr}^{-1}$ and porosities of (a) 0.2 , (b) 0.4 , and (c) 0.1 . Examination of Figure 4.18 shows that variability in the porosity has very little influence on both the lateral and vertical migration of the $\mathrm{CO}_{2}$ plume in the vadose zone. This same conclusion can be inferred from Figures 4.19 and 4.9 which show that the surface exposure risk of $\mathrm{CO}_{2}$ does not deviate significantly from the base-case scenario due to variability in porosity for all three leakage rates.

\section{CONCLUSIONS}

Carbon dioxide stored in deep geologic formations as a supercritical fluid will have a tendency to leak and migrate away from the primary target formation due to its low density and viscosity relative to groundwater. If leaking $\mathrm{CO}_{2}$ reaches the vadose zone, the buoyancy driving force is reversed, and $\mathrm{CO}_{2}$ will tend to float on top of the water table. Nevertheless, pressure driving forces or lack of a vadose zone will cause $\mathrm{CO}_{2}$ to seep out of the ground. Carbon dioxide solubility is quite high in water and leaking $\mathrm{CO}_{2}$ will tend to dissolve in groundwater, although the extent to which this occurs is highly dependent on the form of the leakage, for example leakage as a dispersed plume or as a concentrated fast-flow feature. Natural analogs for gas leakage and seepage occur at natural gas fields and gas storage reservoirs. Natural gas seeps demonstrate that gas migration from great depths can lead to gas seepage. Gas storage leaks have resulted in large lateral migrations and fast gas travel times. Simple estimates of $\mathrm{CO}_{2}$ seepage show that seepage flux is strongly dependent on the area over which seepage occurs, and that large seepage areas are unlikely to result in health and safety risks. Numerical simulations of $\mathrm{CO}_{2}$ migration in the subsurface show strong effects of $\mathrm{CO}_{2}$ solubility, and that leakage rate is the primary control on seepage and surface concentrations, with permeability, permeability anisotropy, and source area next in importance. Other properties such as infiltration rate and porosity are less important in controlling seepage and near-surface $\mathrm{CO}_{2}$ concentrations. This work provides the foundation for development of a coupled framework that considers both subsurface flow and transport and near-surface air dispersion of seeping $\mathrm{CO}_{2}$ for the purposes of modeling $\mathrm{CO}_{2}$ seepage and the resulting $\mathrm{CO}_{2}$ concentrations for health, safety, and environmental risk assessment.

\section{ACKNOWLEDGMENTS}

We thank Larry Myer (LBNL) and Christine Doughty (LBNL) for constructive comments and reviews of this report. This work was supported in part by a Cooperative Research and Development Agreement (CRADA) between BP Corporation North America, as part of the $\mathrm{CO}_{2}$ Capture Project (CCP) of the Joint Industry Program (JIP), and the U.S. Department of Energy (DOE) through the National Energy Technologies Laboratory (NETL), and by the Ernest 
Orlando Lawrence Berkeley National Laboratory, managed for the U.S. Department of Energy under contract DE-AC03-76SF00098.

\section{REFERENCES}

Allison, M. L., 2001, Hutchinson, Kansas: a geologic detective story; Geotimes,46(10), 14-20, October, 2001

Araktingi, R. E., M. E. Benefield, Z. Bessenyei, K. H. Coats, M. R. Tek, Leroy storage facility, Uinta County, Wyoming: a case history of attempted gas-migration control, J. Petrol. Tech., 132, Trans. AIME, 277, January 1984.

Baldocchi, D.D. and K.B. Wilson, Modeling CO2 and water vapor exchange of a temperate broadleaved forest across hourly to decadal time scales, Ecological Modelling, 142, 155-184, 2001.

Bertoldi, B. L., R. H. Johnston, and K. D. Evenson, Ground water in the Central Valley, California - a summary report; United States Geological Survey Professional Paper 1401-A. 44 p., 1991.

Burroughs, E., Rio Vista Gas Field, Summary of California oil fields, 53, No. 2-Part 2, State of California, Department of Conservation, Division of Oil and Gas, 25, 1967.

Clauser, C., Permeability of crystalline rocks, EOS Trans. AGU, 73(21), May 26, 1992.

Cramer, S.D., The solubility of methane, carbon dioxide, and oxygen in brines from $0{ }^{\circ}$ to $300{ }^{\circ} \mathrm{C}$, U.S. Bureau of Mines: Report No. 8706, 16 pp., 1982.

Chung, T.-H., M. Ajlan, L.L. Lee, and K.E. Starling, "Generalized multiparameter correlation for nonpolar and polar fluid transport properties," Ind. Eng. Chem. Res., 27, p. 671, 1988.

Department of Water Resources, Historical ground water levels in Solano County, California Department of Water Resources, 386 p., 1994.

Evenson, K. D., Chemical quality of groundwater in Solano and Yolo Counties, California, United States Geological Survey Water Resources Investigation Report 84-4244, 50 p., 1985.

Falta, R.W., and I. Javandel, K. Pruess, and P.A. Witherspoon, Density-driven flow of gas in the unsaturated zone due to the evaporation of volatile organic compounds, Water Resour. Res., 25(10), 2159-2169, 1989. 
Farrar, C.D., M.L. Sorey, W.C. Evans, J.F. Howle, B.D. Kerr, B.M. Kennedy, C.-Y. King and J.R. Southon., Forest-killing diffuse C)2 emissions at Mammoth Mountain as a sign of magmatic unrest, Nature, 376 (6542), p. 675-678., 1995.

Farrar, C.D., J.M. Neil and J.F. Howle., Magmatic carbon dioxide emissions at Mammoth Mountain, California, U.S. Geological Survey Open-File Report 98-4217, 34p. and 1 plate, 1999.

Flury, M., H. Flühler, W.A. Jury, and J. Leuenberger, Susceptibility of soils to preferential flow of water: a field study, Water Resour. Res., 30(7), 1945-1954, 1994.

Ghodrati, M., and W.A. Jury, A field study of the effecs of soil structure and irrigation method on preferential flow of pesticides in unsaturated soil, J. Contam. Hydrology, 11, 101-125, 1992.

Ghodrati, M., and W.A. Jury, A field study using dyes to characterize the preferential flow of water, Soil Sci. Soc. Am. J., 54, 1558-1563, 1990.

Hippler, S.J., Microstructures and diagenesis in North Sea fault zones: implications for fault-seal potential and fault-migration rates, in AAPG Memoir 67, Seals, Traps, and the Petroleum System, edited by R.C. Surdam, AAPG Tulsa, OK, 103-113, 1997.

Hodgson, S. F., Onshore oil and gas seeps in California; California Division of Oil and Gas, Publication Number TR26, 97 p., 1980.

IEA (International Energy Agency), "Carbon Dioxide Utilization," IEA Greenhouse Gas R\&D Programme, 1997; Table 6.

Johnson, D.S., Rio Vista field-USA, Sacramento basin, Calif., in Foster, N.H., and Beaumont, E.A., eds., Atlas of oil and gas fields, Structural Traps III, AAPG Treatise of Petroleum Geology, Atlas of Oil and Gas Fields, Tulsa, Oklahoma, U.S.A., 1990.

Johnson, K. L., Chemical quality of ground water in Sacramento and Western Placer Counties, California; United States Geological Survey Water Resources Investigation Report 85-4164, 50 p., 1985.

Kaldi, J.G., and C.D. Atkinson, Evaluating seal potential: example from the Talang Akar formation, offshore Northwest Java, Indonesia, in AAPG Memoir 67, Seals, Traps, and the Petroleum System, edited by R.C. Surdam, AAPG Tulsa, OK, 85-101, 1997.

Kung, K-J.S., Preferential flow in a sandy vadose zone: 1. Field observation, Geoderma, 46, 51-58, 1990a. 
Kung, K-J.S., Preferential flow in a sandy vadose zone: 2. Mechanism and implications, Geoderma, 46, 59-71, $1990 \mathrm{~b}$.

Li, Y., and M. Ghodrati, Preferential transport of nitrate through soil columns containing root channels, Soil Sci. Soc. Am. J., 58, 653-659, 1994.

Magee, J.W., J.A. Howley, J.F. Ely, “A predictive model for the thermophysical properties of carbon dioxide rich mixtures," Research Report RR-136, Gas Processors Assoc., Tulsa OK, 35 pp., 1994.

Neuman, S.P., Generalized scaling of permeabilities: Validation and effect of support scale, Geophys. Res. Letts., 21(5), 349-352, 1994.

Neuzil, C.E., How permeable are clays and shales, Water Resour. Res., 30(2), 145-150, 1994.

NIST (National Institute of Science and Technology), NIST Database 14 Mixture Property Database, version 9.08, U.S. Department of Commerce (Oct. 1992).

Oldenburg, C.M., K. Pruess, and S.M. Benson, Process modeling of $\mathrm{CO}_{2}$ injection into natural gas reservoirs for carbon sequestration and enhanced gas recovery, Energy\&Fuels, 15, 293-298, 2001.

Oldenburg and Benson, $\mathrm{CO}_{2}$ injection for enhanced gas production and carbon sequestration, Society of Petroleum Engineers SPE-74367, presented at IPCEM 2002 in Mexico, Feb. 2002.

Page, R. W., Geology of the fresh ground-water basin of the Central Valley, California, with texture maps and sections; United States Geological Survey Professional Paper 1401-C, 54 p., 1986.

Poling, B.E., J.M. Prausnitz, and J.P. O'Connell, The properties of gases and liquids, fifth edition, McGraw Hill, New York, 2001.

Pruess, K., C. Oldenburg, and G. Moridis, TOUGH2 User's Guide Version 2.0, Lawrence Berkeley National Laboratory Report LBNL-43134, 197 pp., November 1999.

Reichle, D. et al., Carbon sequestration research and development 2000, U.S. Department of Energy, DOE/SC/FE-1, 1999.

Sorey, M., B. Evans, M. Kennedy, J. Rogie and A. Cook, Magmatic gas emissions from Mammoth Mountain, California Geology, 52(5), 4-16, 1999.

van Genuchten, M.Th., A closed form equation for predicting the hydraulic conductivity of 
unsaturated soils, Soil Sci. Soc., 44, 892, 1980.

Vargaftik, N.B., Y.K. Vinogradov, and V.S. Yargin, Handbook of Physical Properties of Liquids and Gases, Third Edition, Begell House, New York, 1359 pp., 1996.

Weber-Band, J., Neotectonics of the Sacramento-San Joaquin Delta area, east-central Coast Ranges, California, University of California, Berkeley, doctoral thesis, 216 p., 1998.

Williamson, A. K., D. E. Prudic, and L. A. Swain, Ground-water flow in the Central Valley, California; United States Geological Survey Profession Paper 1401-D, 127 p., 1989. 


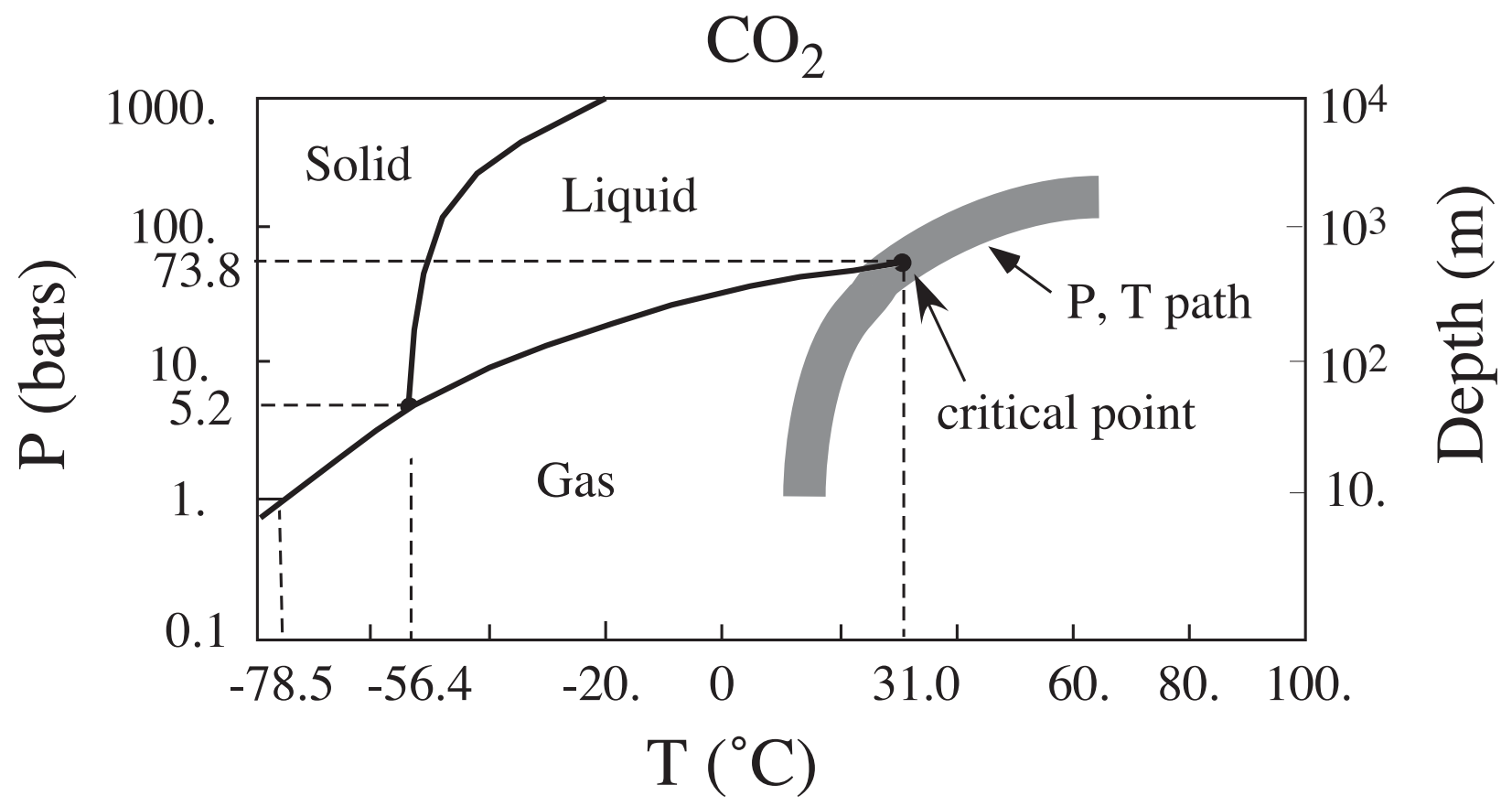

Figure 2.1. Phase diagram for $\mathrm{CO}_{2}$ with approximate $P, T$ path in the subsurface assuming hydrostatic pressure and geothermal gradient of $25^{\circ} \mathrm{C} \mathrm{km}^{-1}$. 


\section{$\mathrm{CO}_{2}$ Density $(\rho)$}

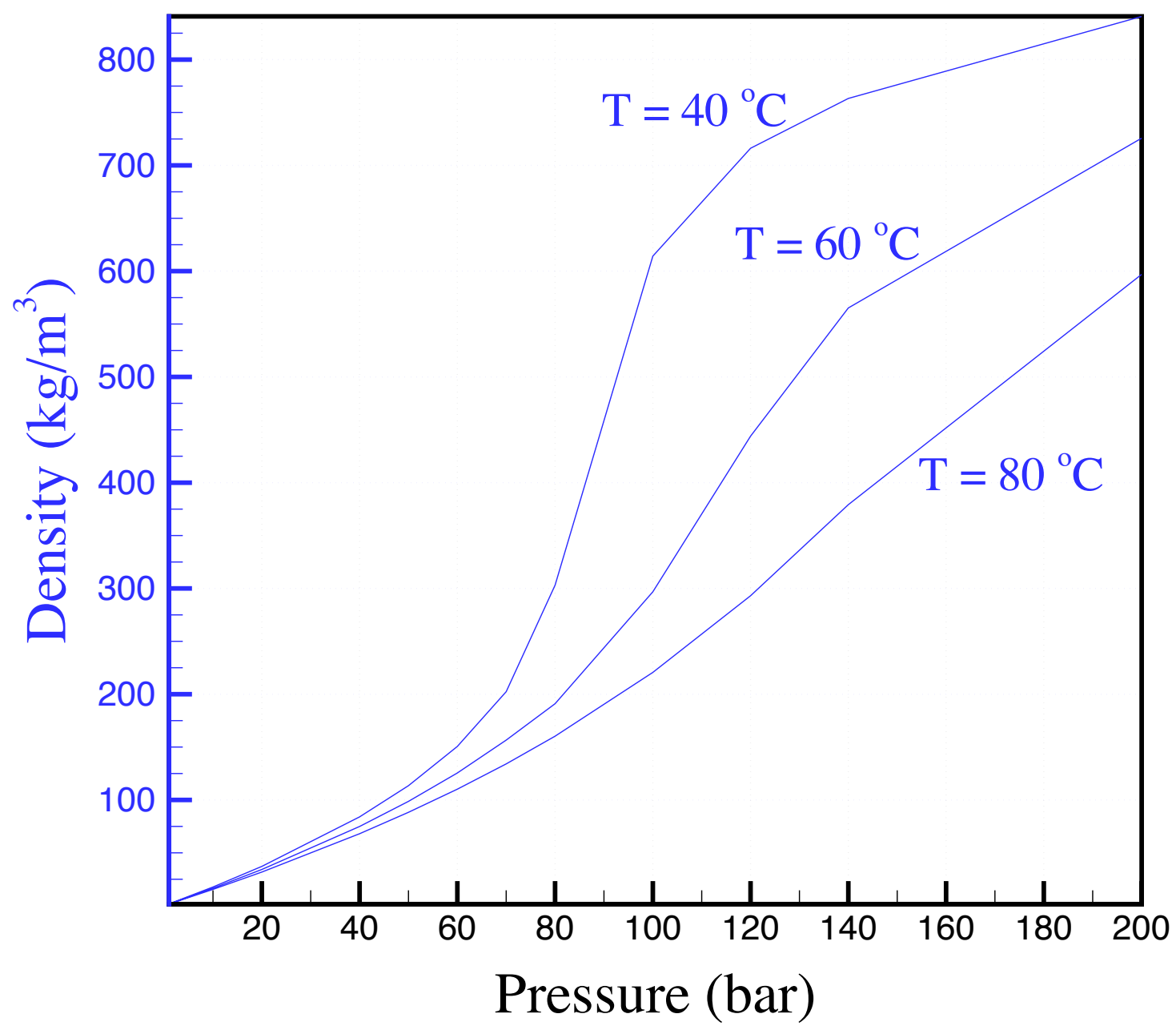

Figure 2.2. Density as a function of pressure at three different temperatures. 


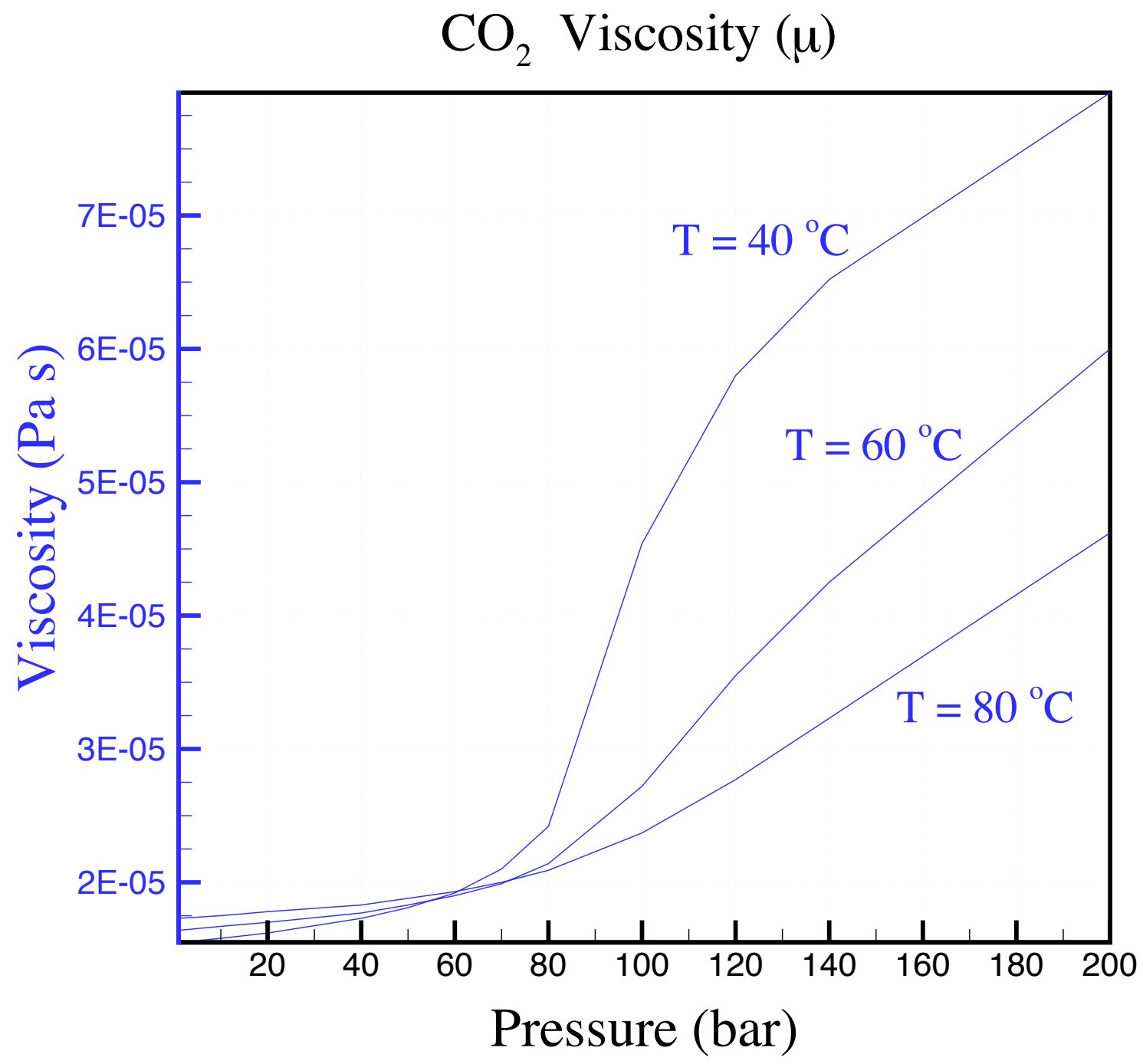

Figure 2.3. Viscosity as a function of pressure at three different temperatures. 


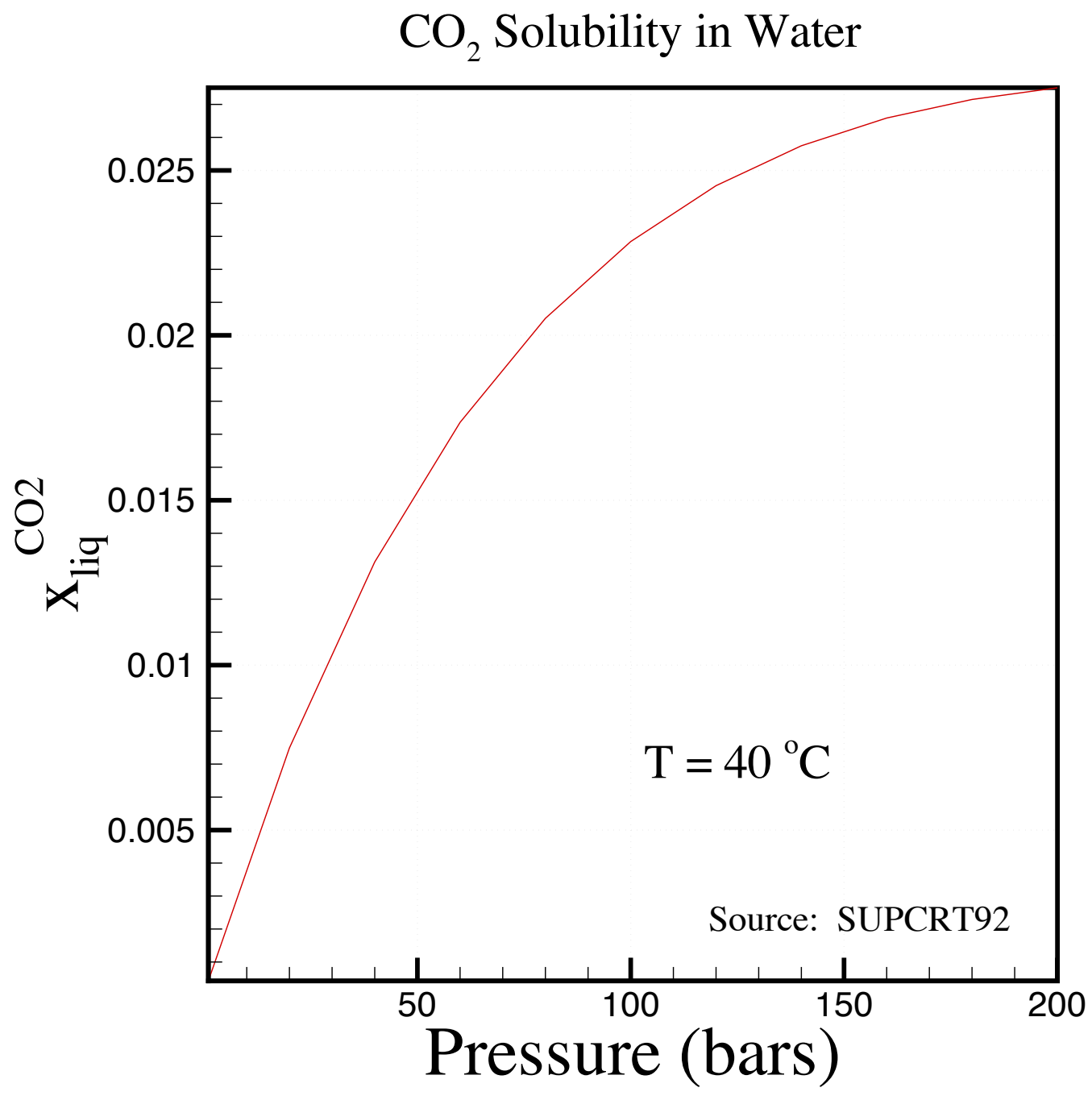

Figure 2.4. Solubility of $\mathrm{CO}_{2}$ in water as a function of pressure at $\mathrm{T}=40^{\circ} \mathrm{C}$. 


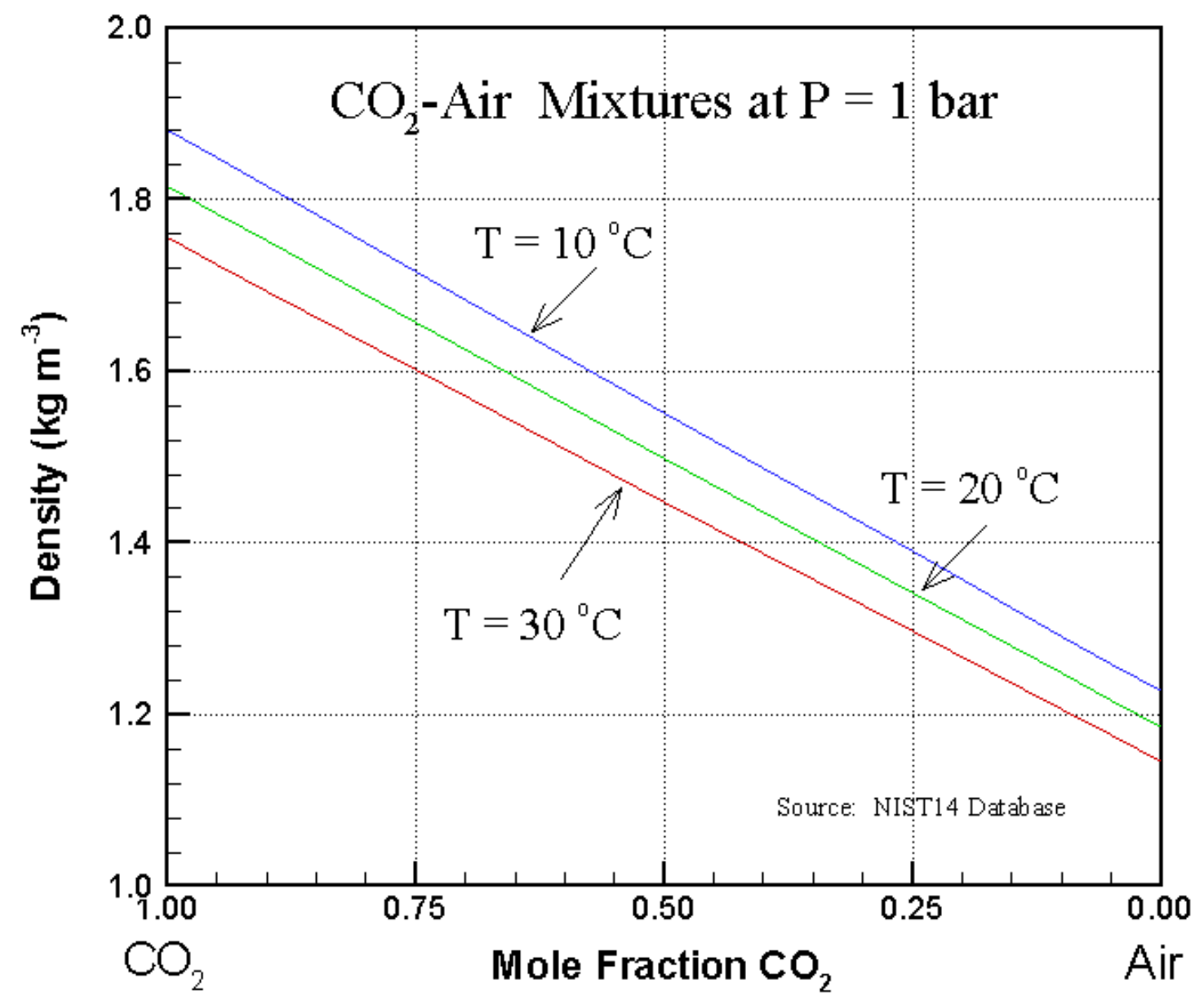

Figure 2.5. Density as a function of concentration in the system $\mathrm{CO}_{2}$-air. 


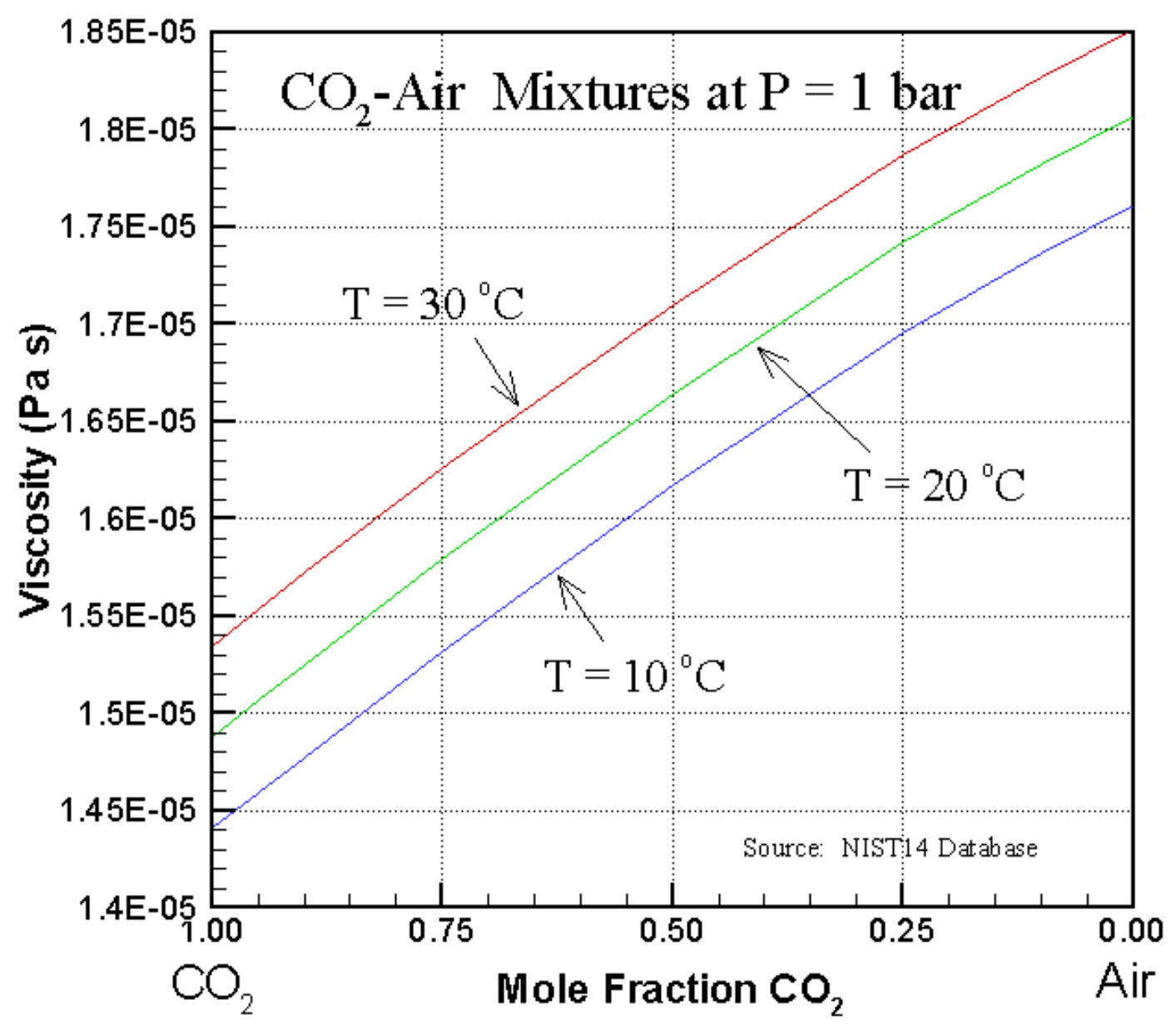

Figure 2.6. Viscosity as a function of concentration in the system $\mathrm{CO}_{2}$-air. 


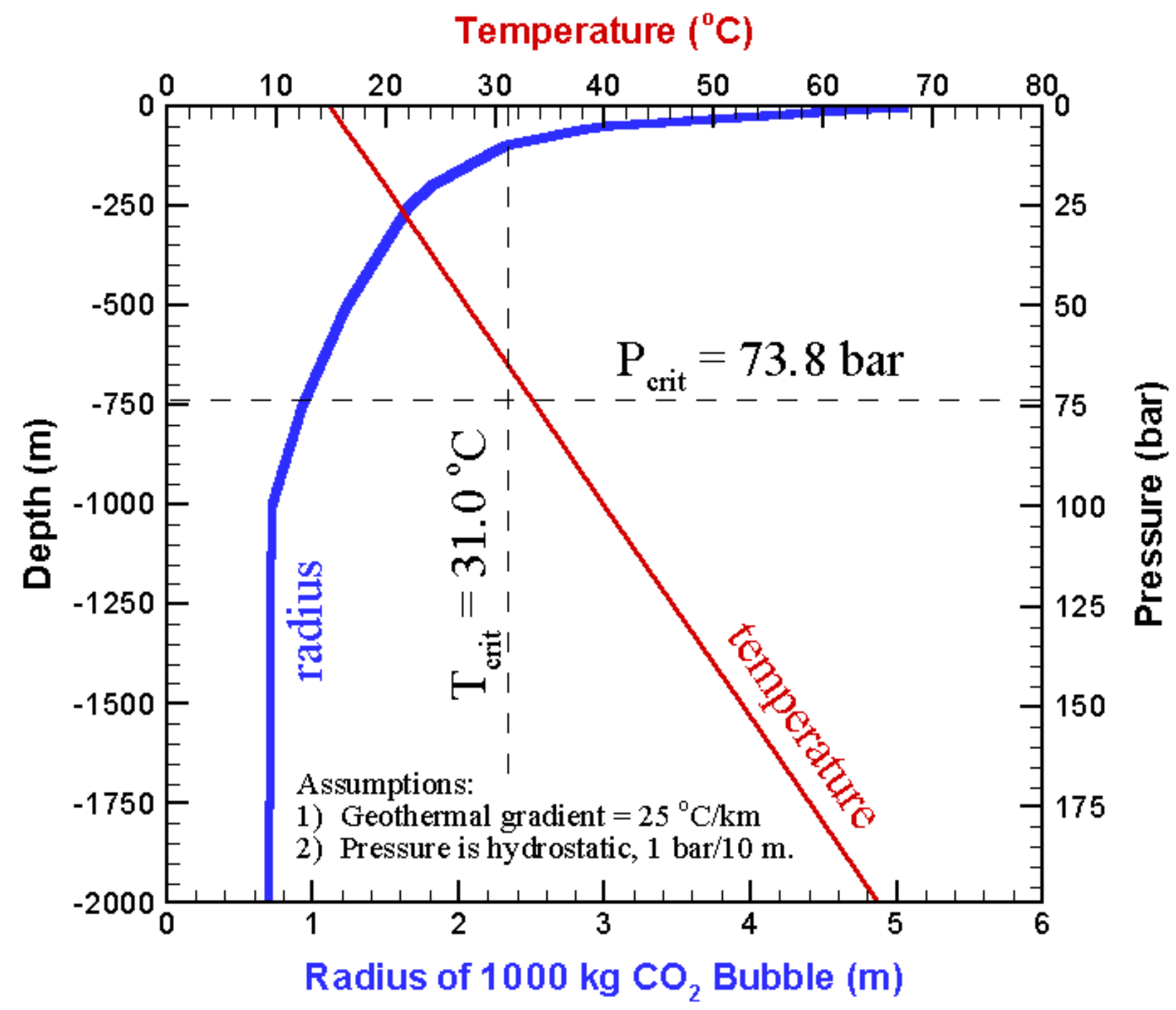

Figure 3.1. Hypothetical radius of a spherical $\mathrm{CO}_{2}$ bubble at typical subsurface temperatures and pressures. 


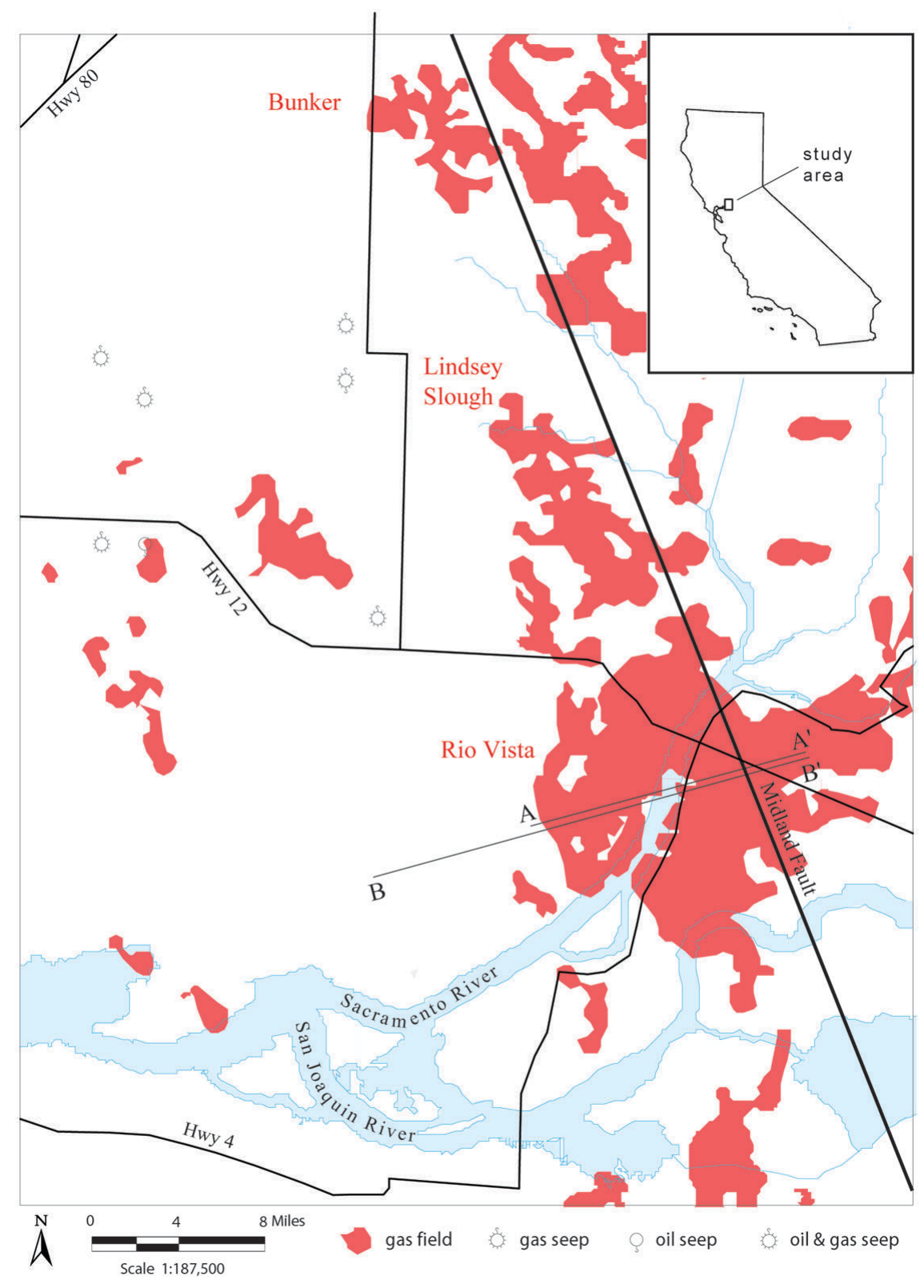

(modified from 1999 California Division of Oil and Gas District 6 oil, gas and geothermal field map)

Figure 3.2. Location map of the Rio Vista area. 


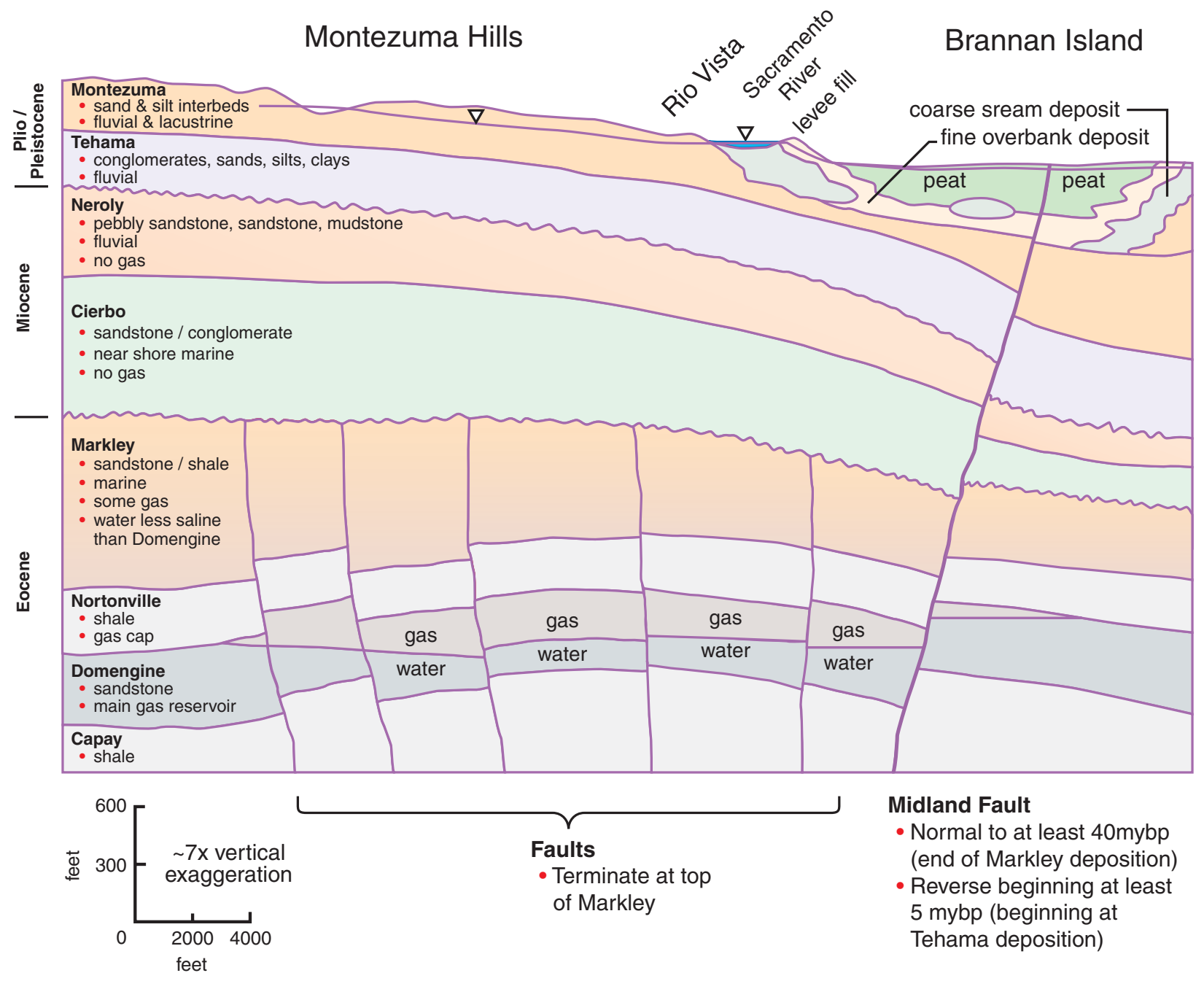

Figure 3.3. Cross section of the Rio Vista area. 
small amounts of gas migrate upsection and updip to water table

small amounts of gas migrate upsection out of Paleogene Strata

gas migrates updip through faults and is trapped in sands in domes

gas is produced in

Cretaceous shales and migrates upsection

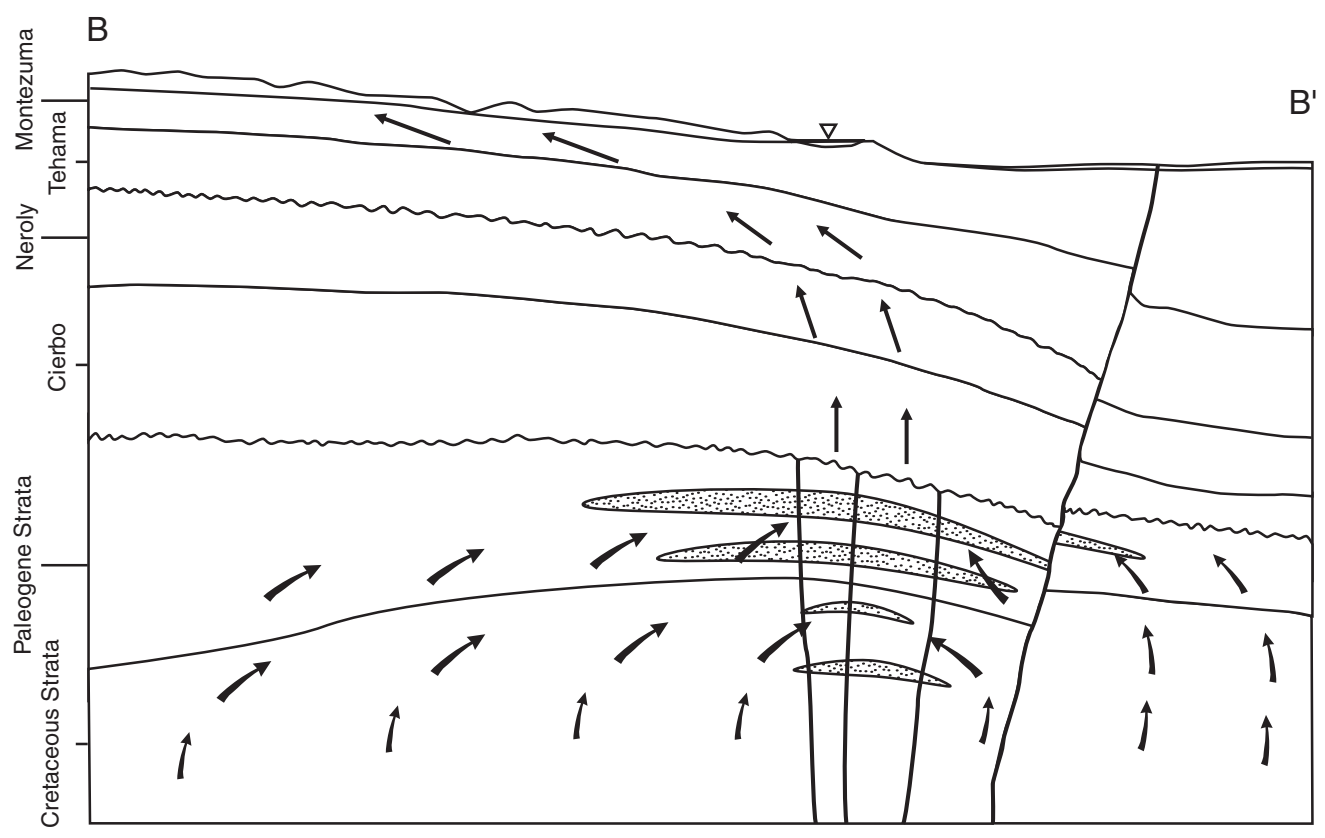

Figure 3.4. Conceptual model of gas leakage at Rio Vista. 


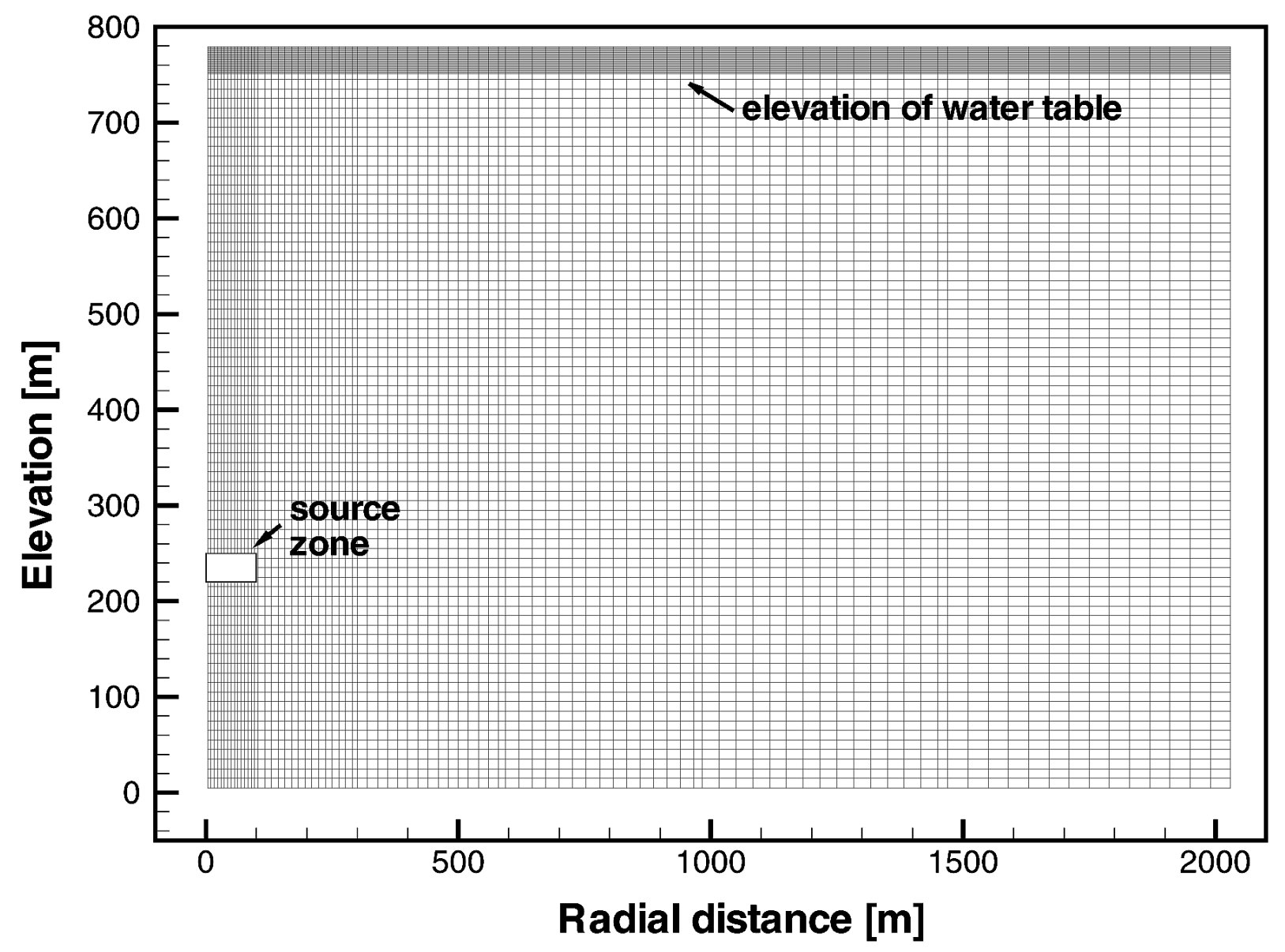

Figure 4.1. Numerical mesh for the saturated zone model 


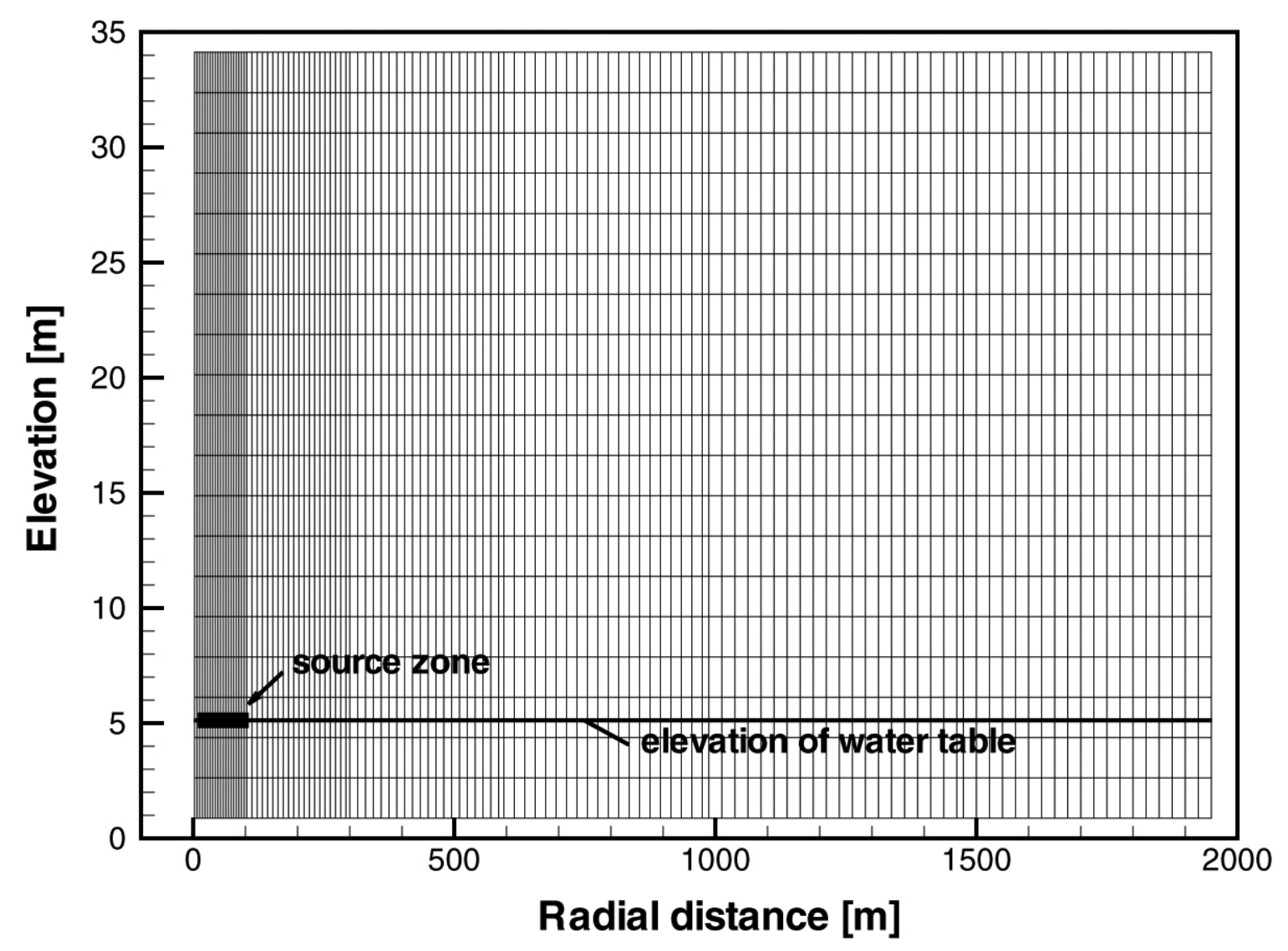

Figure 4.2. Numerical mesh for the vadose zone model. 


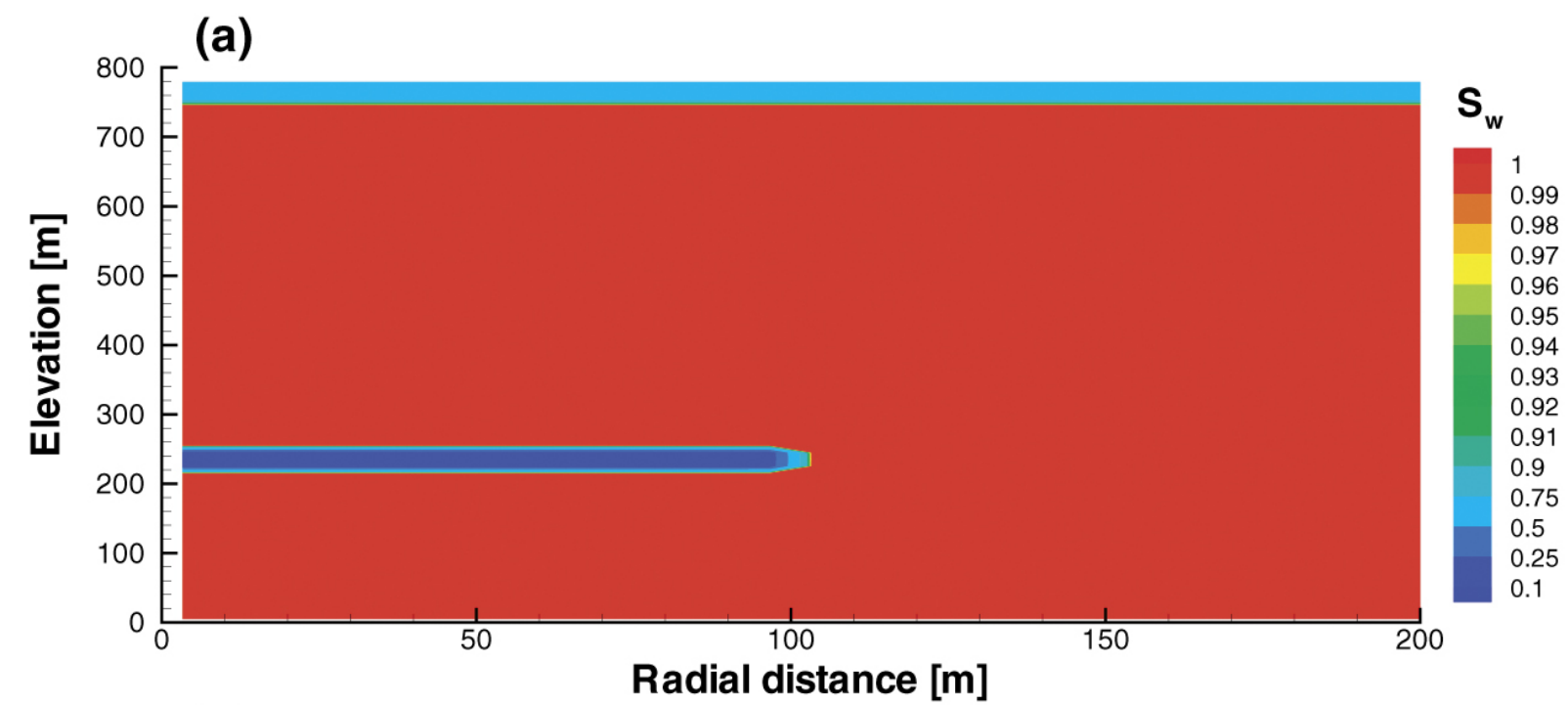

(b)

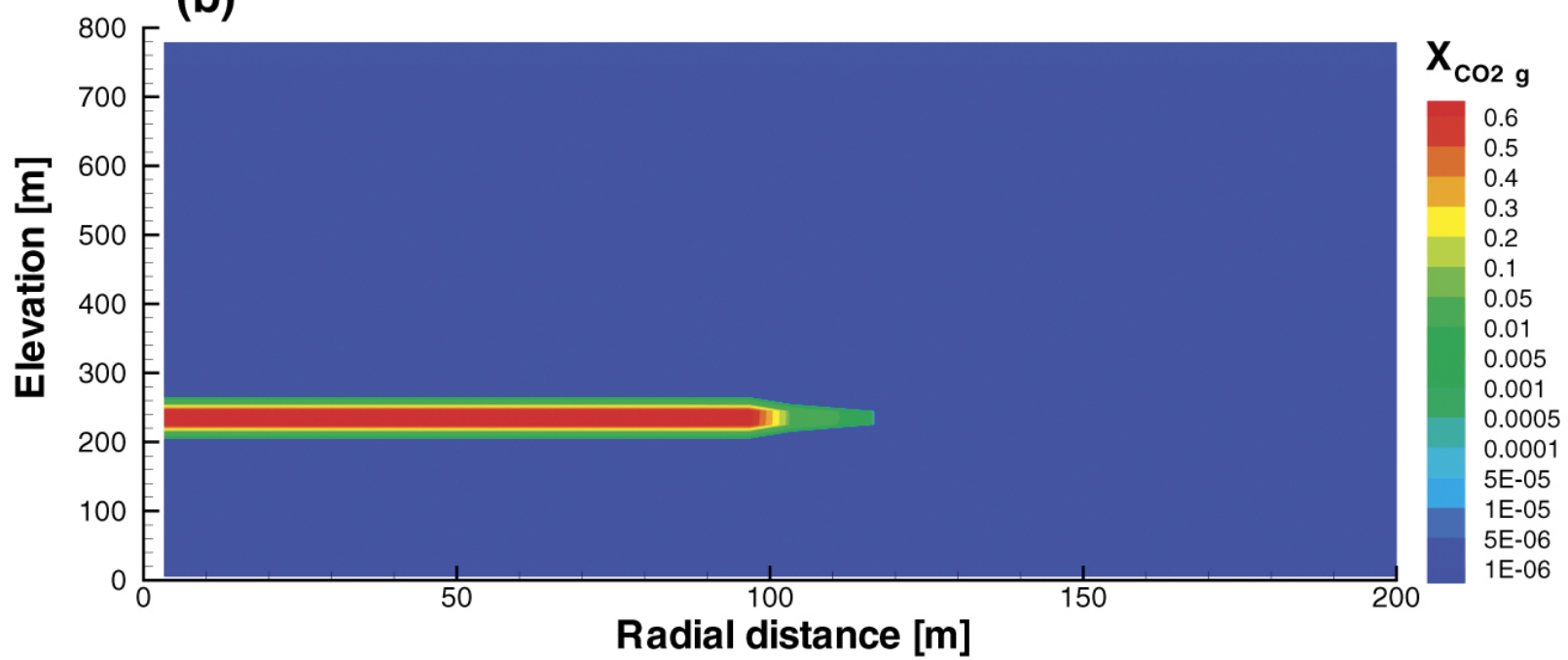

Figure 4.3. (a) Water saturations at initial time showing the bubble and (b) the mass fraction of $\mathrm{CO}_{2}$ in the gas phase showing the composition of the bubble. 
(a)

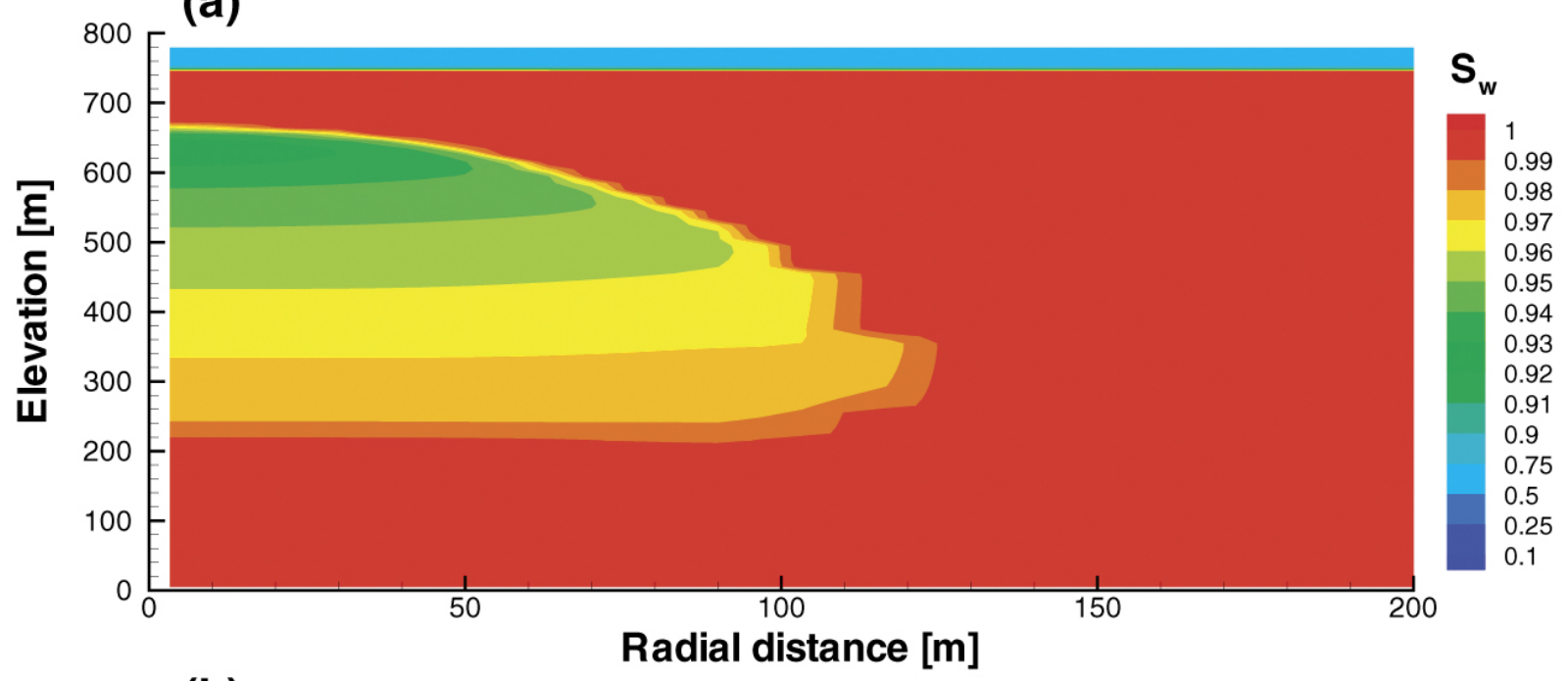

(b)

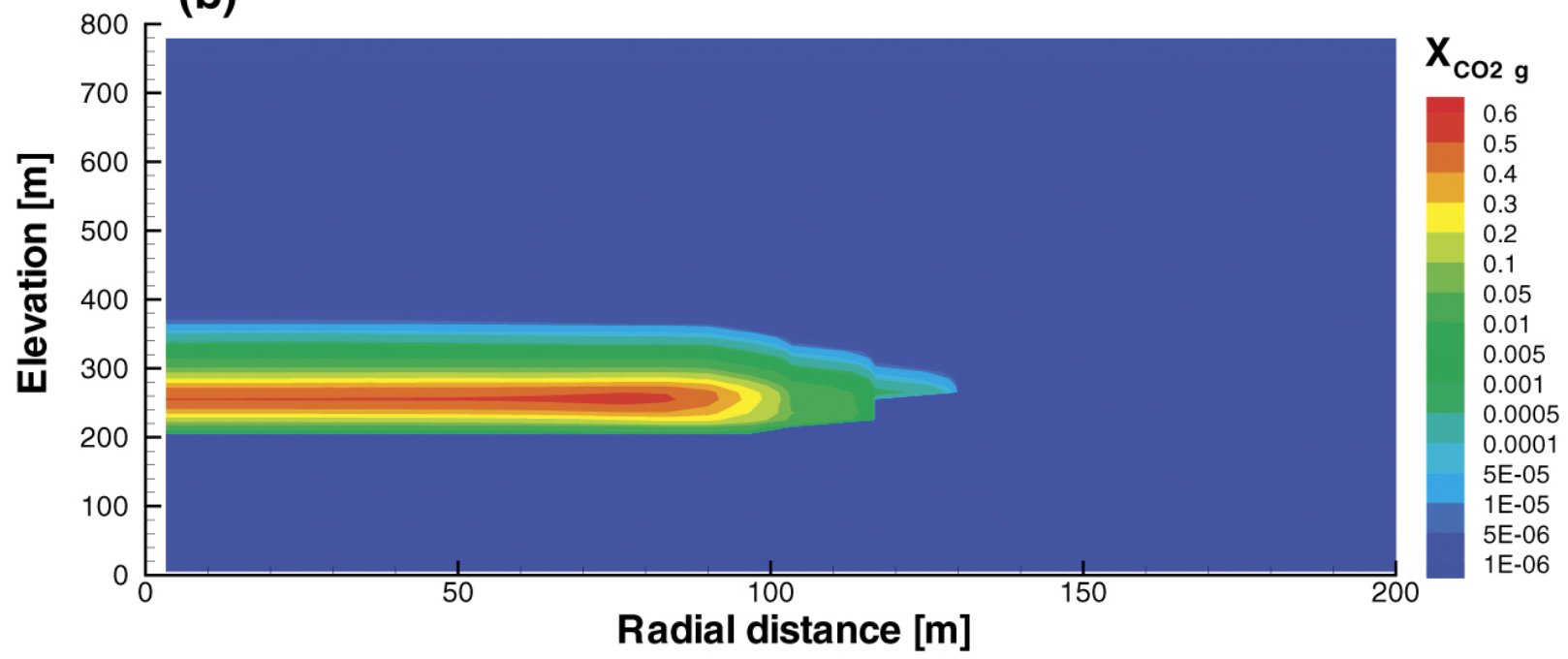

Figure 4.4. (a) Water saturations at a time of 0.5 years showing the upward migration of the bubble and (b) the mass fraction of $\mathrm{CO}_{2}$ in the gas phase. 
(a)

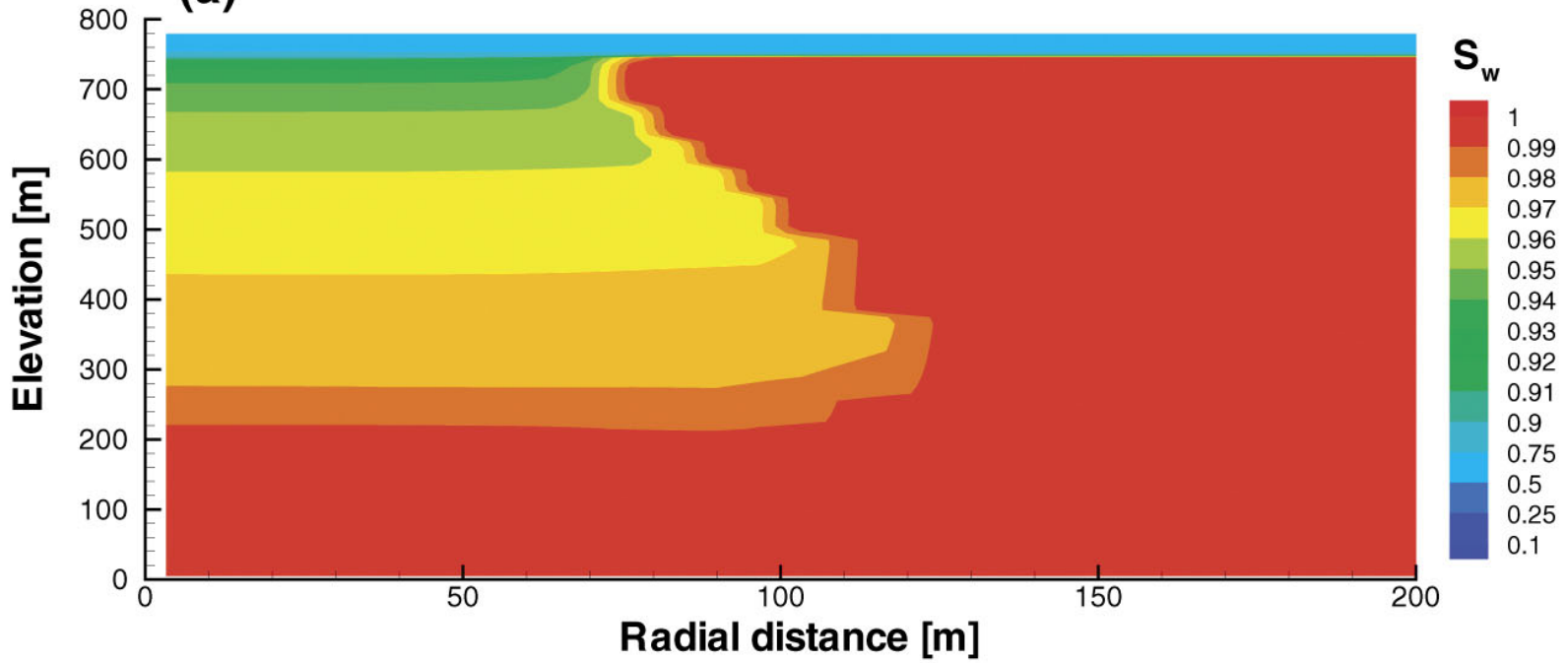

(b)

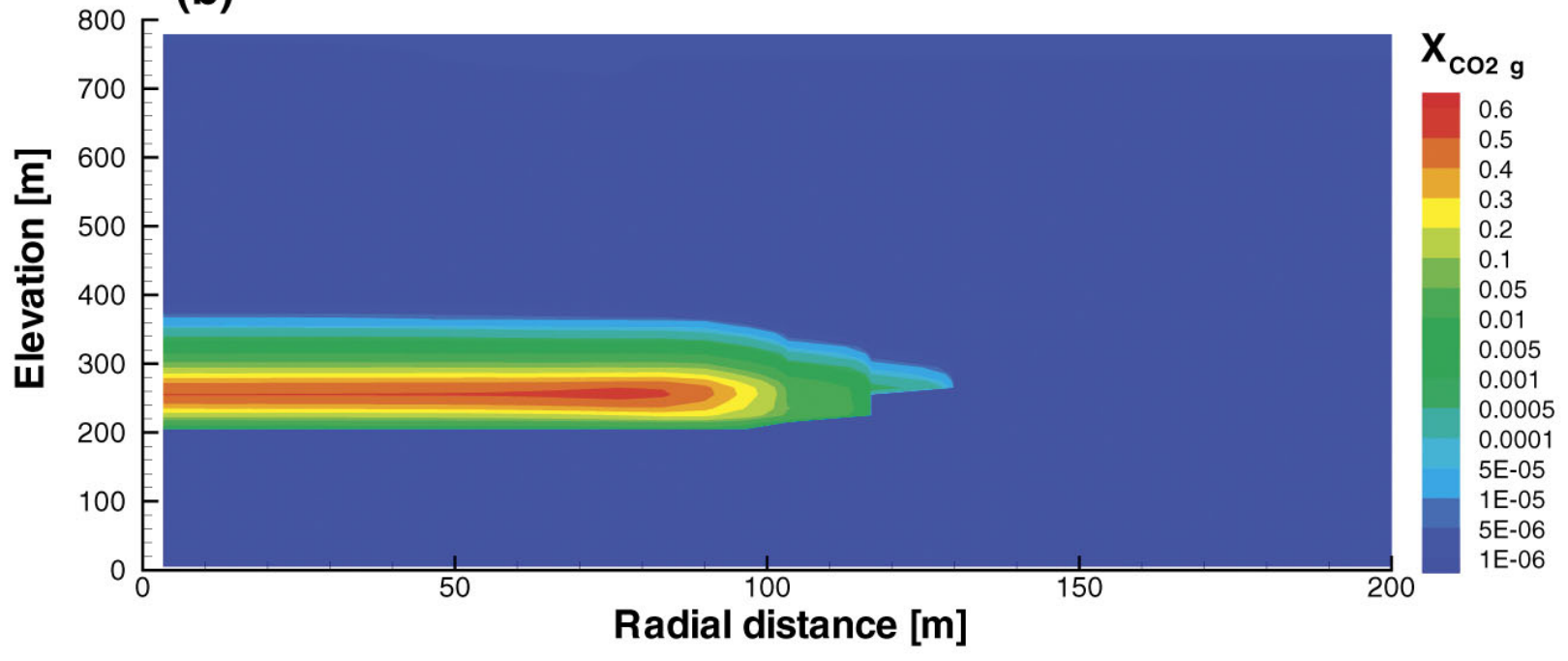

Figure 4.5. (a) Water saturations at a time of one year showing the breakthrough of the bubble at the water table and (b) the mass fraction of $\mathrm{CO}_{2}$ in the gas phase. 
(a)

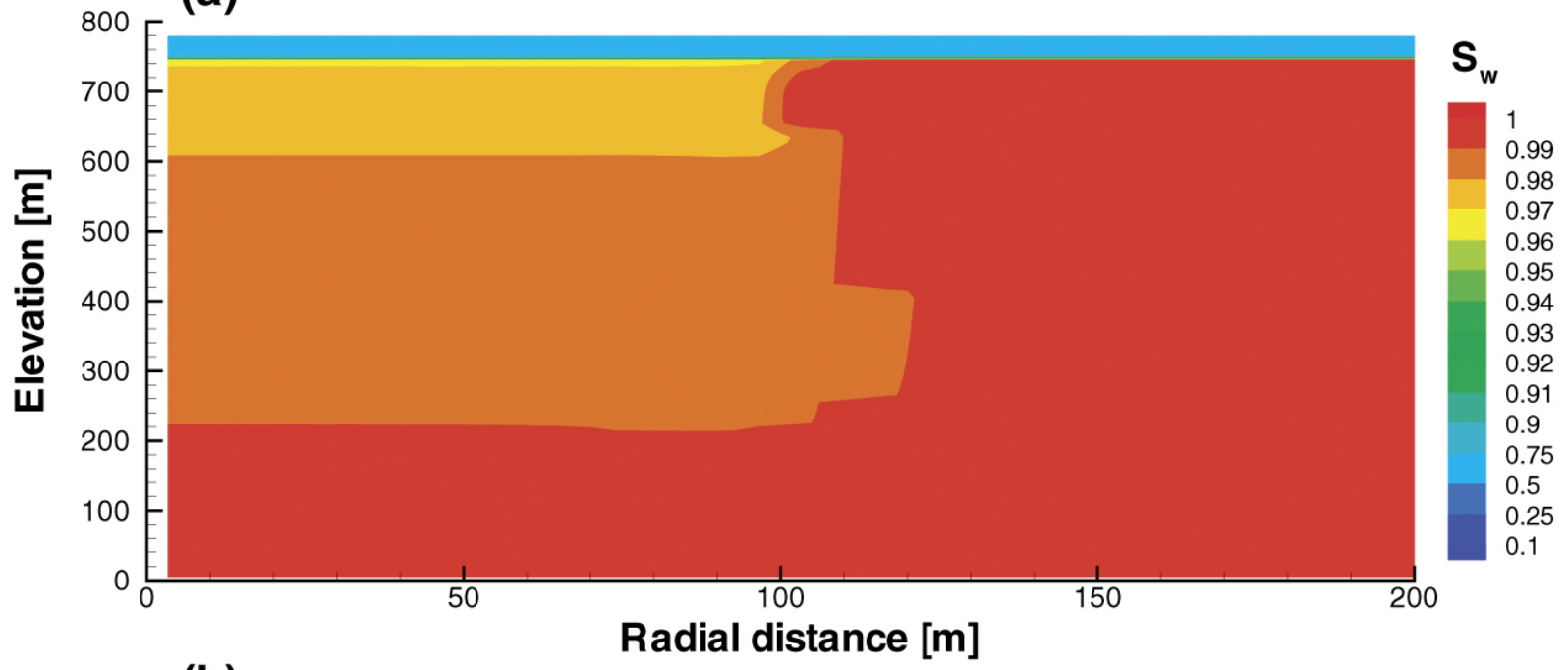

(b)

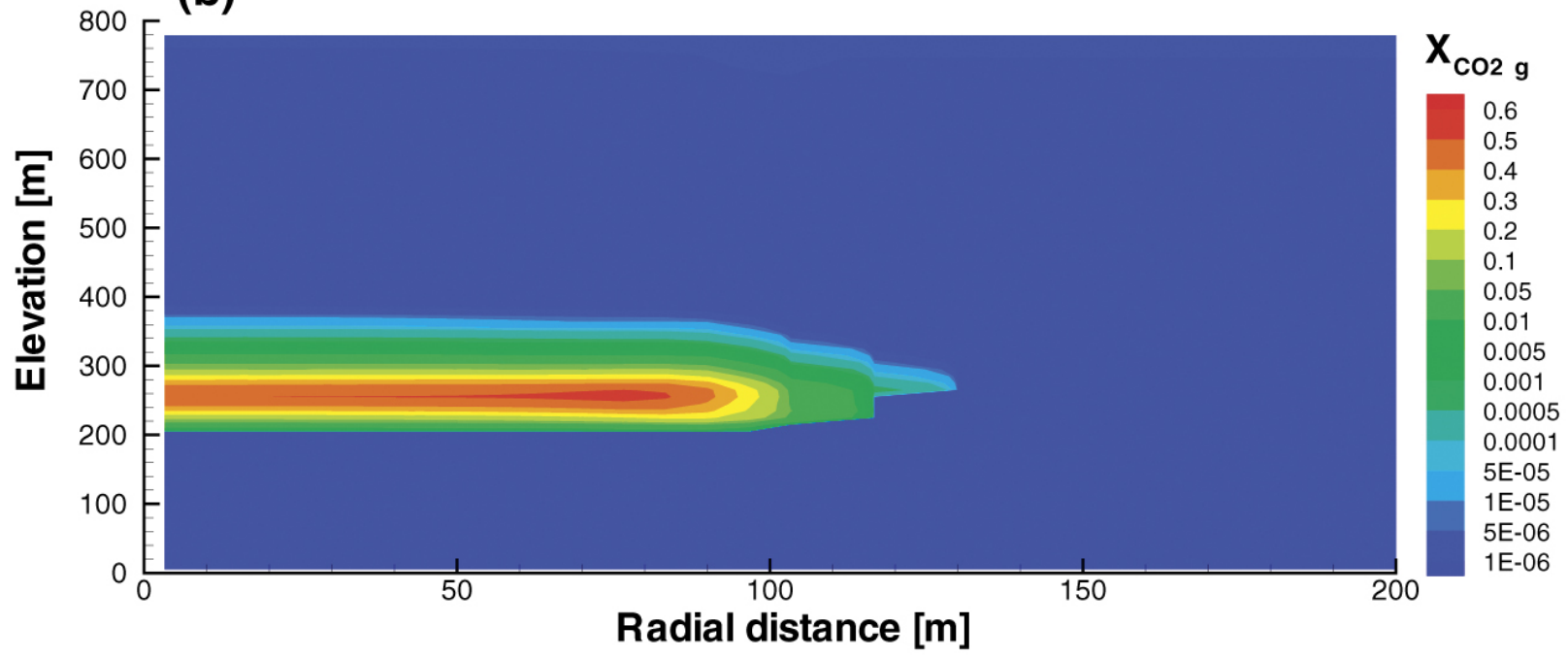

Figure 4.6. (a) Water saturations at a time of ten years showing the long-term influence of the bubble in the saturated zone and (b) the mass fraction of $\mathrm{CO}_{2}$ in the gas phase. 
(a)

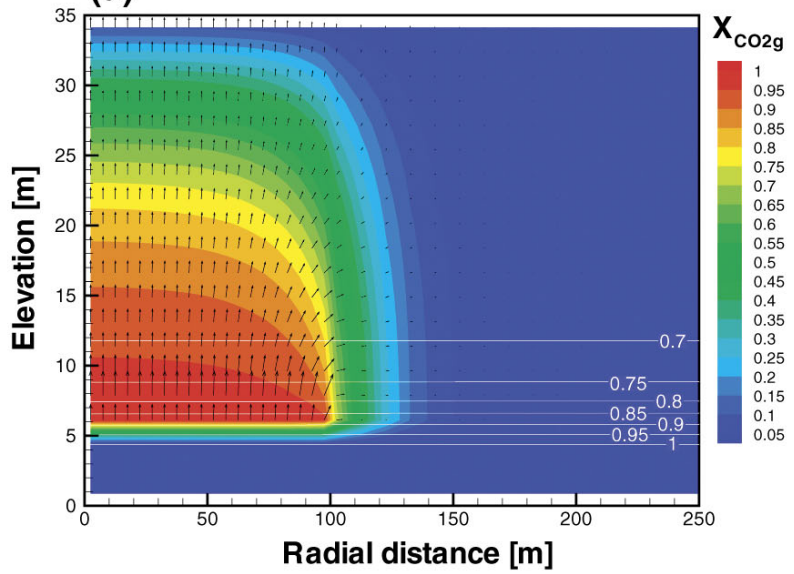

(c)

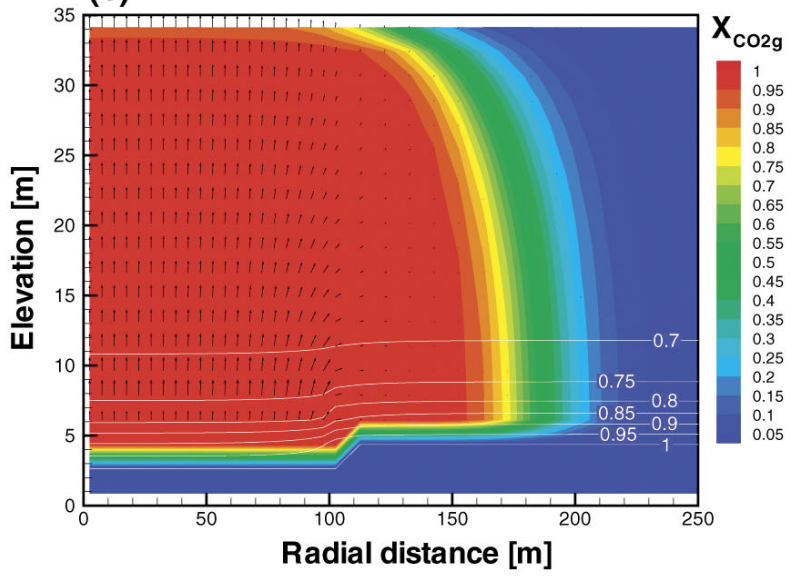

(b)

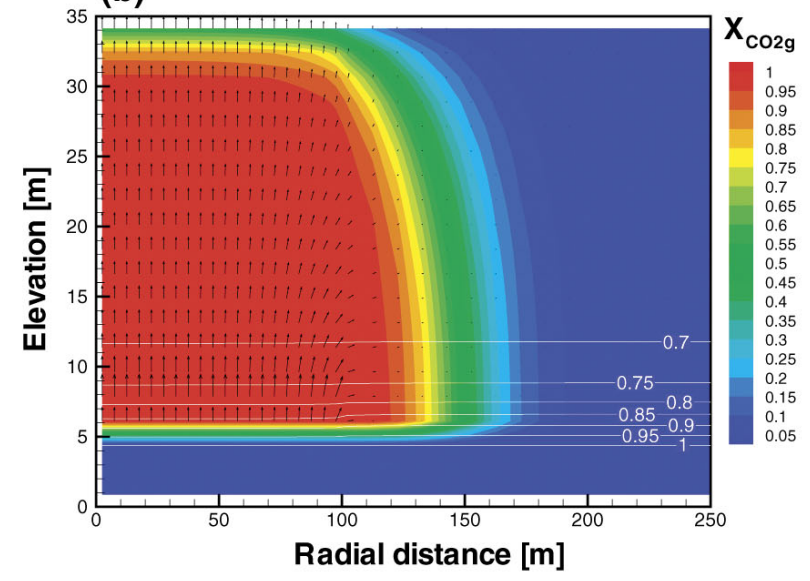

Figure 4.7. Colored contours indicate the mass fraction of $\mathrm{CO}_{2}$ in the gas phase, labeled contours indicate the water saturation, and vectors indicate the Pore velocity of the gas phase for the base scenario with a leakage rate of (a) $4 \times 10^{4} \mathrm{~kg} \mathrm{yr}^{-1}$, (b) $4 \times 10^{5} \mathrm{~kg} \mathrm{yr}^{-1}$ and (c) $4 \times 10^{6} \mathrm{~kg} \mathrm{yr}^{-}$ I. The maximum vector size represents a value of (a) $0.054 \mathrm{~m} \mathrm{~d}^{-1}$, (b) $0.53 \mathrm{md}^{-1}$ and (c) $3.6 \mathrm{~m} \mathrm{~d}^{-1}$. 

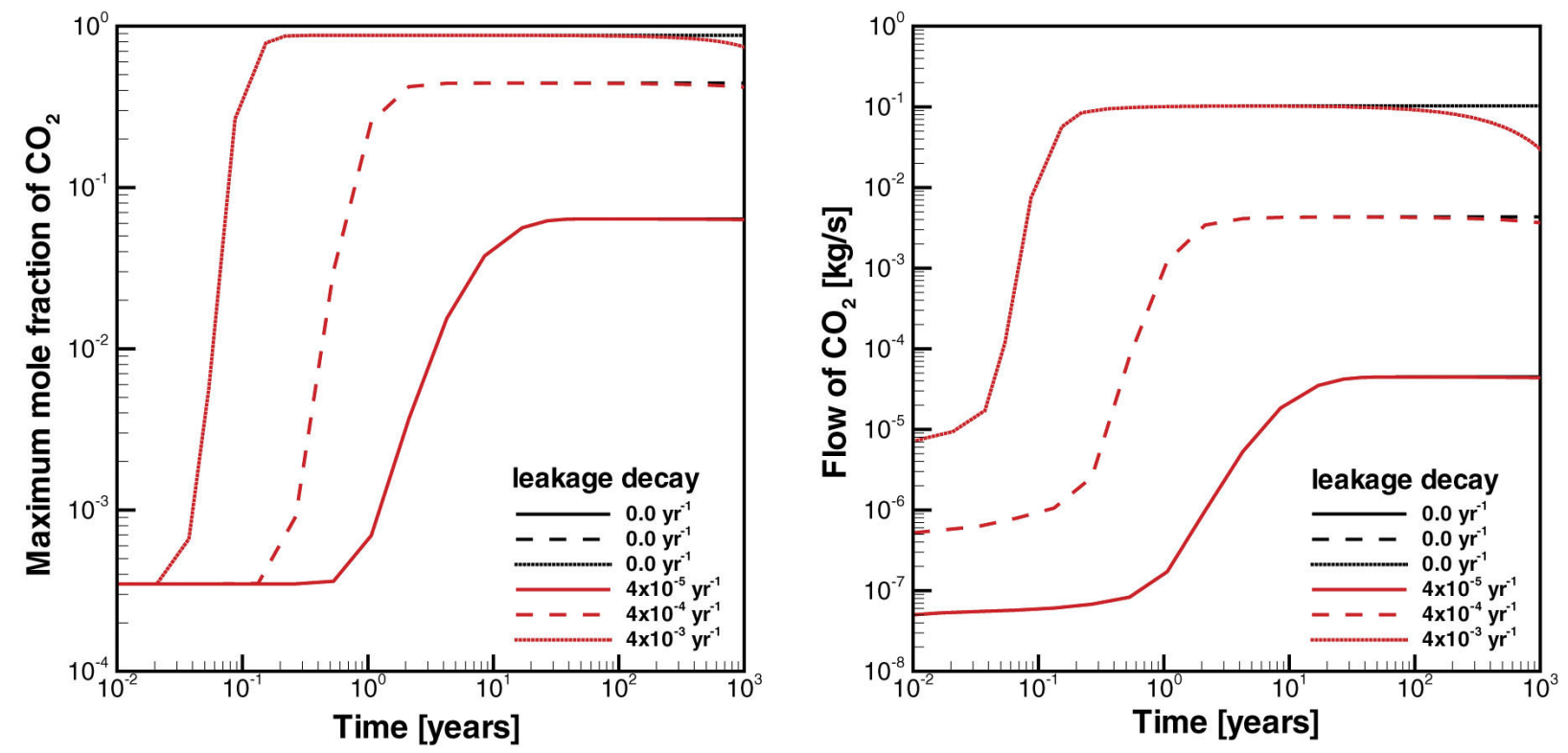

Figure 4.8. The maximum surface mole fraction of $\mathrm{CO}_{2}$ in the gas phase and total flow of $\mathrm{CO}_{2}$ crossing the ground surface boundary as a function of time for various constant (black lines) and decaying (red lines) leakage rates. The black solid, dashed and dotted lines represent constant leakage rate of $4 \times 10^{4} \mathrm{~kg} \mathrm{yr}^{-1}$ to $4 \times 10^{5} \mathrm{~kg} \mathrm{yr}^{-1}$ and $4 \times 10^{6} \mathrm{~kg} \mathrm{yr}^{-1}$, respectively. 

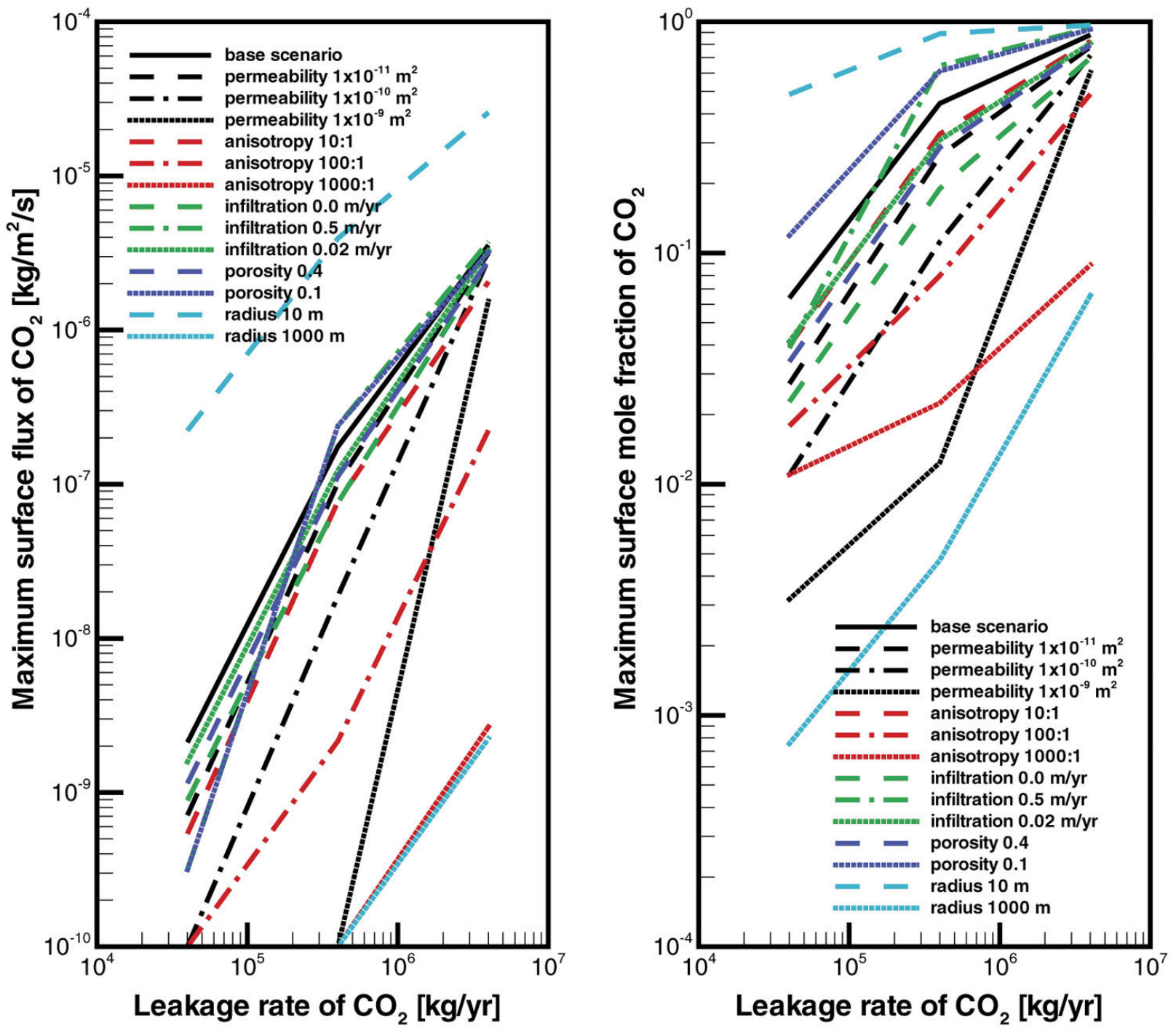

Figure 4.9. The maximum surface flux of $\mathrm{CO}_{2}$ crossing the surface boundary and the maximum surface mole fraction of $\mathrm{CO}_{2}$ as a function of time. The solid, dashed and dotted lines represent constant leakage rate of $4 \times 10^{4} \mathrm{~kg} \mathrm{yr}^{-1}$ to $4 \times 10^{5} \mathrm{~kg}_{\mathrm{yr}} \mathrm{r}^{-1}$ and $4 \times 10^{6} \mathrm{~kg}_{\mathrm{gr}} \mathrm{r}^{-1}$, respectively, for all scenarios. 
(a)

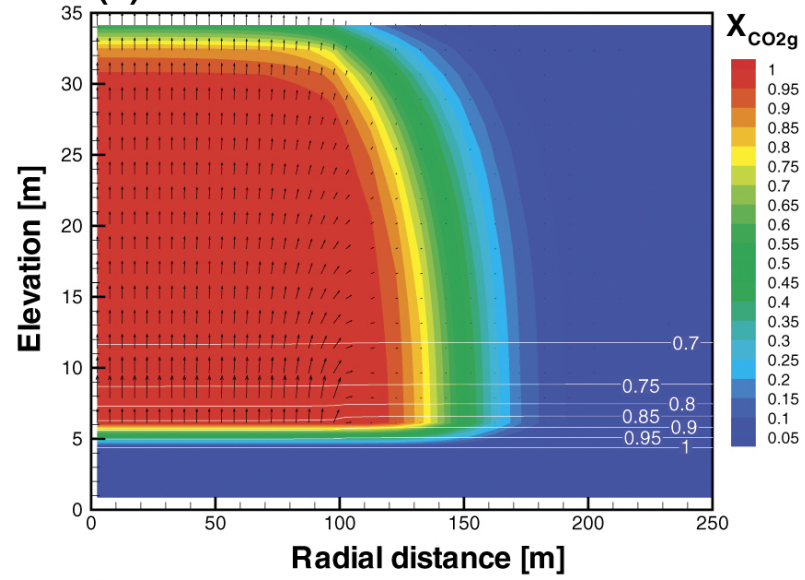

(c)

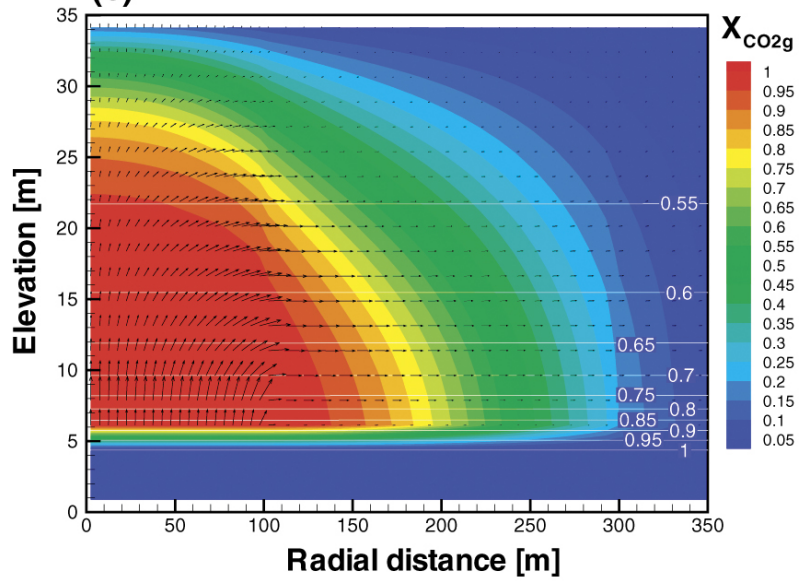

(b)

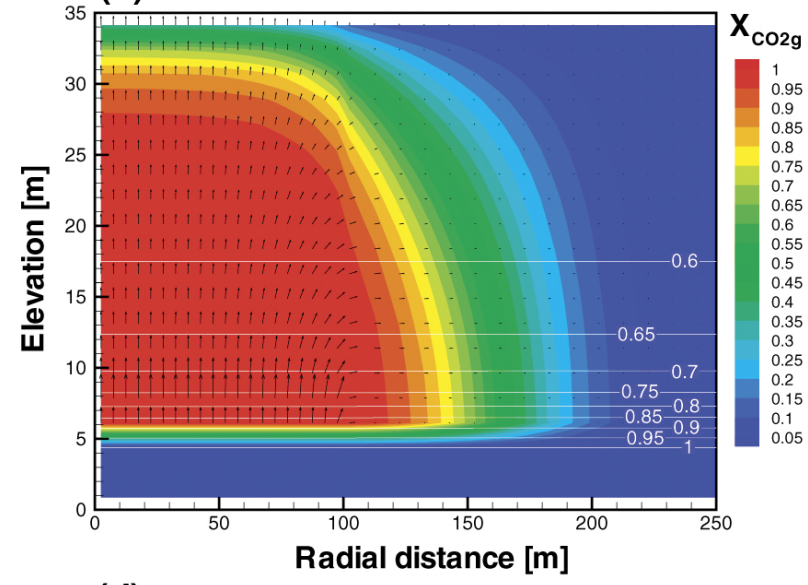

(d)

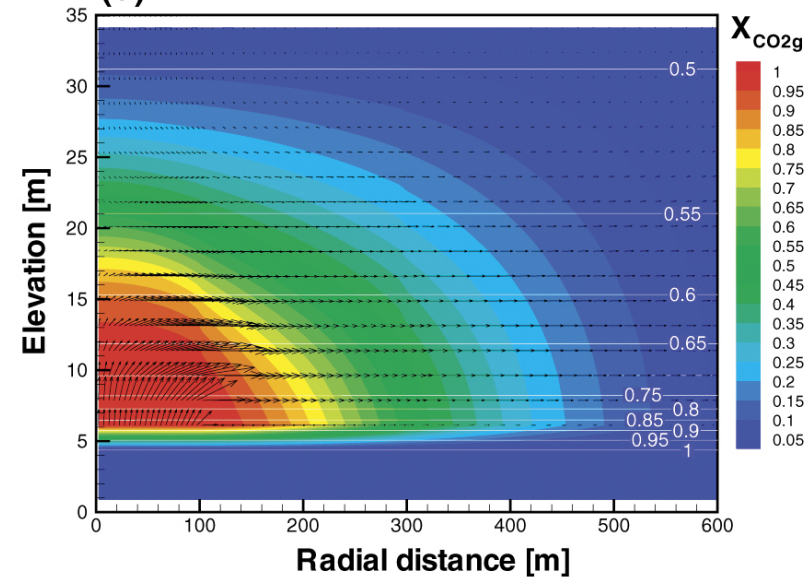

Figure 4.10. Colored contours indicate the mass fraction of $\mathrm{CO}_{2}$ in the gas phase, labeled contours indicate the water saturation, and vectors indicate the pore velocity of the gas phase for a leakage rate of $4 \times 10^{5} \mathrm{~kg} y r^{-1}$ with a permeability of (a) $1 \times 10^{-12} \mathrm{~m}^{2}$, (b) $1 \times 10^{-11} \mathrm{~m}^{2}$, (c) $1 \times 10^{-10}$ $\mathrm{m}^{2}$ and (d) $1 \times 10^{-9} \mathrm{~m}^{2}$. The maximum vector size represents a value of (a) $0.53 \mathrm{~m} \mathrm{~d}^{-1}$, (b) $0.56 \mathrm{~m}$ $d^{l}$, (c) $0.57 \mathrm{md}^{1}$ and (d) $1.0 \mathrm{md^{l }}$. 
(a)

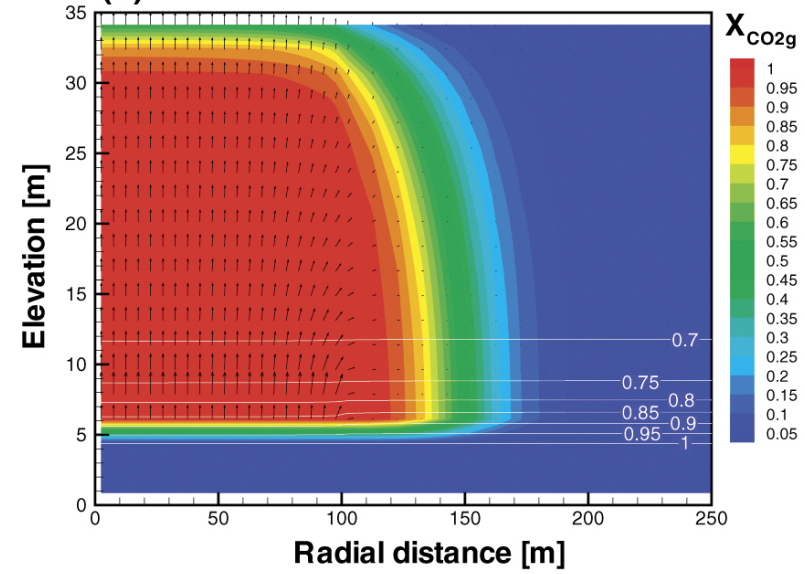

(c)

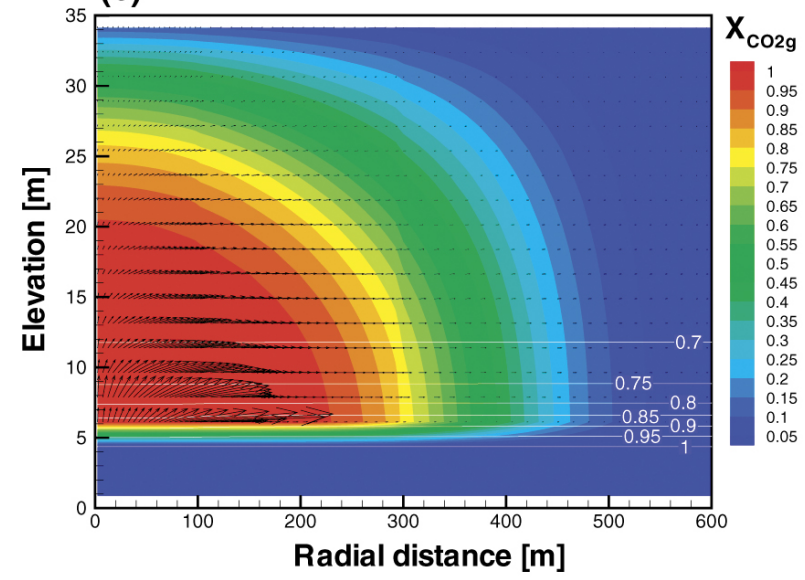

(b)

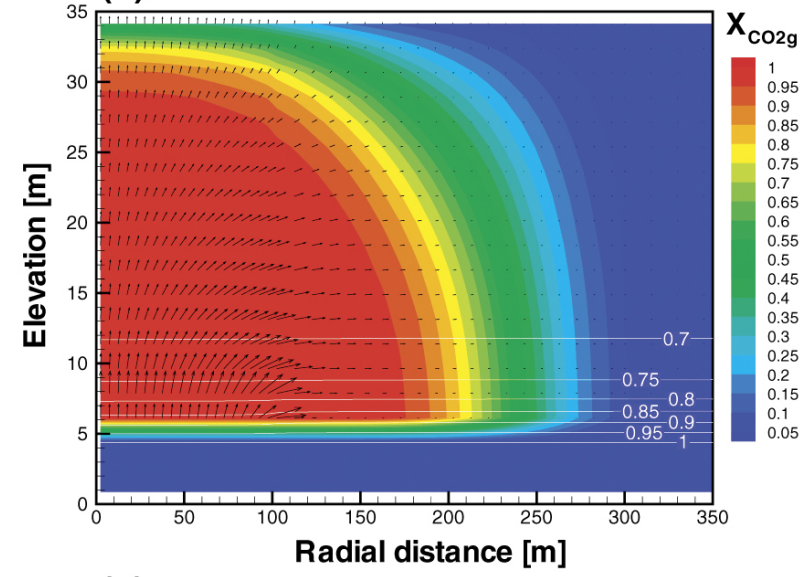

(d)

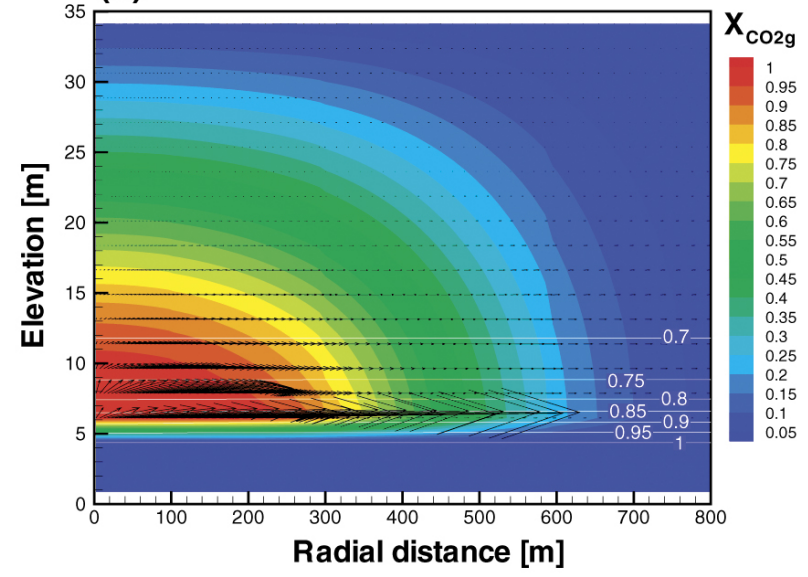

Figure 4.11. Colored contours indicate the mass fraction of $\mathrm{CO}_{2}$ in the gas phase, labeled contours indicate the water saturation, and vectors indicate the pore velocity of the gas phase for a leakage rate of $4 \times 10^{5} \mathrm{~kg} \mathrm{yr}^{-1}$ with an anisotropy of (a) $1: 1$, (b) $10: 1$, (c) $100: 1$ and (d) 1000 $\therefore$ 1. The maximum vector size represents a value of (a) $0.53 \mathrm{~m} \mathrm{~d}^{1}$, (b) $0.53 \mathrm{md}^{1}$, (c) $3.2 \mathrm{md^{1 }}$ and (d) $8.4 m d^{1}$. 

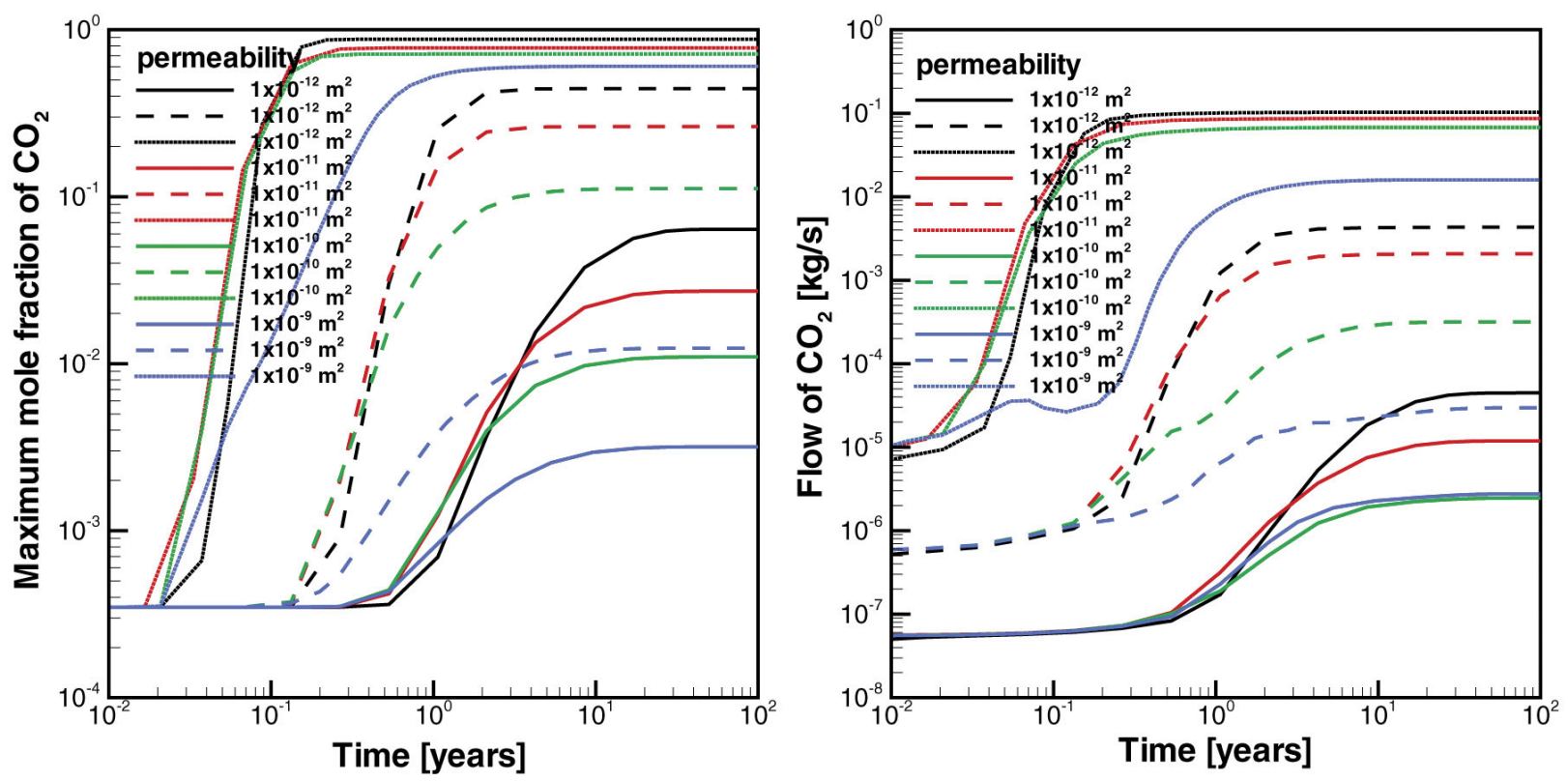

Figure 4.12. The maximum surface flux of $\mathrm{CO}_{2}$ crossing the surface boundary and the maximum surface mole fraction of $\mathrm{CO}_{2}$ as a function of time for permeability scenarios of $1 \times 10^{-12} \mathrm{~m}^{2}, 1 \times 10$ ${ }^{11} \mathrm{~m}^{2}, 1 \times 10^{-10} \mathrm{~m}^{2}$ and $1 \times 10^{-9} \mathrm{~m}^{2}$. The solid, dashed and dotted lines represent constant leakage

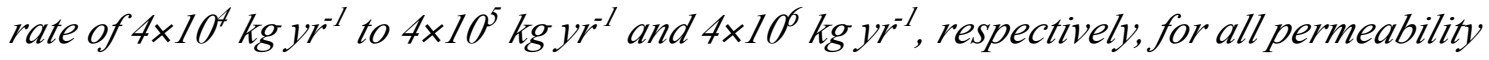
scenarios. 

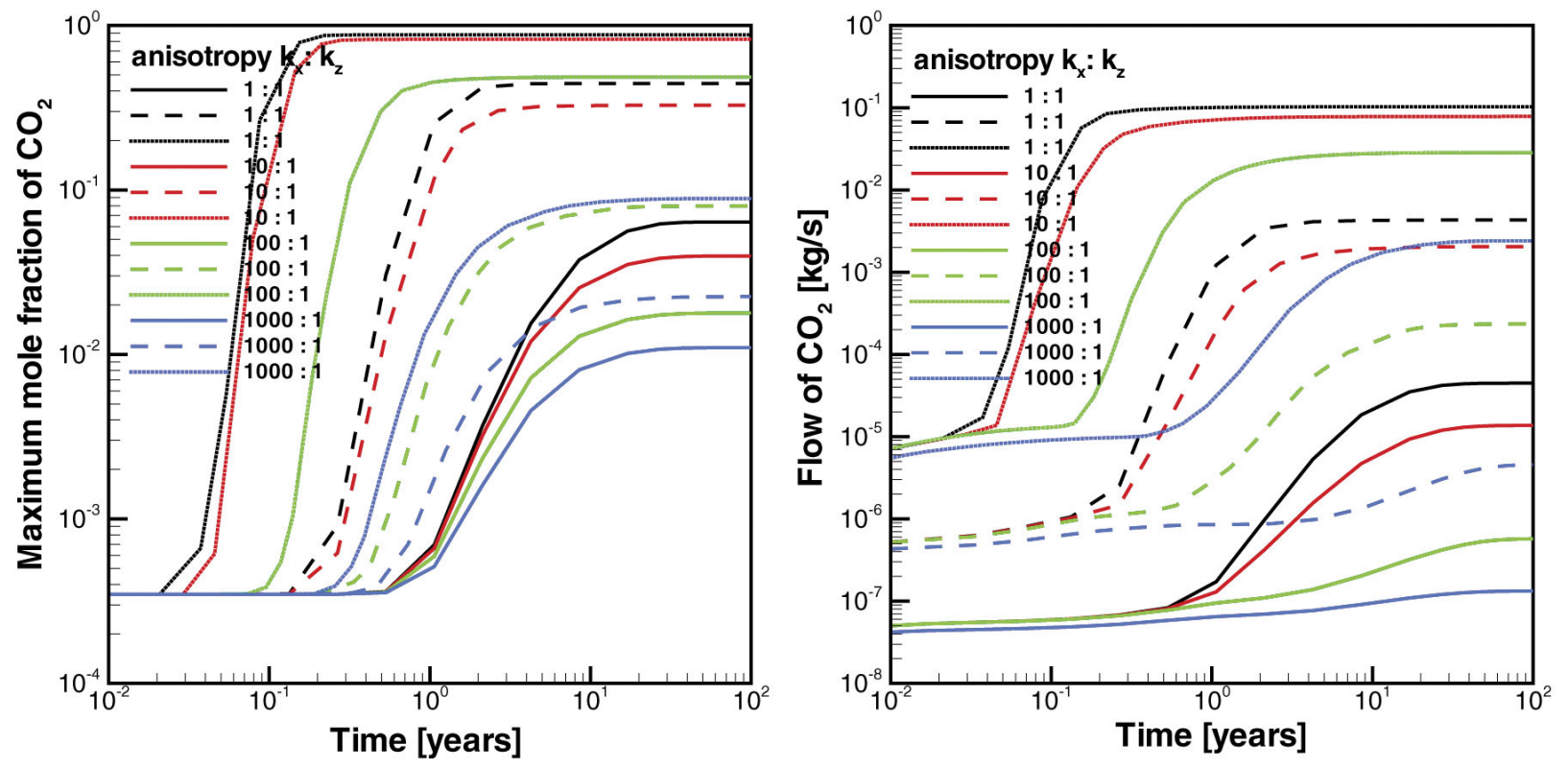

Figure 4.13. The maximum surface flux of $\mathrm{CO}_{2}$ crossing the surface boundary and the maximum surface mole fraction of $\mathrm{CO}_{2}$ as a function of time for anisotropy scenarios of $1: 1,10: 1,100: 1$ and $1000: 1$. The solid, dashed and dotted lines represent constant leakage rate of $4 \times 10^{4} \mathrm{~kg}_{\mathrm{yr}} \mathrm{r}^{-1}$

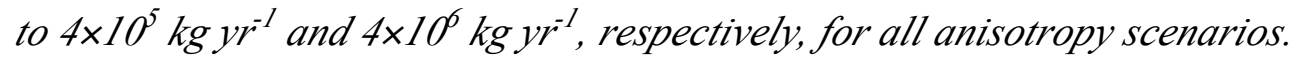


(a)

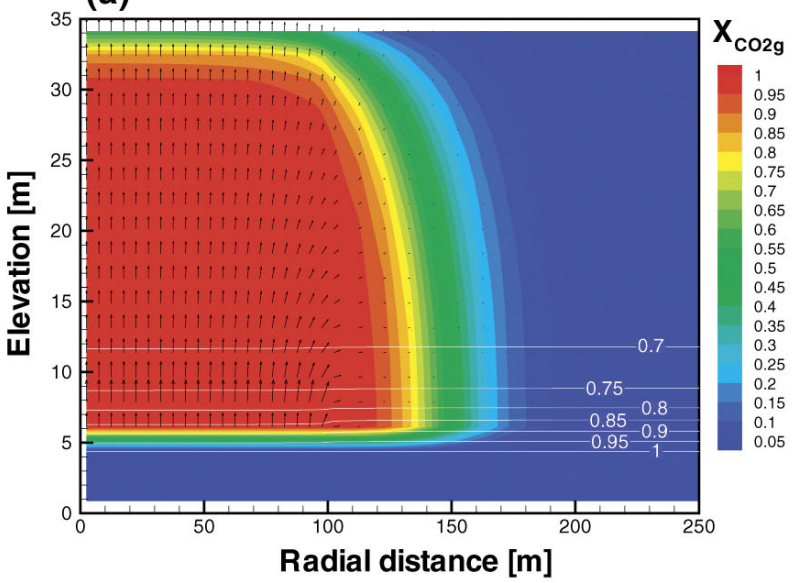

(c)

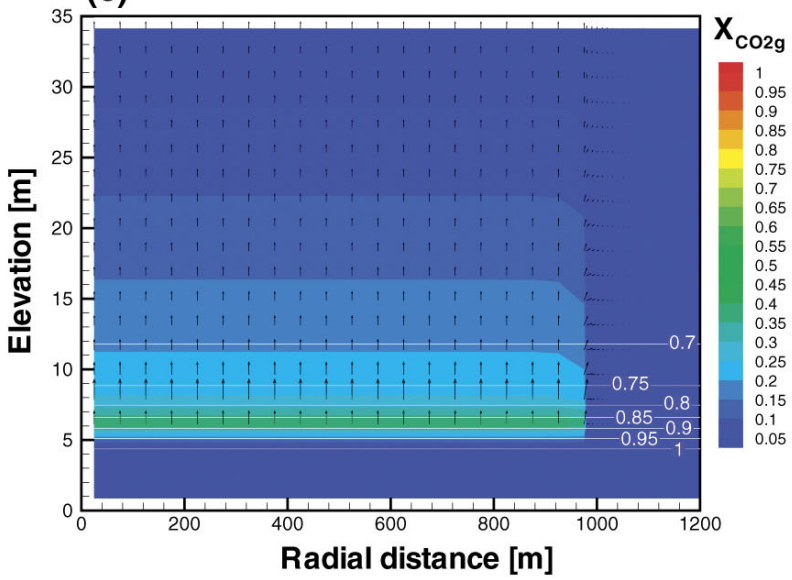

(b)

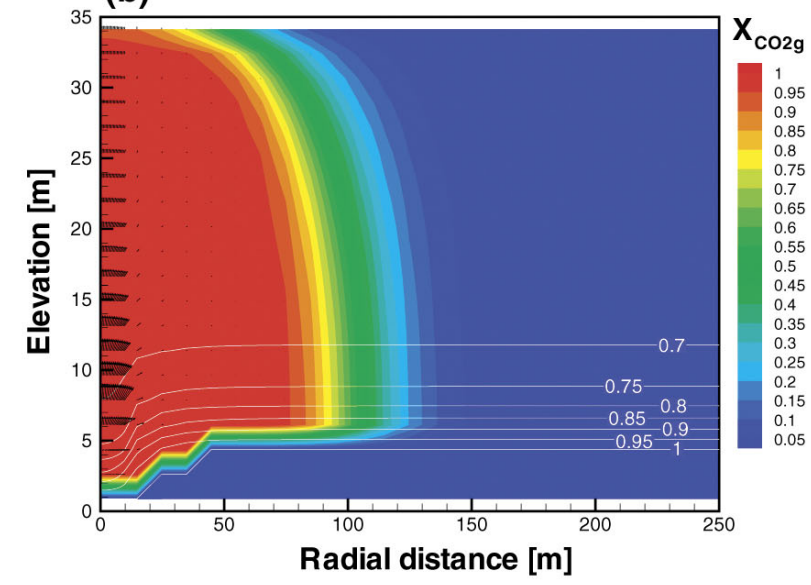

Figure 4.14. Colored contours indicate the mass fraction of $\mathrm{CO}_{2}$ in the gas phase, labeled contours indicate the water saturation, and vectors indicate the pore velocity of the gas phase for a leakage rate of $4 \times 10^{5} \mathrm{~kg} \mathrm{yr}^{-1}$ with a source radius of (a) $100 \mathrm{~m}$, (b) $10 \mathrm{~m}$ and (c) $1000 \mathrm{~m}$. The maximum vector size represents a value of (a) $0.53 \mathrm{~m} \mathrm{~d}^{1}$, (b) $17 \mathrm{md}^{1}$ and (c) $0.0048 \mathrm{~m} \mathrm{~d}$. 

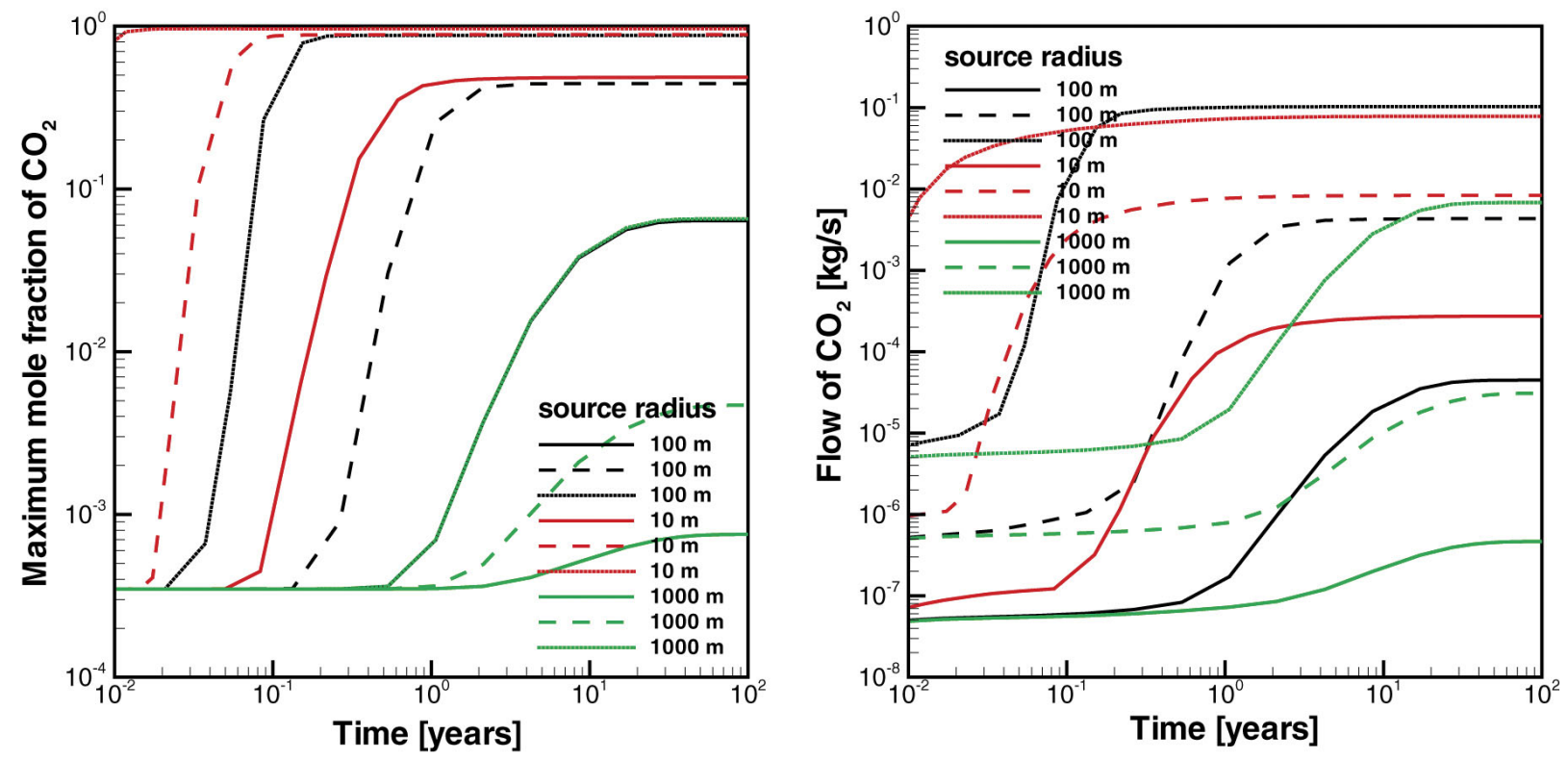

Figure 4.15. The maximum seepage flux of $\mathrm{CO}_{2}$ crossing the surface boundary and the maximum surface mole fraction of $\mathrm{CO}_{2}$ as a function of time for source radius scenarios of $100 \mathrm{~m}, 10 \mathrm{~m}$ and $1000 \mathrm{~m}$. The solid, dashed and dotted lines represent constant leakage rate of $4 \times 10^{4} \mathrm{~kg} \mathrm{yr}^{-1}$ to

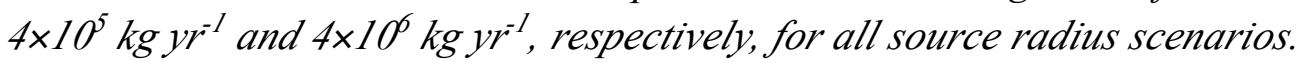


(a)

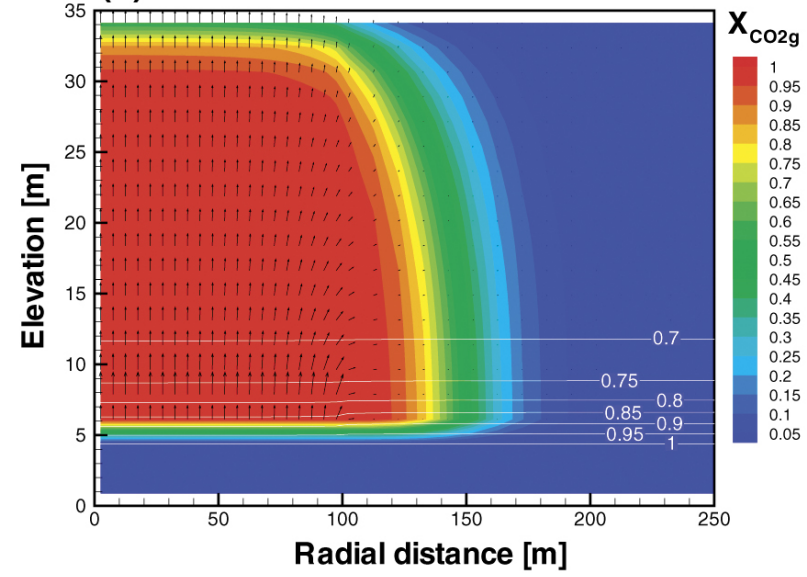

(c)

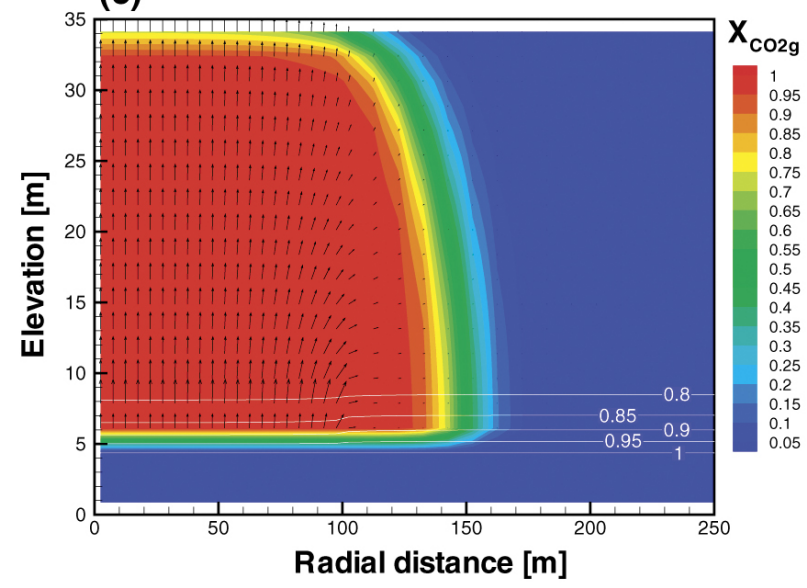

(b)

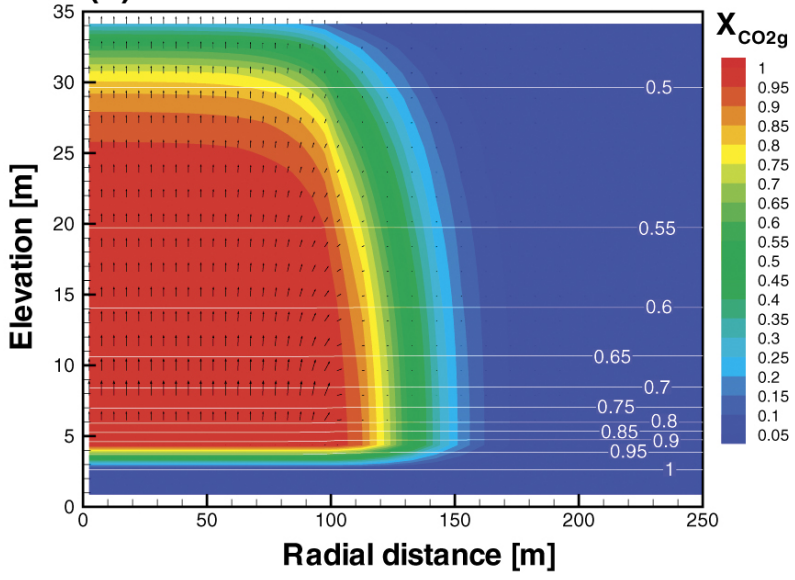

(d)

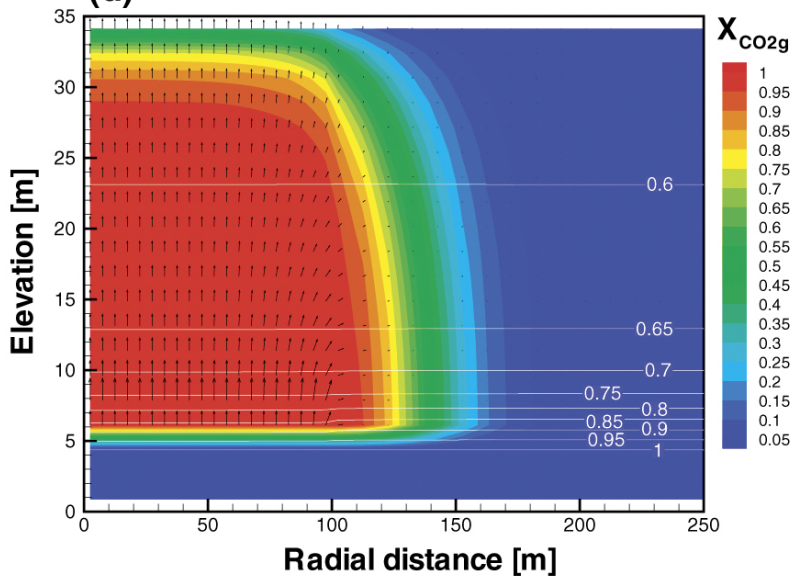

Figure 4.16. Colored contours indicate the mass fraction of $\mathrm{CO}_{2}$ in the gas phase, labeled contours indicate the water saturation, and vectors indicate the pore velocity of the gas phase for a leakage rate of $4 \times 10^{5} \mathrm{~kg} \mathrm{yr}^{-1}$ with an infiltration rate of (a) $0.1 \mathrm{myr}^{-1}$, (b) $0.0 \mathrm{myr}$, (c) $0.5 \mathrm{~m}$ $y r^{-1}$ and (d) $0.02 \mathrm{~m} \mathrm{yr}^{-1}$. The maximum vector size represents a value of (a) $0.53 \mathrm{~m} \mathrm{~d}^{-1}$, (b) 0.34 $m d^{1}$, (c) $0.57 m d^{1}$ and (d) $0.52 \mathrm{md}^{1}$. 

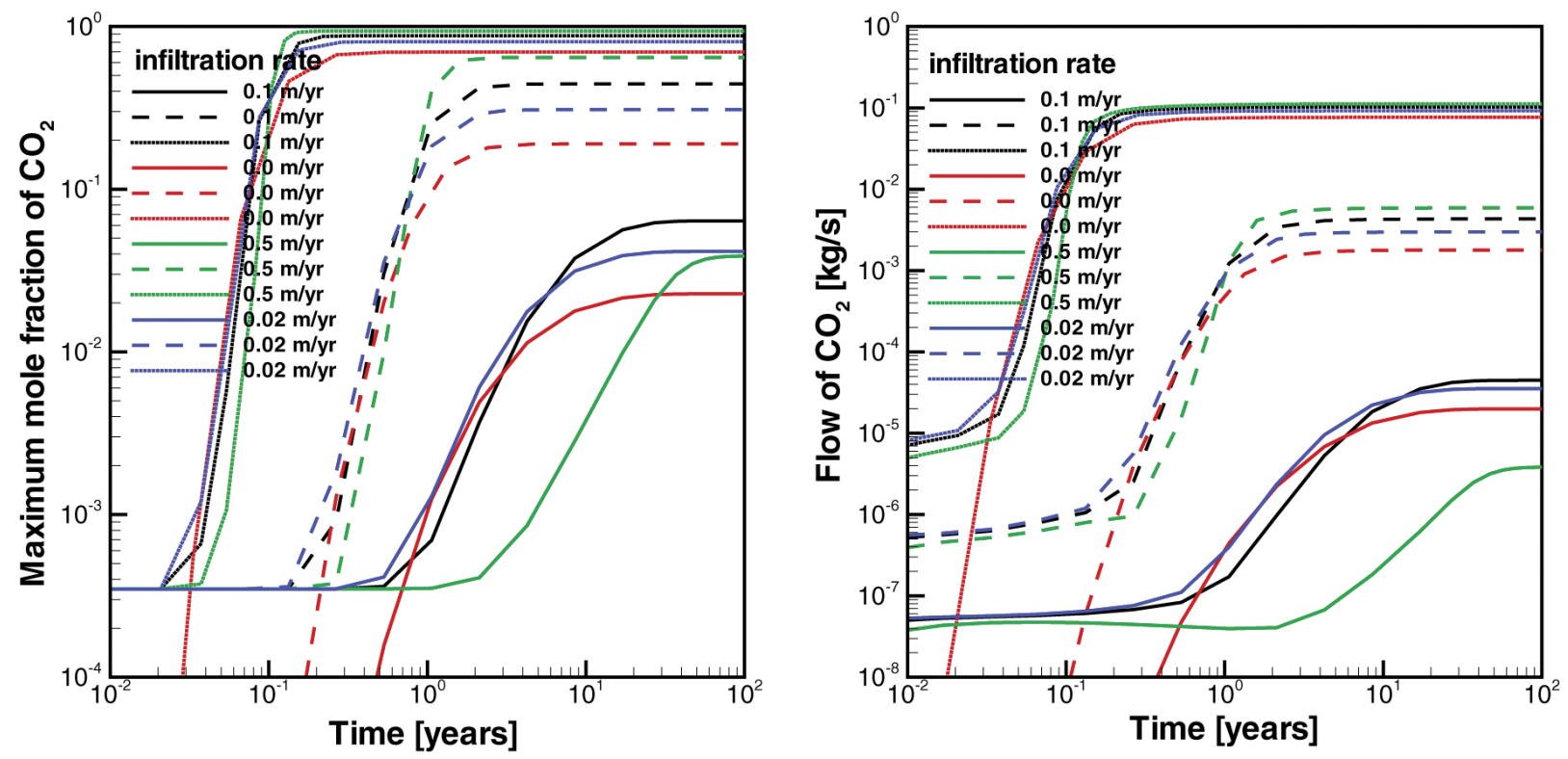

Figure 4.17. The maximum seepage flux of $\mathrm{CO}_{2}$ crossing the surface boundary and the maximum surface mole fraction of $\mathrm{CO}_{2}$ as a function of time for infiltration rate scenarios of $0.1 \mathrm{~m} \mathrm{yr} \mathrm{r}^{-1}, 0.0$ $m y r^{-1}, 0.5 \mathrm{~m} \mathrm{yr}^{-1}$ and $0.02 \mathrm{myr}^{-1}$. The solid, dashed and dotted lines represent constant leakage

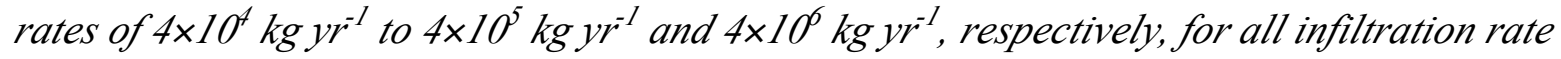
scenarios. 
(a)

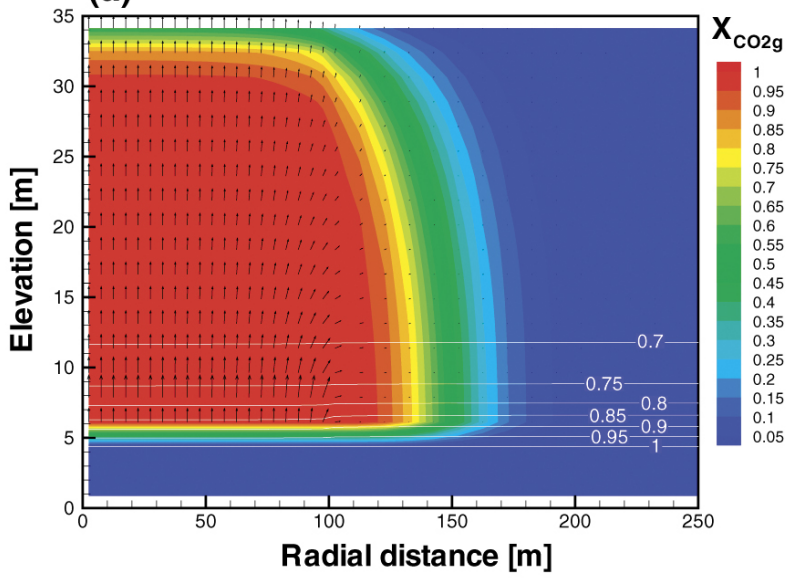

(c)

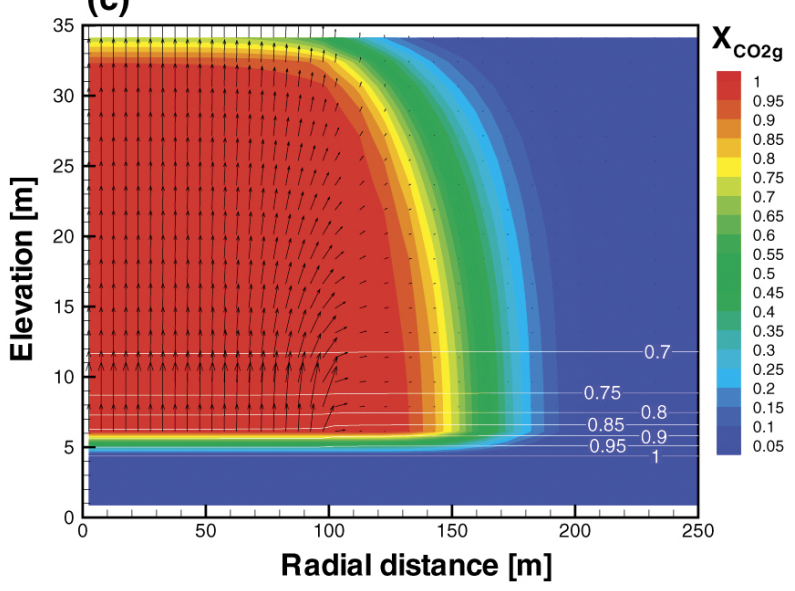

(b)

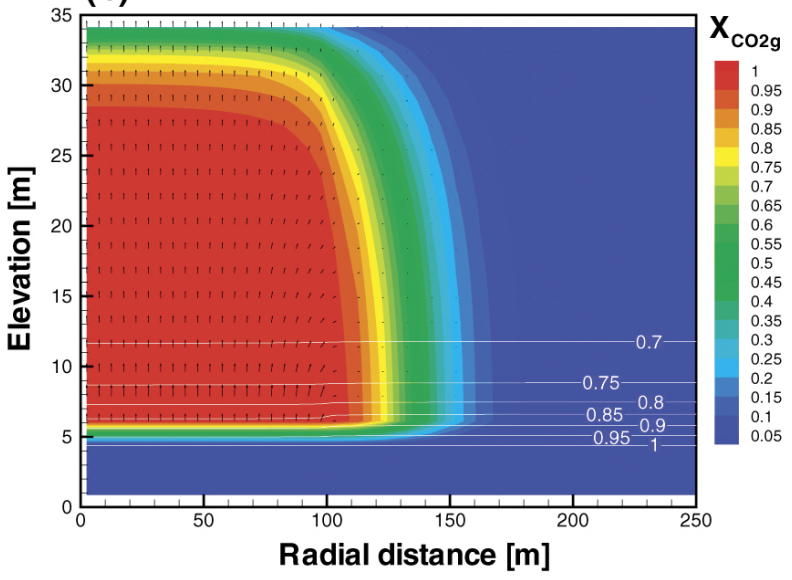

Figure 4.18. Colored contours indicate the mass fraction of $\mathrm{CO}_{2}$ in the gas phase, labeled contours indicate the water saturation, and vectors indicate the pore velocity of the gas phase for a leakage rate of $4 \times 10^{5} \mathrm{~kg} \mathrm{yr}^{-1}$ with a porosity of (a) 0.2 , (b) 0.4 and (c) 0.1 . The maximum vector size represents a value of (a) $0.53 \mathrm{~m} \mathrm{~d}^{1}$, (b) $0.26 \mathrm{md}^{1}$ and (c) $1.07 \mathrm{~m} \mathrm{~d}^{1}$. 

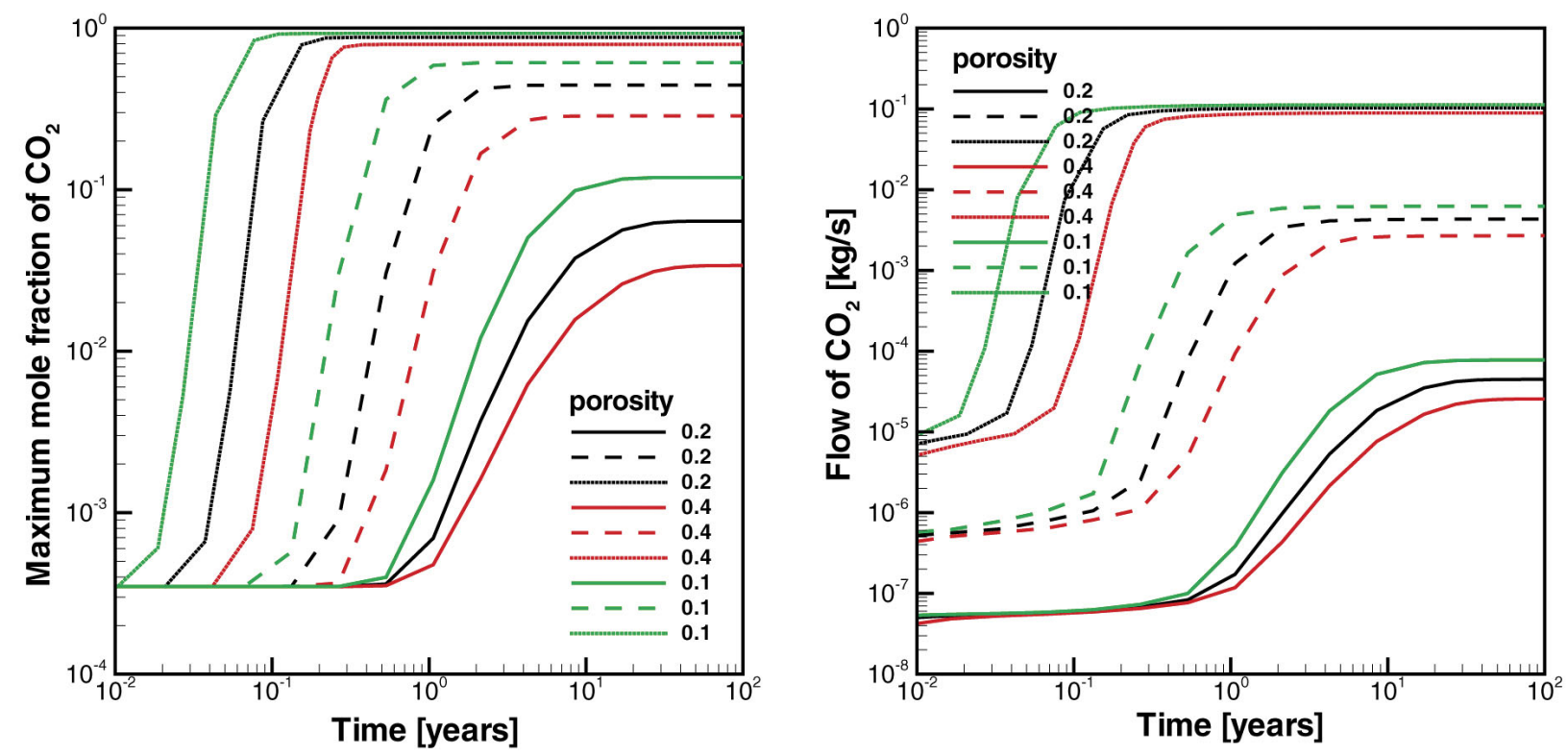

Figure 4.19. The maximum surface flux of $\mathrm{CO}_{2}$ crossing the surface boundary and the maximum surface mole fraction of $\mathrm{CO}_{2}$ as a function of time for porosity scenarios of 0.2, 0.4 and 0.1. The solid, dashed and dotted lines represent constant leakage rate of $4 \times 10^{4} \mathrm{~kg} \mathrm{yr}^{-1}$ to $4 \times 10^{5} \mathrm{~kg} \mathrm{yr}^{-1}$ and $4 \times 10^{6} \mathrm{~kg} \mathrm{yr}^{-1}$, respectively, for all porosity scenarios. 